\title{
UCRL-ID-143298
}

\section{Containment Prospectus}

\author{
for the

\section{PIANO \\ Experiment}

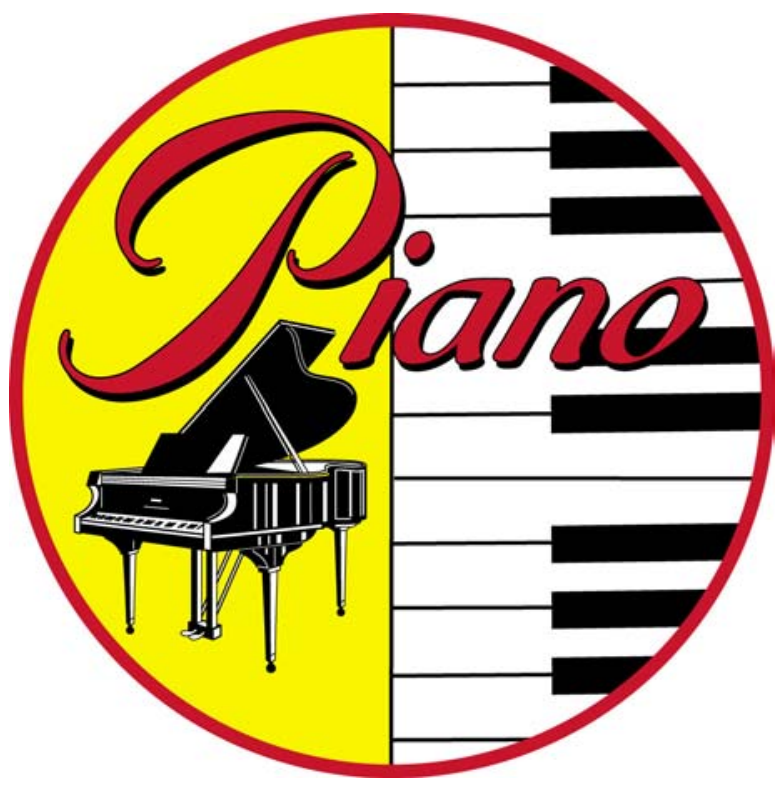

Norman R. Burkhard

Containment Scientist

Lawrence Livermore National Laboratory

March 23, 2001

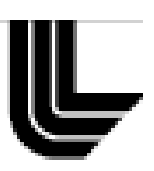




\section{DISCLAIMER}

This document was prepared as an account of work sponsored by an agency of the United States Government. Neither the United States Government nor the University of California nor any of their employees, makes any warranty, express or implied, or assumes any legal liability or responsibility for the accuracy, completeness, or usefulness of any information, apparatus, product, or process disclosed, or represents that its use would not infringe privately owned rights. Reference herein to any specific commercial product, process, or service by trade name, trademark, manufacturer, or otherwise, does not necessarily constitute or imply its endorsement, recommendation, or favoring by the United States Government or the University of California. The views and opinions of authors expressed herein do not necessarily state or reflect those of the United States Government or the University of California, and shall not be used for advertising or product endorsement purposes.

This work was performed under the auspices of the United States Department of Energy by the University of California, Lawrence Livermore National Laboratory under contract No. W-7405-Eng-48.

This report has been reproduced directly from the best available copy.

Available to DOE and DOE contractors from the Office of Scientific and Technical Information

$$
\text { P.O. Box } 62
$$

Oak Ridge, TN 37831-0062

Prices available from (423) 576-8401

http:/ /apollo.osti.gov/bridge/

Available to the public from the

National Technical Information Service

U.S. Department of Commerce

5285 Port Royal Road

Springfield, VA 22161

http:/ / www.ntis.gov/ordering.htm

\section{OR}

Lawrence Livermore National Laboratory

Technical Information Department's Digital Library

http:/ / www.llnl.gov/tid/Library.html 


\section{Table of Contents}

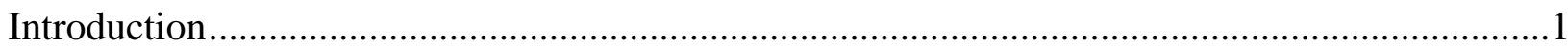

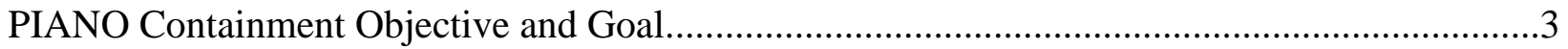

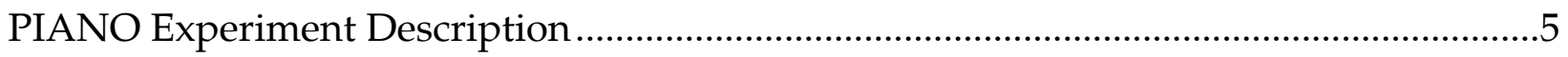

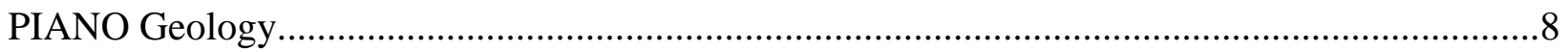

PIANO Blast and Quasi-Static Gas Pressure .................................................................. 10

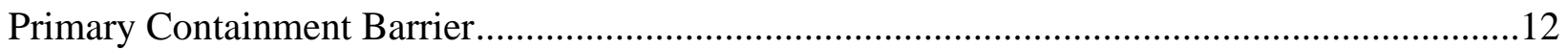

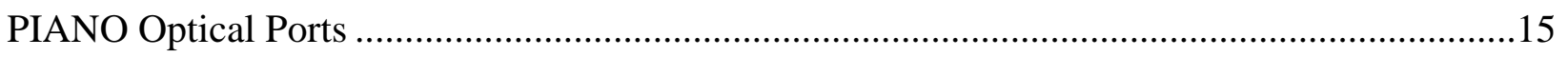

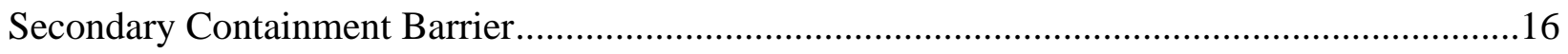

Containment Vessel \#1 and \#2 Wall Treatment ....................................................................18

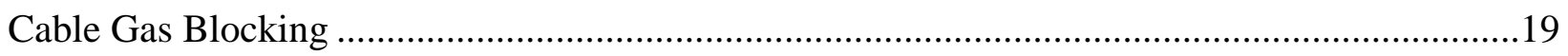

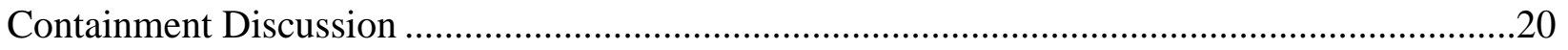

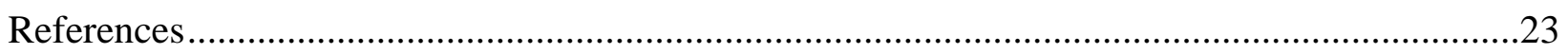

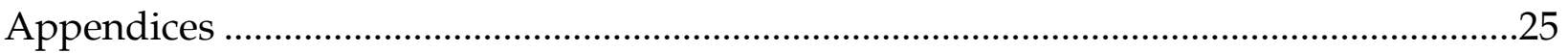




\section{Table of Contents}

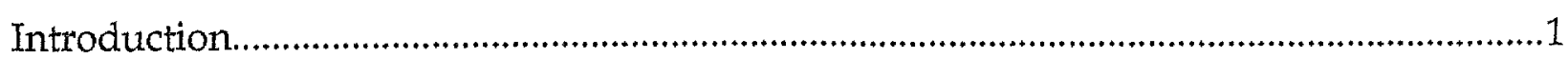

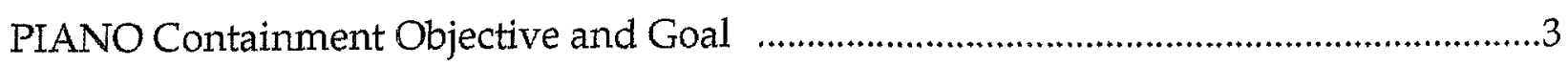

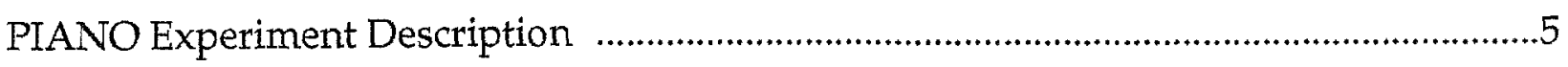

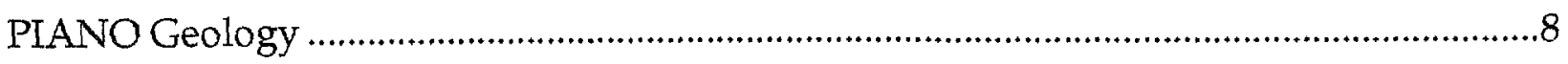

PIANO Blast and Quasi-Static Gas Pressure ……........................................................10

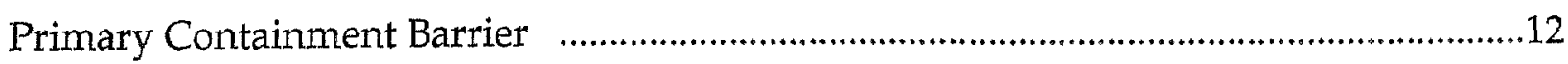

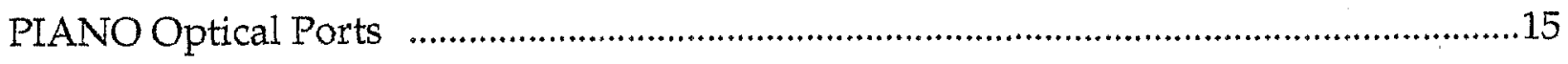

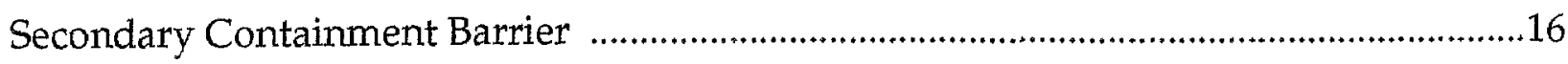

Containment Vessel \#1 and \#2 Wall Treatment …..........................................................18

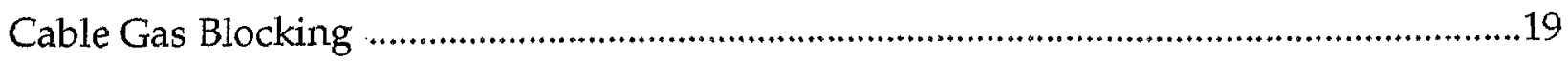

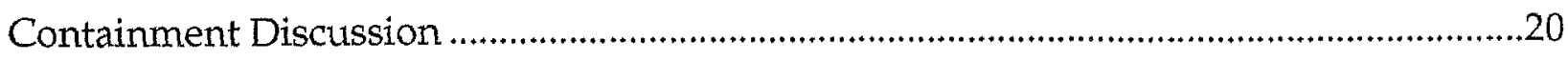

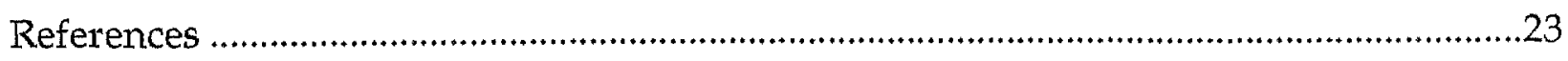

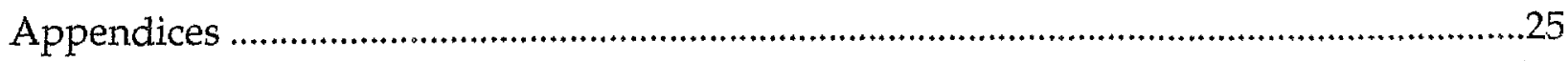




\section{Containment Prospectus for the PIANO Experiment}

\section{Introduction}

PIANO is a dynamic, subcritical, zero-yield experiment intended for execution in the U1a.102C drift of the U1a complex at the Nevada Test Site (NTS) (Figure 1). The data from the PIANO experiment will be used in the Stockpile Stewardship Program to assess the aging of nuclear weapon components and to better model the long-term performance of the weapons in the enduring stockpile.

The PIANO experiment is composed of one experimental package. The experimental package will have high explosive (HE) and special nuclear material (SNM) in a subcritical assembly.

The containment plan for the PIANO series of experiments utilizes a twocontainment-vessel concept. The first containment vessel is formed by the primary containment barrier that seals the U1a.102C drift. The second containment vessel is formed by the secondary containment barrier in the U100 drift.

The PIANO experiment is the final experiment to be conducted in the U1a.102C alcove. It will be an "open" experiment - meaning that PIANO will not utilize a confinement vessel as the previous OBOE experiments in this alcove did. We expect that the SNM from the PIANO experiment will be fully contained within the first containment vessel. 


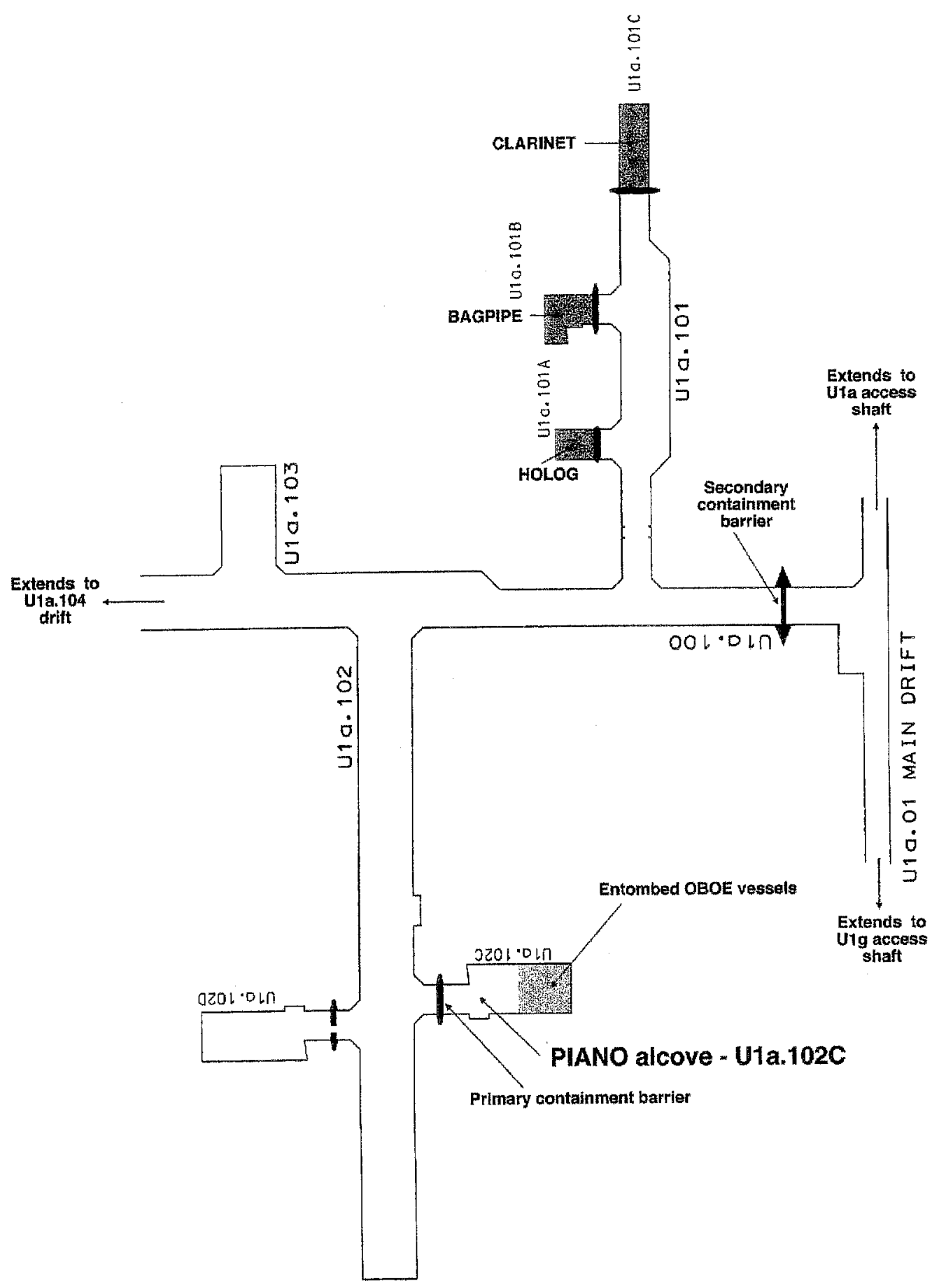

Figure 1. The PIANO experiment is located in the U1a.102C alcove. 


\section{PIANO Containment Objective and Goal}

The LLNL containment objective for the PIANO experiments (and for all LLNL subcritical experiments) is to assure that no SNM will be released to any uncontrolled environment as a result of the experiment. The specific PIANO containment goal is to confine all SNM to the zero room and/or the alluvium surrounding the zero room.

The PIANO containment design will use the time-tested concept of two nested containment vessels to assure this objective. The first containment vessel (Vessel \#1) includes the zero-room in the U1a.102C drift, the primary containment barrier, and the alluvium surrounding the zero-room. The second containment vessel (Vessel \#2) includes the volume of Vessel \#1, the volume of the U1a.100 drifts inside the secondary containment barrier, the volume of the U1a.101, the secondary containment barrier, and the alluvium surrounding these drifts. Figure 2 illustrates the two containment vessels.

A primary containment barrier, the fibercreted walls of the zero-room, and the alluvium on the face of the zero-room will be used to contain the SNM in the zero-room. The primary barrier has been designed to contain the PIANO experiment. We fully expect that no SNM will be released into the diagnostics rooms outside the primary containment barrier.

The secondary containment barrier in the U1a.100 drift will protect the rest of the U1a complex from contamination if the primary containment barrier fails to provide containment. This is unlikely in the PIANO experiment series since the primary containment barrier has been designed to withstand the shock and/or gas pressure from the experiment. The secondary barrier has been designed to fully contain the HE gases and SNM debris, as if the primary containment barrier did not exist.

The two nested containment vessels provide assurance that the LLNL PIANO containment objective (i.e. no SNM will be released to any uncontrolled environment as a result of the PIANO experiment) will be achieved. 


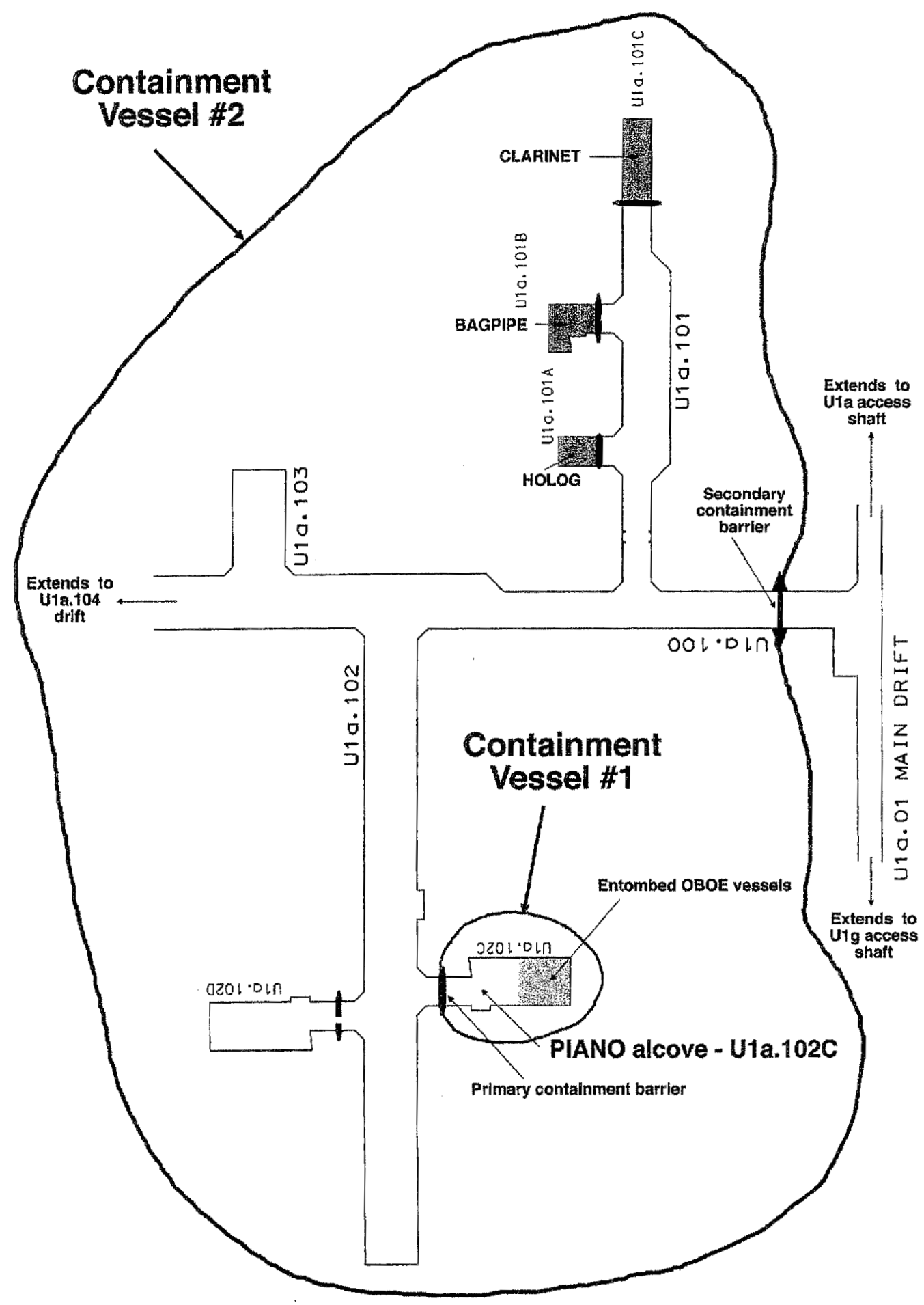

Figure 2. Two nested containment vessels assure that no SNM will be released to any uncontrolled environment. 


\section{PIANO Experiment Description}

The PIANO experiment will have a single assembly of chemical HE and SNM, which will be put inside an experiment cube in the zero-room. The PIANO experiment will have less than $5 \mathrm{lbs}$. of LX-14. Some of the experimental energy will be used to destroy mirrors in the optical beam lines immediately after the experiment.

The diagnostics data from the experiment will be recorded outside of the zero-room. Some data will be transmitted over electrical or fiberoptic cables to recording instrumentation outside the zero-room. Other data will exit the zero-room through optical viewing ports.

The essential features of the PIANO experiment for containment are:

1. Experimental HE weight is less than $5 \mathrm{lbs}$ of LX-14 (or its equivalent).

2. The two-nested-containment-vessel concept will be utilized.

The PIANO experiment is placed inside an experiment cube (Figure 3 ). The cube is placed on an experiment table, which will be about $11 \mathrm{ft}$ from the primary containment barrier and about 40 inches from a shrapnel shield (see Appendix 7). The shrapnel shield protects the optical ports in the primary barrier from experimental debris. The location of the shrapnel shield can be seen in Figure 4 . The size of the shrapnel shield prevents any shrapnel from the experiment from directly impacting the optical ports in the primary barrier.

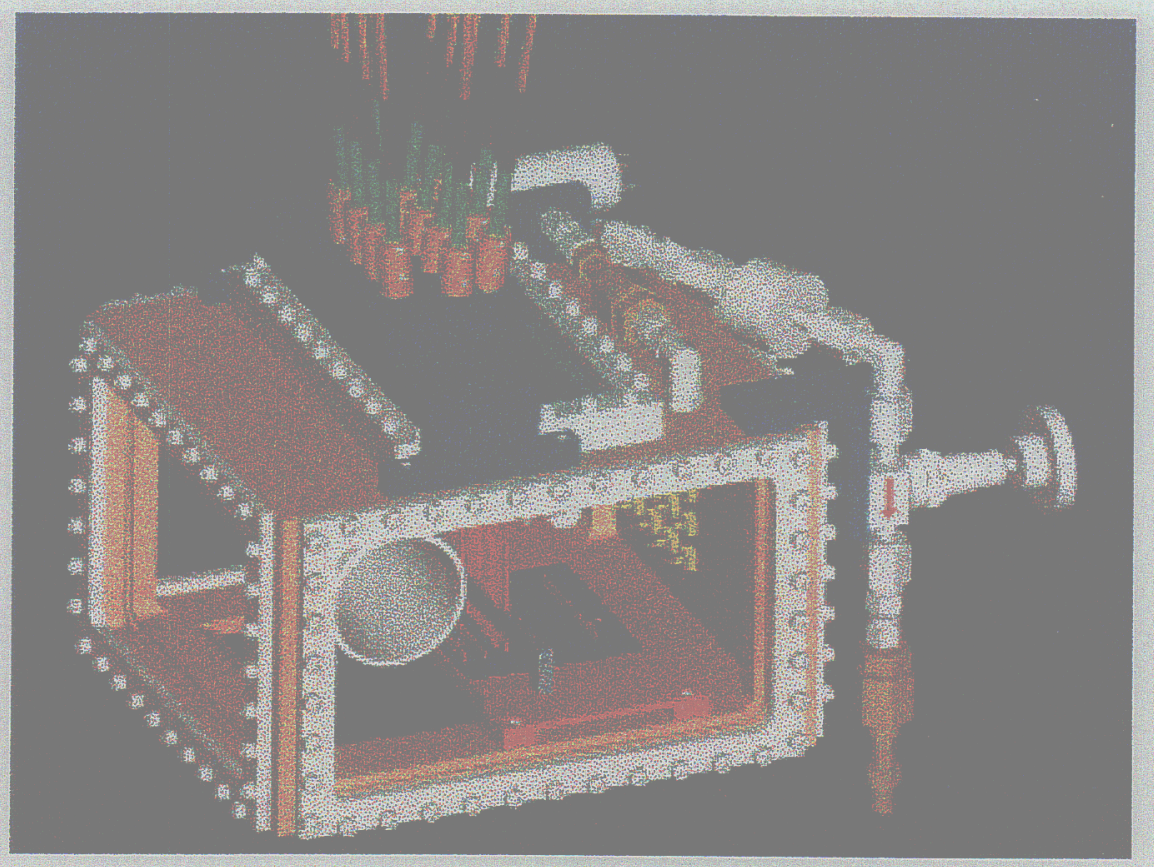

Figure 3. Illustration of PIANO experiment cube containing the HE. 


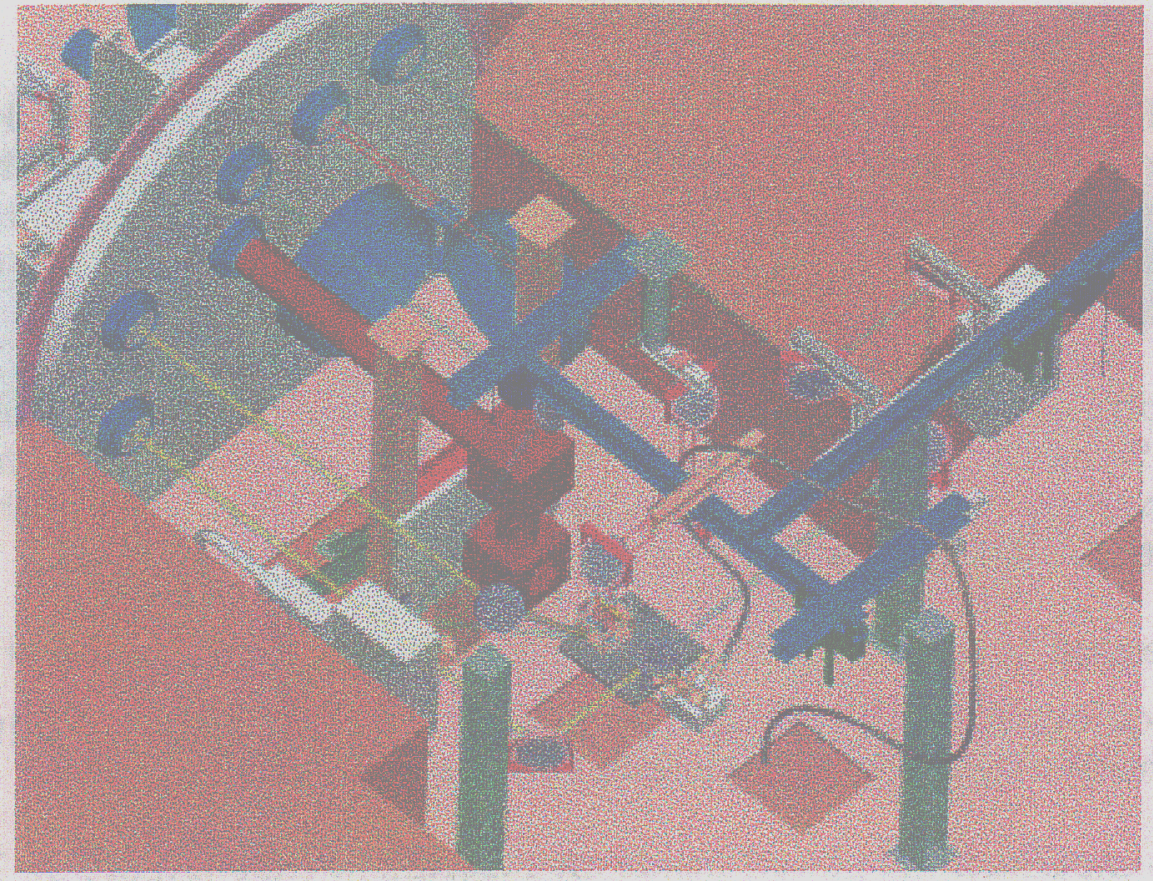

Figure 4. Layout of PIANO experiment showing optical beam lines and the approximate size of the shrapnel shield.

The PIANO diagnostics suite is quite extensive and is illustrated in Figure 5. All six optical ports in the primary barrier have been utilized for this experiment. Mega-Sun ${ }^{\mathrm{TM}}$ flash lamps will be used to light the experiment instead of HE-driven candles. This reduces the pressure loads on the containment barriers and improves the dry-run simulations prior to experiment execution. 


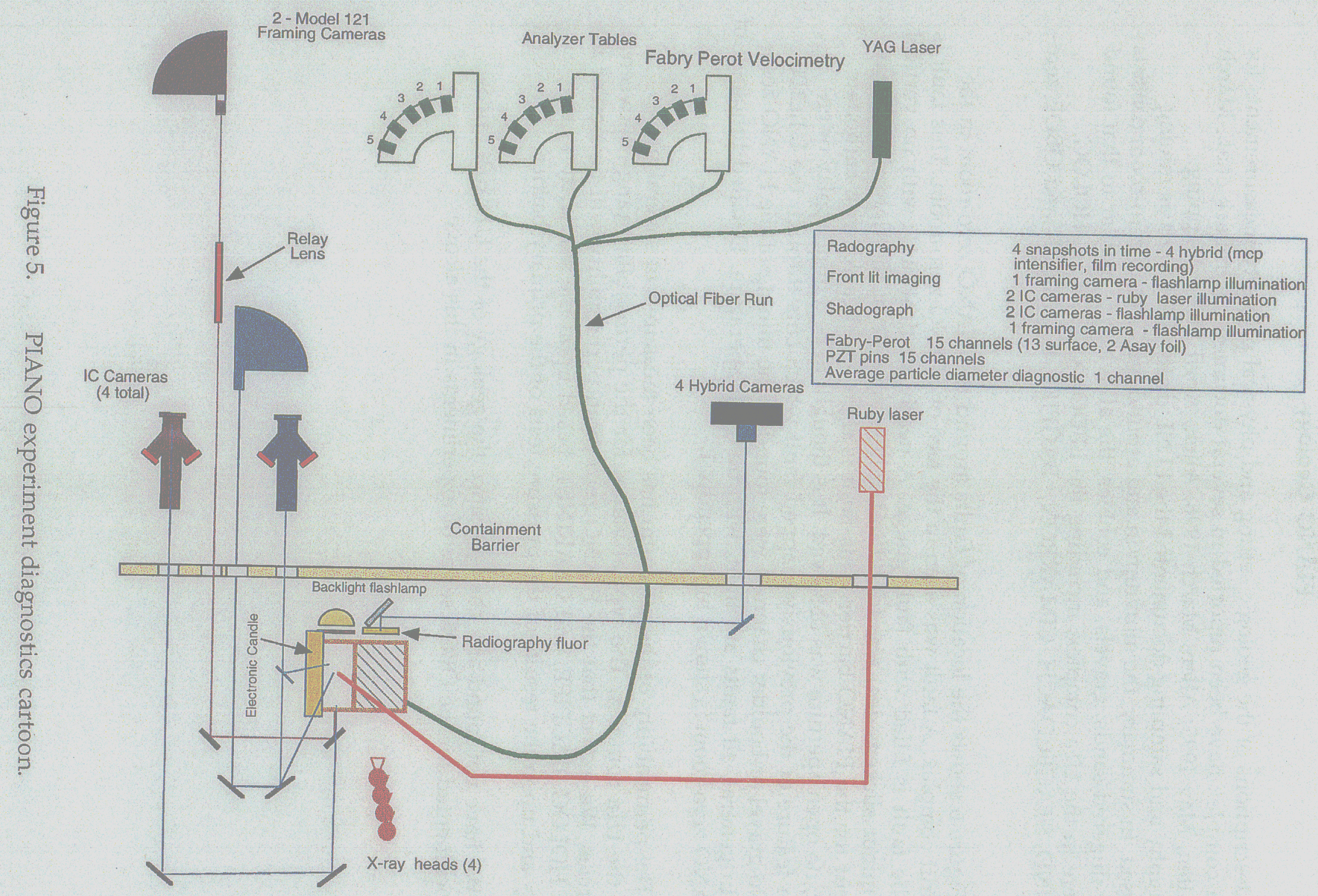




\section{PIANO Geology}

Descriptions of the geologic setting and physical property measurements for the U1a complex have been reported in several documents (Drellack et.al., March 1989; Allen, May 1995; Allen, March 1996; Allen, April 1999). Mapping, photography and sampling documented the LLNL drifts and rooms as mining progressed. In summary, the alluvium in and around the PIANO zero-room consists of inter-fingered sands, gravels, and cobbles; the alluvium is similar to that found elsewhere in the U1a complex, including the LEDOUX, KISMET, HOLOG, REBOUND, STAGECOACH, CIMARRON, BAGPIPE, CLARINET and OBOE zerorooms.

Figure 6 shows the location of faults around the PIANO zero-room in the U100 drift complex. A fault was seen in the face of PIANO zero-room. This fault is tight; the fault is filled with fault gouge. A nearly vertical fault with no vertical offset (minor slickensides) was found in the heading side of the right rib keyway notch cut for the PIANO barrier. This fault is tight and healed with carbonate cement; no open aperture was observed. It is thought to be a minor splay or enechelon feature of the previously mapped fault which cuts through the U1a.100 drift. No gravel or boulder channels were found in the mining of the PIANO zeroroom. In general, all faults are tight, with no open aperature. Detailed lithology of the PIANO zero-room is shown in Appendix 1.

The permeability of the alluvium has been measured in several places within the U1a complex. The typical values for the permeability range between $1-5$ darcies. We expect that the PIANO zero-room permeability will be similar to that of HOLOG, BAGPIPE, and CLARINET, based upon the similarity in the geology and upon the results of the pressure tests of the primary barrier.

We have not found any changes since the geology of the U1a.102C alcove was documented for the $\mathrm{OBOE}$ series of experiments in this alcove. 


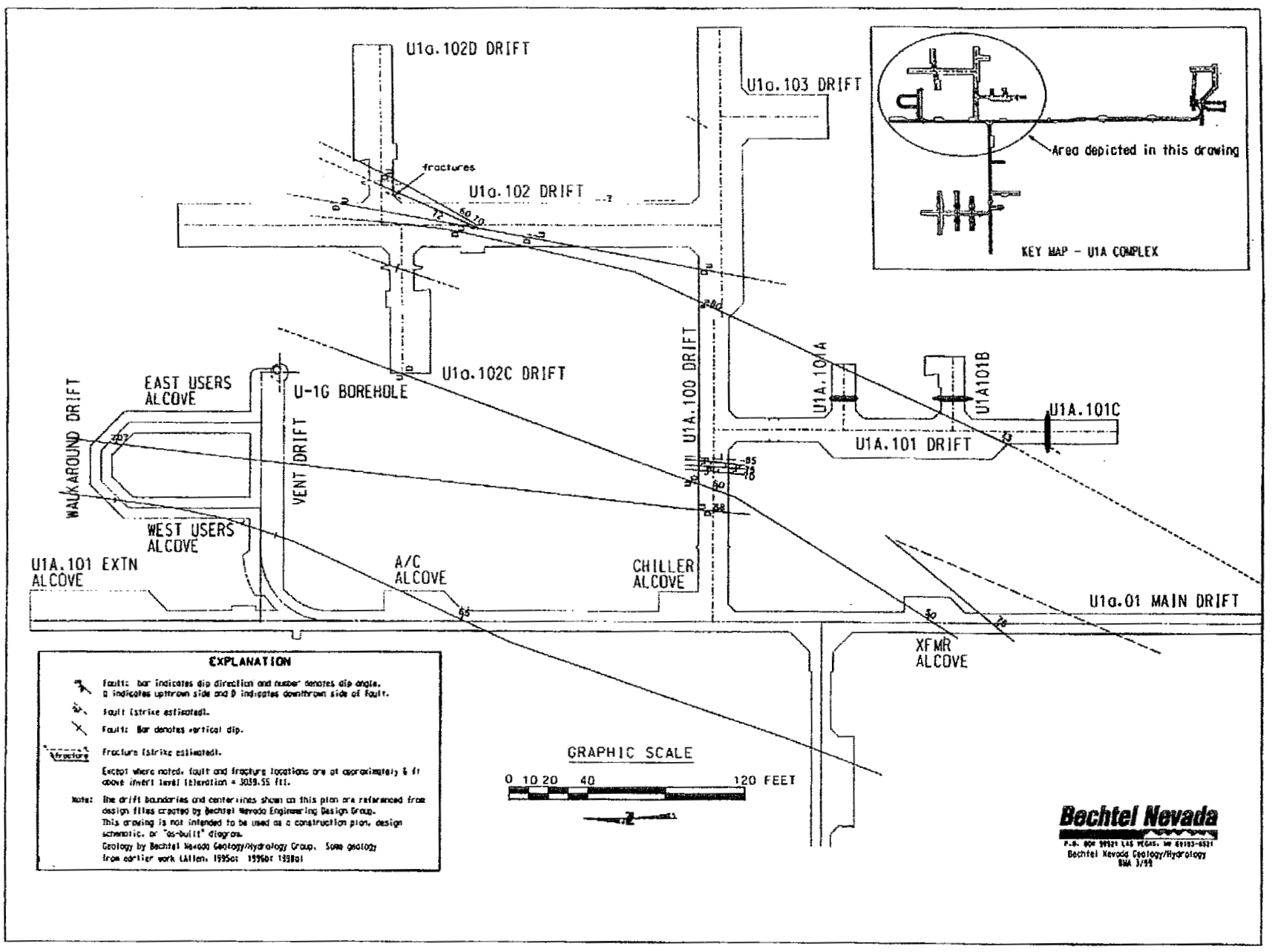




\section{PIANO Blast and Quasi-Static Gas Pressure}

We want the primary containment barrier to contain the shock and quasistatic gas pressure produced by the HE detonation. The BLASTX code Version 4.0 (Britt et. al., 1998) was used to estimate the shock and quasi-static gas pressure in the zero-room. BLASTX results indicate that following an initial short-lived shock with peaks which range from about $65-100 \mathrm{psi}$, a quasi-static gas pressure of about $3.7 \mathrm{psi}$ would be formed. This pressure would rapidly drop due to thermal conduction and porous flow of the detonation gas into the face of the zero-room. The BLASTX calculations were made without the shrapnel shield, with an LX-14 HE equivalency of 1.2 , and without the moderating influence of the experiment cube itself. The absence of the shrapnel shield in the calculations means that our calculations are conservative because the shrapnel shield would both reflect the shock away from the primary barrier and consume some of the energy from the shock front. A typical pressure profile is shown in Figure 7.

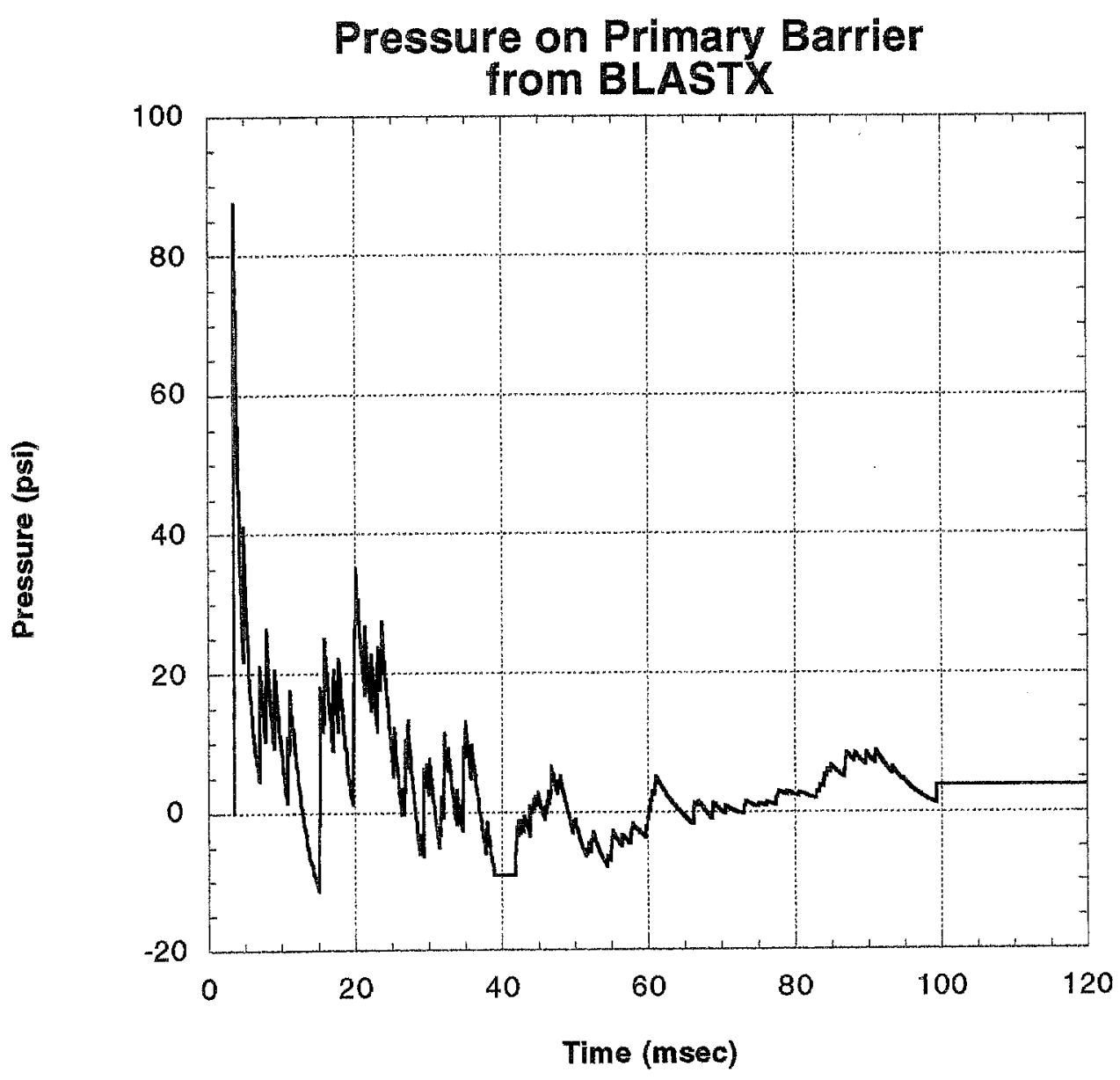

Figure 7. Pressure on the primary containment barrier at closest approach to the experiment. 
The zero-room volume used for the calculation was 12,366 cubic feet; the actual zero-room volume is about 12,838 cubic feet. No attempt was made to calculate the effect that the experiment cube has upon the pressures; however, it is obvious that the pressures are reduced by the experiment cube since it takes energy to break the cube apart so that the shock and gas pressure can escape. Both of these assumptions about the calculations also make the calculated pressures conservative for barrier design purposes.

The HE equivalency of LX-14 has been re-examined by John Pastrnak of LLNL. The BLASTX manual gives a HE equivalency of 1.8 for LX-14. This value seemed to be rather large. Pressures smaller than predicted (using a HE equivalency of 1.8) were observed on BAGPIPE. Recalculation of BAGPIPE pressures with a smaller HE equivalency gave estimated pressures which are in general agreement with the measured BAGPIPE pressures. TNT equivalency tables from the DOETIC and TM5 manuals give a value of 1.17 (see Appendix 2). Pastrnak contacted the BLASTX developers; after discussion with them, they decided to run the SAIC RAGE hydrocode for us to obtain peak pressure and shock impulse ratios as a function of scaled distances. From these calculations and from consideration of experimental and empirical data from LLNL Site 300 and from previous LLNL subcriticals, we decided that a HE equivalency of 1.2 for LX-14 would be a conservative value for the PIANO experiment. The Pastrnak memo on the TNT equivalency for LX-14 is included in Appendix 3.

PIANO cannot realistically produce any shock pressure on the secondary containment barrier. The shock must first escape from the PIANO zero-room. The most probable failure mode would be a failure of a glass optical port. After the shock escapes through the failed port, it would then have to go around two right angle corners and travel a considerable distance before meeting the secondary barrier. Any shock, which escapes from the zero-room, would be rather small by the time it reached the secondary barrier. An estimate of the quasi-static gas pressure on the secondary barrier was made by assuming that the primary containment barrier was absent. BLASTX was used to calculated the gas pressure in a large room whose volume was the same as the drift volume inside the secondary barrier. The initial gas pressure was calculated to be $0.15 \mathrm{psi}$; the pressure would rapidly fall to $0.02 \mathrm{psi}$. The pressure is very small because the volume of the secondary containment vessel is very large ( 363,770 cubic feet).

There will not be any gas bottles in the zero-room during experiment execution. The Mega-Sun ${ }^{\mathrm{TM}}$ flash lamps will contain a negligible amount of gas. Each flash lamp (a 2-inch-diameter 10-inch-long plastic tube) will contain 0.018 cubic feet of xenon at a pressure of about 40 psi. Lighting requirements for PIANO are being currently determined; it is anticipated that two flash lamps will be used during the experiment. The worst case scenario would involve 6 flash lamps. Bursting 6 flash lamps in the zero-room would provide an additional pressure rise in the zero-room of less than 0.001 psi. 


\section{Primary Containment Barrier}

The primary containment barrier is the structure in the U1a.102C drift which "seals" the drift forming the zero-room. This barrier is a duplicate of the primary containment barriers used for BAGPIPE and CLARINET with only a few minor modifications. This barrier was used as the primary containment barrier for the OBOE series of experiments in this alcove. The primary barrier has never been challenged during the OBOE series of experiments. The barrier has not been stressed with either shock or gas pressures from an OBOE experiment, as the OBOE experiment vessels successfully confined all $\mathrm{HE}$ products within the experiment vessel.

The primary containment barrier was constructed from steel I-beams, 1-inch steel plate, and fibercrete. The primary barrier was firmly attached to the drift walls by a grout keyway and to a steel pedestal captured by grout under the drift invert. The drift invert is covered with six inches of concrete. The penetrations through the primary containment barrier include a 42-inch-I.D. manway (craw1 tube), six 16.38-inch optical LOS pipes, and one airline/grout tube. There are no other penetrations through the primary containment barrier. The main drawings for this barrier are included in Appendix 4.

The 42-inch manway will be secured prior to detonation using two Class 75TB closures. These closures are rated for $175 \mathrm{psig}$ at $250^{\circ} \mathrm{F}$. On BAGPIPE and CLARINET, we used a modified closure for the inner closure on the manway. For PIANO, the manway with the two closures has been built as a unit by the manufacturer with the inner closure designed to be closed from the inside of the tube. The manway system is being used in its rated condition. We believe that this will provide a greater assurance that the manway will perform as rated.

The six optical LOS pipes will be used to transmit optical diagnostics data from the zero-room to the diagnostic recording equipment on the other side of the primary containment barrier. Minor modifications have been made to the optical LOS pipe design when compared to the BAGPIPE and CLARINET optical LOS pipes. These design changes were implemented for the $\mathrm{OBOE}$ experiment. The details of the modified design will be discussed in a later section.

For the OBOE experiments, the airline/grout tube was constructed from 10inch Schedule 60 pipe. During an OBOE experiment, the 10-inch pipe was closed with a 10 -inch butterfly victaulic valve and a blind flange. For the PIANO experiment, a modified blind flange with redundant valves will be used to close this opening. A Class 300 10-inch blind flange is being modified to hold two 4-inch Schedule 80 pipes. On the portal side of the barrier, the 4 -inch pipes will be closed with two 4-inch Class 300 valves on each pipe. The weight of the valves and of the valve support structure have been included in the analyses of the barrier conducted for the PIANO experiment. 
All seams in the one-inch steel plate are continuously welded. The crawl tube, the optical LOS pipe assemblies, and the airline/grout line are continuously welded to the 1-inch steel plate. The steel plate will be spot-welded to the I-beam structure on the diagnostics room side of the primary containment barrier. All welds were inspected. The pressure integrity of the primary barrier was tested by overpressurizing the zero-room to 2 psig. Any leaks in the weld discovered during this pressurization test were rewelded and then retested.

All welds on the zero-room side of the 1-inch steel plate were covered with Gluvit ${ }^{\mathrm{TM}}$. This material is a waterproof epoxy sealer. It is commonly used to seal leaky rivets on aluminum and steel ships. The Gluvit ${ }^{\mathrm{TM}}$ moves with the ship's hull as it vibrates and flexes and does not part from the members to which it is bonded. When used to seal steel ship hulls, a 10-mil coat will withstand greater than $4000 \mathrm{lbs}$ per sq. $\mathrm{ft}$. water pressure $(\sim 28 \mathrm{psi})$.

The barrier is attached to the alluvium via a grout keyway that securely fastens the barrier to the formation. A 2.5-foot-wide steel channel (part of which is formed by the 1-inch steel plate) was secured by rockbolts to the formation behind the keyway to secure. The keyway is approximately 2.5 feet side and 4 feet deep. The grout pipes in the keyway were carefully monitored to insure a complete fill of the grout ring with grout. After the grout had set up for 28 days, the other grout pipes in the grout ring were used to pressure grout around the keyway grout ring. Pressure grouting should fill any voids in either the alluvium or voids that might have formed at the interface between the keyway grout ring and the alluvium. That being the case, the absolute minimum unimpeded path length through the alluvium around the primary containment barrier exceeds 8 feet.

Finally, fibercrete was applied in a minimum thickness of six inches in two 3-inch passes over the primary containment barrier, the exposed portion of the keyway, and the zero-room walls. This is done before the invert is poured in the zero-room. In essence, we are forming a fibercrete "bottle" in the zero-room whose opening is on the face of the zero-room. A dense pattern of 1/2-in.-diam 5-in. long Nelson studs were welded to the steel plate before fibercreting to help secure the fibercrete to the steel plate and prevent spalling of the fibercrete after detonation.

The primary containment barrier has been designed to withstand blast and gas pressures during the PIANO experiment. Dynamic and static analyses have been conducted on the design including individual components of the design. The steel used in barrier construction has been tested and inspected to assure that the steel meets specifications. The analyses of the barrier were conducted at LLNL (Noble, 2000 - see Appendix 2). The finite element model used in the analysis builds upon the computational model used for the BAGPIPE experiment. That model was in good agreement with experimental values from the BAGPIPE experiment and with modal testing conducted on that barrier. The major conclusions of the finite element modeling are the following. 
Every structural component, with the sole exception of the fibercrete and grout while they are in tension, has a safety factor equal to or greater 3.0. In most cases, the safety factor is considerably larger than this. All weld loads are below the allowable resistance set by the American Welding Society. It should also be noted that for the steel materials, the dynamic yield was used to calculate the safety factors. This is a conservative assumption.

The fibercrete on the front of the barrier is expected to be damaged during the experiment; it is intended to absorb some of the energy from the blast. Hence, high tensile stresses are seen in some portions of the fibercrete in the calculations; however, this is not a containment concern since the fibercrete is doing exactly what it was designed to do. It is protecting the steel structure from the blast pressures. On the portal side of the barrier just below the manway at the girder-grout interface, there is a very small localized region of high tensile stress in the calculations. This tensile stress occurs in the grout for only a very short time period. The local tensile cracking does not affect the load-carrying capability of the structure. The region of high tensile stress only penetrates about $1 / 3$ of the thickness of the grout. These calculations used an elastic model to simulate the grout. If a more sophisticated grout material model, which included strain rate effects, were used in the calculations, it is very likely that no damage would be predicted in the grout. This is because at high strain rates, the tensile strength of grout can increase by a factor ranging from 1 to 6 . In summary, this is not a containment concern and is also not a structural concern. From a containment viewpoint, the structural failure of the primary barrier during the PIANO series of experiments is simply not a credible event.

As an additional containment measure, the diagnostics room side of the primary containment barrier will be covered with Versi-Foam ${ }^{\mathrm{TM}}$. The foam will act as the additional containment barrier for plutonium particulates. We view the possibility of seepage as extremely unlikely since the barrier has been designed and carefully constructed to withstand the pressure challenge from the PIANO experiment. However, with the amount of expensive diagnostics equipment in the nearby diagnostics rooms, the Versi-Foam ${ }^{\mathrm{TM}}$ should be an effective yet inexpensive additional barrier assuring containment within Vessel $\# 1$. 


\section{PIANO Optical Ports}

The primary containment barrier will contain six optical ports. The PIANO experiment will utilize all six optical ports.. During the PIANO experiment, all ports will contain either of two glass window assemblies. The PIANO optical port design follows the optical port design successfully used on HOLOG, BAGPIPE, and CLARINET. The PIANO optical port assemblies follow a pedigree that was documented in the HOLOG prospectus. The fundamental design features of the assembly have been thoroughly field- and laboratory-tested. For PIANO, there are minor changes to the spool piece into which the optical port assembly is mounted. This change was fully documented to the CRP for the OBOE series of experiments which are being conducted in the alcove. The changes were done to facilitate the alignment of the port assemblies during construction.

The optical ports are housed within steel circular housings which are welded into the primary containment barrier (see Appendix 6). The PIANO design uses optical port assemblies that are directly mounted to the steel circular housing that is welded into the containment barrier. Each optical port assembly is mounted on a steel circular housing made from 17-inch OD steel pipe with 1.5-inch wall thickness). The optical assembly is bolted to the steel circular housing with twelve bolts using two Buna-N O-rings to seal this connection. Each working optic port in the containment barrier will have two port assemblies.

The optical glass in a port assembly is made from 2-inch-thick 9-inchdiameter BK-7 glass. The optical glass is supported by two BJG \#9 bell jar Buna-N gaskets in the optical port assembly. A Buna-N O-ring supported by two backup rings is used to complete the sealing of the optical glass in the optical port assembly.

The optical port assemblies will be mounted in the primary containment barrier using a procedure which has been written to assure that the o-rings have been properly installed. The assembly procedures follow those developed for HOLOG include optical measurements to determine whether stress concentrations have been induced in the glass during the assembly process.

All optical port assemblies are protected from direct shrapnel impact by shrapnel shields. A large shrapnel shield is positioned about 40 inches from the PIANO experiement and occludes all optical ports from direct shrapnel attack. In addition, the optical ports have a snout to help protect the glass from reflected shrapnel. The snout was deployed previously on BAGPIPE and other open subcritical experiments. 


\section{Secondary Containment Barrier}

A secondary containment barrier was constructed in the U1a.100 drift for the HOLOG experiment. We intend to use this barrier as the secondary containment barrier for PIANO. The tunnel volume between the PIANO primary containment barrier in the U1a.101C drift and the secondary containment barrier in the U1a.100 drift will house the PIANO experiment's diagnostics instrumentation. The secondary containment barrier, the tunnel drift volume between the secondary and primary containment barriers, and the alluvium around the drift form Vessel $\# 2$ in the two nested containment vessel concept.

The PIANO experiment could, with absolute and total failure of the primary barrier, produce a maximum pressure of $0.14 \mathrm{psi}$ on the secondary containment barrier. The secondary containment barrier was designed to withstand a 7.6-psi static design load. This design load was selected during the construction of HOLOG and was based upon the maximum load the barrier would see given a $50 \mathrm{lb} \mathrm{HE}$ experiment in the tunnel volume that then existed. The Vessel \#2 volume is now considerably larger and the PIANO experiment is considerably smaller than $50 \mathrm{lb}$.

No significant changes have been made to the secondary barrier since it was constructed and used for HOLOG. The details of the secondary barrier design were presented in the HOLOG prospectus and will not be repeated here (see Appendix 5). Two wheels were added during the OBOE series of experiments to the bottom of each door to ease the door closing process during final button-up. The wheels do not support any of the door weight after the door is bolted shut.

The following is a short summary of the design and operational features of this barrier:

The secondary containment barrier has a large passageway to allow normal access to the 100 drift complex. These passageways will be sealed by two steel doors that are supported by a late-time beam.

No cables pass through the secondary containment barrier. All cables pass through Vistanex boxes located in the tunnel invert on the working point side of the secondary containment barrier. All cables are either factory gas-blocked or discretely gas blocked in the Vistanex box.

The penetrations through the secondary containment barrier include a hatch (for late-time man access), chilled water lines (for cooling of diagnostics equipment), and ventilation and air lines. The hatch through the secondary containment barrier will allow access to the 100 drift complex during button-up and reentry operations. This hatch will be bolted and gasketed tight during button-up operations. The water lines using for cooling electronic equipment in the 
diagnostics room will each have two redundant valves to close the water lines before zero-time. A large tank of chilled water in the diagnostics area will be used to circulate chilled water between the button-up and event reentry. The valves in the water lines will have up-hole readout of the status of valve closure so that the closure of the water lines can be positively assessed from the surface before zerotime. The valves are pressure-rated for 600 psi. The ventilation line through the secondary containment barrier will be interrupted during the button-up operations. The ventilation line will be closed with a blind flange and the butterfly valve in the ventilation line will be closed.

We intend to operate the secondary containment barrier on PIANO as we did on HOLOG, BAGPIPE, CLARINET, and the OBOE series. The secondary barrier will be pressure-tested before final button-up. This pressure test has been conducted on each LLNL sub-critical which has used this barrier as the secondary containment barrier. Occasionally, very small bubble-type leaks have been detected at the sill beam/grout interface. Liberal application of Gluvit ${ }^{\mathrm{TM}}$ has been used to seal these leaks. The leaks are believed to be caused by the heavy equipment, which traverses through the barrier during normal mining operations in the U1a.100 drift. The pressure testing provides assurance that the barrier will perform as designed and intended during the PIANO experiment. 


\section{Containment Vessel \#1 and \#2 Wall Treatment}

The walls of the zero-room and the diagnostics room are completely covered with fibercrete; the sole exception is a portion of the face of the zero-room. It is covered with fibercrete in order to provide the HE gases from the PIANO experiment with a path to porously flow into the alluvium away from the primary containment barrier and reduce any residual gas pressure in the zero-room. The fibercrete was installed in two passes to minimize or eliminate cracking in the fibercrete. The fibercrete was reinforced with a steel fiber. The fibercrete has a minimum compressive strength of 6000 psi in 28 days.

The fibercrete helps improve drift stability and reduces the potential of dust contamination for the complicated optical diagnostics which will be fielded on PIANO. In the zero-rooms, the fibercrete was troweled to embed the steel fibers and to eliminate the fibers as both a dust collector and a safety hazard. To further reduce the possibility of dust contamination, all fibercreted walls are covered with an elastomeric coating. As a by-product of treating the walls in this fashion to reduce dust contamination, the permeability of the fibercreted walls is reduced from the alluvial permeability of about 2 darcies to a permeability in the millidarcy range. This helps increases the effective path length for porous flow from the zero-room.

A portion of the face of the zero-room is not covered with fibercrete. A steel stud wall was constructed over top portion of the face; the steel stud wall was covered with a treated fabric (similar to furnace filter material) to reduce dust contamination for the optical diagnostics in the zero-room. 


\section{Cable Gas Blocking}

No cables pass through the primary or secondary containment barriers in the U1a.100 drift complex. All cables which exit the PIANO zero-room will go through one of the Vistanex boxes placed in the tunnel invert. Cables which will also exit the PIANO diagnostics room will go through Vistanex boxes placed in the tunnel invert just inside the secondary containment barrier. The cable gas blocking techniques used on PIANO closely follow what was successfully utilized on HOLOG, BAGPIPE, CLARINET, and OBOE. The Vistanex boxes on the PIANO series of experiments will be filled with either Vistanex or Holt Melt, depnding upon the availability of either material at NTS at Vistanex box fill time. Hot Melt is a generic substitute for Vistanex. Information about this material was presented to the CRP during the LANL CIMARRON presentation.

All cables will be either factory gas-blocked or discretely gas blocked in the field. The discrete cable gas blocking methods follow conventional underground nuclear testing practices. This includes the use of discrete blocks on multi-conductor cables and"birdcages" on delicate fiber optical. All gas blocks are located in the Vistanex boxes in the tunnel invert. Cable separators were installed to physically maintain cable separation of the cables in the invert when the cables were captured by the invert concrete pour. Table 1 lists the cable inventory and the type of gas blocking utilized for the cable which exit the PIANO zero-room.

\section{Table 1}

$\begin{array}{ll}\text { Cable Type (Gas blocking) } & \text { Quantity } \\ \text { RF-44 (Factory gas blocked) } & 66 \\ \text { MP-46 (Field gas blocked) } & 18 \\ \text { 3 Conductor \#8 (Field gas blocked) } & 4 \\ \text { Fiber optic cables (Birdcage) } & 53 \text { (4 birdcages) } \\ \text { X-ray cable (Field gas blocked) } & \leq 8 \\ \text { "C" cables (Pressure feedthrough) } & 34 \\ \text { Mega-Sun cables (Field gas blocked) } & \leq 4\end{array}$

The PIANO zero-room Vistanex boxes are placed in the drift invert on the working point side of the primary containment barrier. The Vistanex box itself is of typical DNA design; this typical design has been successfully utilized for many years on horizontal underground nuclear tests and eliminated the transport of gas and/or particulates down the cables and/or cable bundle past the box. The tubes which carry the cables into the Vistanex box will be totally filled with Sulfaset. This helps block the cable bundle and confines the Vistanex to the box. The Vistanex box will be placed below the drift invert on the working point side of the barriers. If gas and/or particulates migrate through the cables to the Vistanex box, the gas and/or particles will be still contained on the zero-room side of the primary containment barrier. The Vistanex box will be filled from the zero-room through two fill tubes to ensure a complete filling of the box. Pipe caps will then be reinstalled on the fill tubes in the zero room. 


\section{Containment Discussion}

The containment goal is to keep the SNM from the PIANO experiment contained within Containment Vessel \#1. The containment design must address the containment of any solid, liquid, and/or gaseous plutonium compounds.

The plutonium will be melted and blown to smithereens. The molten plutonium will react with the high explosive gases and the zero-room air producing a solid-phase plutonium aerosol and particulates. However, the size distribution and the chemical compositions of the resulting plutonium-bearing debris are somewhat uncertain.

The transport of gaseous plutonium compounds is not a credible threat on the PIANO experiment. The LLNL Isotope Sciences Division provided the following expert opinion regarding gaseous plutonium compounds and the possibility of plutonium aerosol transport in U1a alluvium for the HOLOG experiment. Their opinion is also applicable to the PIANO experiment (and probably all other subcritical experiments in U1a).

The possibility of producing volatile $\mathrm{Pu}$ compounds, which could be transported through the surrounding media in U1a experiments, is not consistent with the properties of any known volatile Pu compounds. The few volatile organo-plutonium compounds that are known are air and moisture sensitive and can be produced over only a fairly narrow temperature range in inert atmospheres. The HOLOG chamber will contain normal air with $50 \%$ or greater humidity. The surrounding media has $10 \mathrm{wt} \%$ or greater water content and is quite porous. There are no known actinide organo-compunds with high enough vapor pressure at room temperatures to migrate through the media at ambient temperatures. In the first subcritical experiments, the released energy will cause the majority of the plutonium to melt, thus precluding the formation of any organo-metallic compounds due to the high temperatures and the presence of water vapor and oxygen. The residual products of the high explosive, which have been calculated to reach $4000^{\circ} \mathrm{K}$ contain only small amounts of organics such as $\mathrm{CH}_{4}$, $\mathrm{CH}_{3}$, etc., compared to large residual $\mathrm{H}_{2} \mathrm{O}$ (gas), $\mathrm{CO}$ (gas), $\mathrm{C}$ (solid), $\mathrm{H}_{2}$ (gas), etc. Some of the hot $\mathrm{Pu}$ metal will undoubtedly react with oxygen-containing gases to form $\mathrm{PuO}_{2}$, a small amount of which may volatilize as $\mathrm{PuO}_{3}$ (gas) or $\mathrm{PuO}_{2}(\mathrm{OH})_{2}$ (gas), if the temperature exceeds $1273^{\circ} \mathrm{K}$. As this $\mathrm{Pu}$-containing gas cools, $\mathrm{Pu}$ vapor species will decompose to form fine particles of $\mathrm{PuO}_{2}$ (solid) which will be in the form of an aerosol. Although this type of aerosolized material can easily transport in a flowing gas, the bulk of the finely-divided solid should quickly coat out on the internal surfaces of the zero-room; any residuals will be trapped in the porous ground as the supporting gas $\left(\mathrm{N}_{2}, \mathrm{CO}\right.$, etc.) slowly permeates through it. Porous, damp ground 
should act as a thick HEPA filter, and should prevent aerosolized $\mathrm{Pu}$ from reaching access drifts or the surface.

We conclude that the transport of gaseous plutonium compounds is not a credible threat on the PIANO experiment. The data from the KISMET experiment supported by experience on the other subcritical experiments in U1a support the contention that the alluvium will act as a thick HEPA.

The impeded path from the PIANO zero-room face to the PIANO diagnostics drift is about 50 feet. If the fibercrete failed near the primary barrier (permitting the HE gas to have direct access to the alluvium near the primary barrier), the impeded path would be about 8 feet. The keyway for the primary barrier has been designed to take most of the pressure loading from the barrier in compression and minimizes our reliance upon the shear and/or tensile strengths of the grout. This design helps insure that the keyway grout will remain essentially impermeable after the experiment. Most of the plutonium will be deposited as soot on the fibercrete or alluvium. Any plutonium that is swept into the drift walls will be very effectively filtered from the HE gas by the alluvium (Wohletz et. al., 1996).

The experiment produces blast and gas pressures, which the primary barrier has been designed to withstand. The optical ports in the primary barrier are protected from direct shrapnel attack by a shrapnel shield close to the experiment and by a shield on the front of each optical port. The two most probable pathways, which could lead to a containment failure, are 1) through pinholes in the welds in the primary containment barrier and 2) around the primary containment barrier through enhanced flow channels in the alluvium.

The primary containment barrier has been engineered to withstand the dynamic and static loads that the PIANO experiment will place upon it. The structural components have large safety factors. The primary barrier will not massively fail during experiment execution. Pinholes in the welds, if they exist, would be a credible pathway that could lead to a containment failure. During construction, all welds were inspected; all welds not meeting welding standards were rewelded. After the steel barrier was constructed, the zero-room was pressure tested. All leaks were identified and those welds were rewelded. After the welds were pressure-tight, all welds on the zero-room side of the primary barrier were covered with Gluvit ${ }^{\mathrm{TM}}$. The diagnostics-room side was covered with Versi-Foam ${ }^{\mathrm{TM}}$. Both of these coatings also seal the primary barrier so that if any welds develop pinholes during the experiment, the welds themselves will either remain sealed (by Gluvit ${ }^{\mathrm{TM}}$ ) or will have another barrier behind them (the Versi-Foam ${ }^{\mathrm{TM}}$ ) to stop seepage from entering the diagnostics area. A 6-inch-thick layer of fibercrete (sealed with an elastomeric coating) was emplaced across the front of the steel barrier to add more strength and further protect the welded seams and the steel structure. We believe that this barrier has several levels of redundancy built into the design that will help prevent seepage from occurring through the barrier. 
We have not found any flow channels that would enhance SNM transport through the alluvium around the primary containment barrier. We have pressuregrouted around the keyway in order to fill any small voids, which might have existed. We have found nothing in the geology that was abnormal for the U1a alluvial environment. The alluvium in the walls of the PIANO zero-room looks similar to the alluvium in other SCE zero-rooms.

We conclude that, while the transport of SNM outside Containment Vessel \#1 is a credible threat on the PIANO experiment, the likelihood of this occurring is very small. There are redundancies in the design of Containment Vessel \#1 that will prevent any SNM from reaching the diagnostics room. We fully expect that the LLNL containment goal (to keep the SNM contained within Containment Vessel \#1) will be completely achieved. 


\section{References}

Allen, B. M., 1995, "Preliminary Geologic Site Characterization of the LYNER Horizontal Drift Complex, Yucca Flat, Nevada Test Site".

Allen, B. M., 1996, "Preliminary Geologic Site Characterization of the LYNER. U1a.100 and U1a.101 Drifts, Yucca Flat, Nevada Test Site".

Allen, B. M., 1996, "Preliminary Geology of the LYNER U1a.03 Drift".

Allen, B. M., 1999, "Geology in the U1a.102C and U1a.102D Drifts, U1a Complex".

Britt, J. R. et. al., 1998, “BLASTX Version 4.0 - A User's Manual for the BLASTZ Code, Version 4.0, U.S.A.E. Waterways Experiment Station.

Burkhard, N. R., 1996, "Containment Prospectus for the HOLOG Experiment", Lawrence Livermore National Laboratory.

Burkhard, N. R., 1997, "Changes to the Containment Plan for the HOLOG Experiment - Revision 1", Lawrence Livermore National Laboratory.

Burkhard, N. R., 1998, "Containment Prospectus for the BAGPIPE Experiment", Lawrence Livermore National Laboratory.

Burkhard, N. R., 1998, "Containment Prospectus for the CLARINET Experiment", Lawrence Livermore National Laboratory.

Burkhard, N. R., 1999, "Containment Prospectus for the OBOE Experiments", Lawrence Livermore National Laboratory, UCRL-ID-134378.

Drellack et. al., 1989, "Geology of the U1a.01 Horizontal Drift Complex, southwestern Yucca Flat, Nevada Test Site".

Kunkle, Thomas, 1996, "Containment Information for REBOUND", Los Alamos National Laboratory.

Noble, C., 2000, "A Blast Analysis of a Steel Barrier Design Used for Subcritical Experiments", Lawrence Livermore National Laboratory, UCRL-ID-141447.

Pastrnak, John, "Update Status of LX-14/TNT Equivalency for BLASTX Calculations", Lawrence Livermore National Laboratory memo (See Appendix), September 25, 2000.

Wohletz et al., 1996, "KISMET Tungsten Dispersal Experiment", Los Alamos National Laboratory, LA-13227. 


\section{Appendices}

1. Geology of the U1a.102C Drift

2. A Blast Analysis of a Steel Barrier Design (UCRL-ID-141447)

3. LX-14 TNT Equivalency Memo

4. Primary Barrier Drawings

5. Secondary Barrier Drawings

6. Optical Port Drawings

7. Shrapnel Shield Sketch 
Appendix 1

Geology of the U1a.102C Drift 


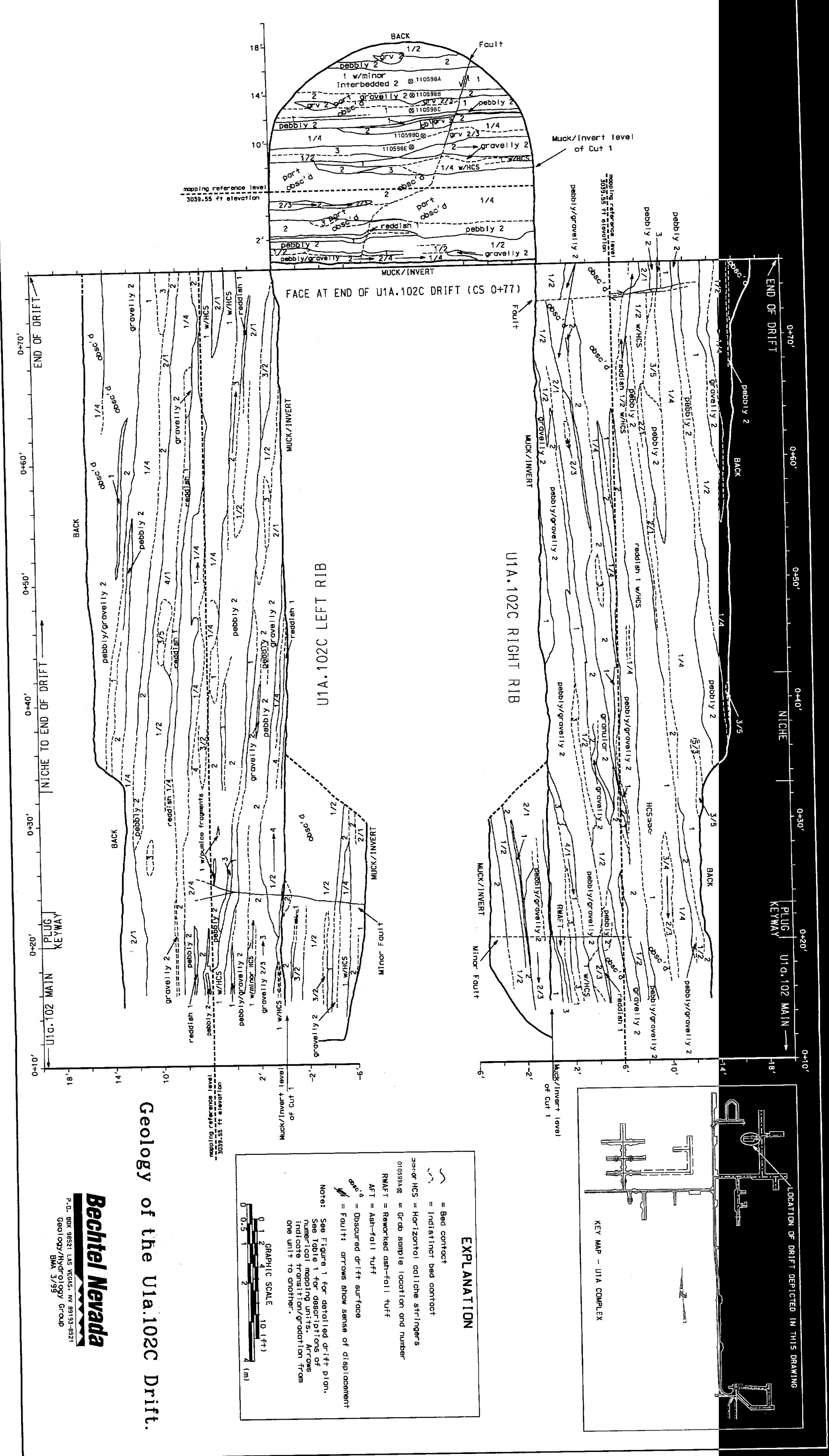




\section{Appendix 2}

A Blast Analysis of a Steel Barrier Design

Used for Subcritical Experiments 
U.S. Department of Energy

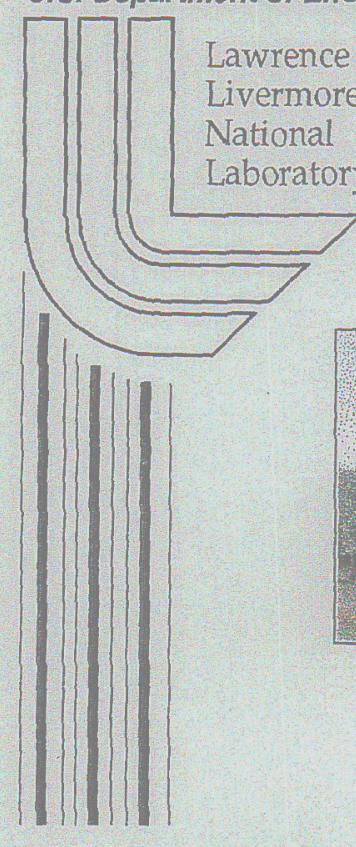

\section{A Blast Analysis of a Steel Barrier Design Used for Subcritical Experiments}

C. Noble ${ }^{\dagger}$

+ Structural and Applied Mechanics Group, LLNL

\section{August 2000}
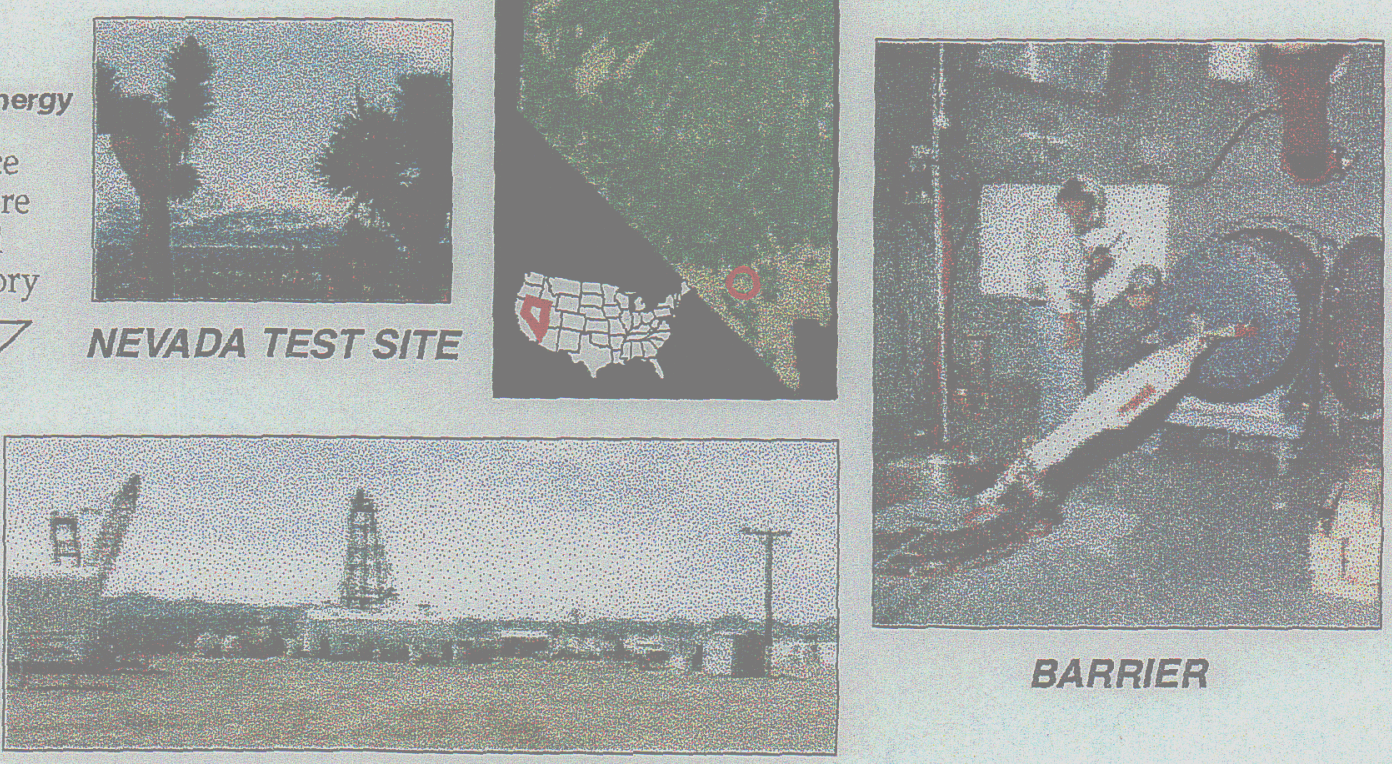

BARRIER

U1A COMPLEX 


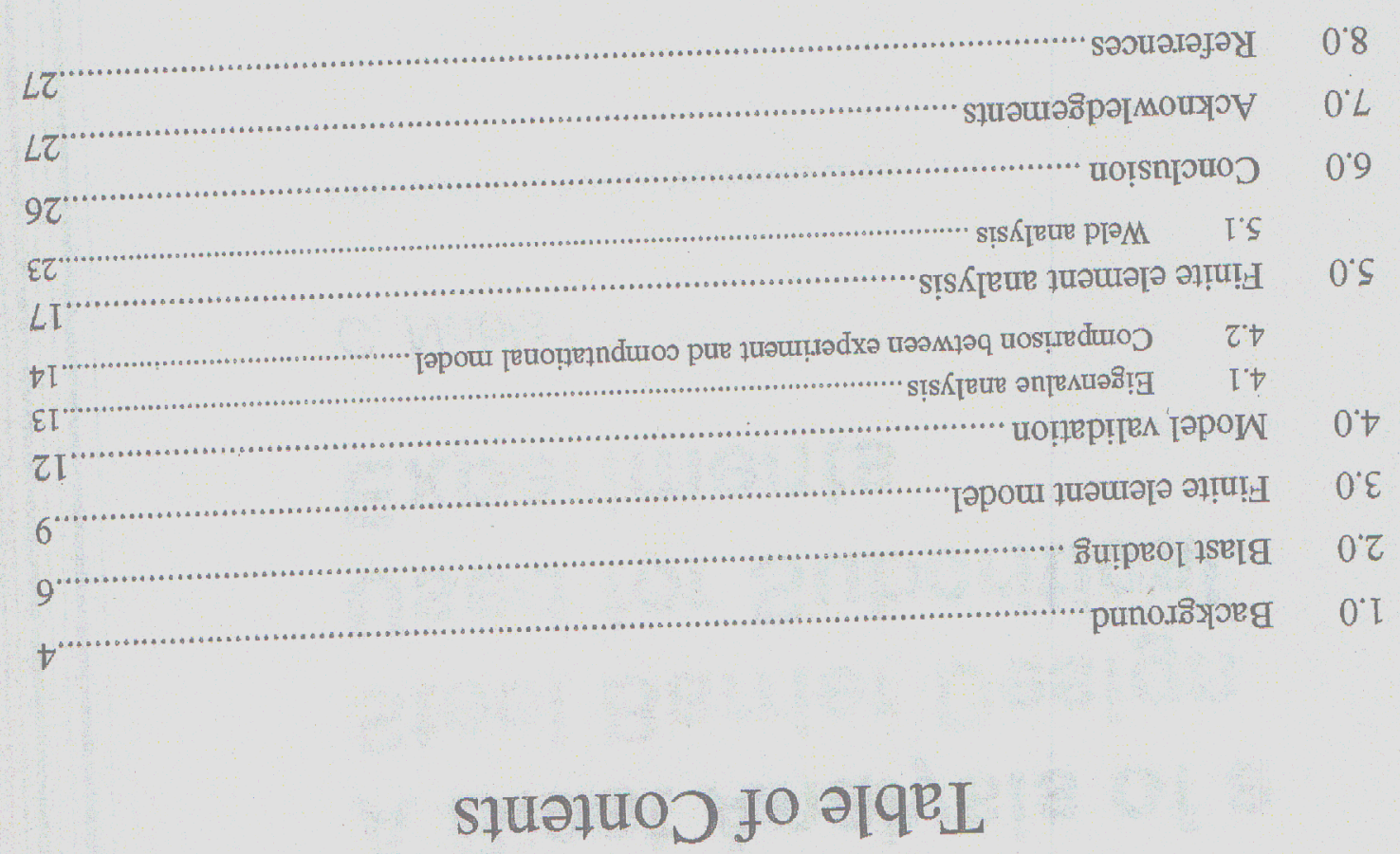


FIGURE 1. U1A.102C barrier configuration: a) elevation looking towards working point side or experiment side; b) elevation looking towards portal side or tunnel side; c) section $\mathrm{A}$.

FIGURE 2. a). Experiment configuration for final experiment of U1A.102C alcove; b). pressure comparison between Bagpipe design pressures and U1A.102C barrier predicted pressures.

FIGURE 3. Finite element model used in hydrocode simulation. .................................8

FIGURE 4. Pressure comparison between ALE3D, TM5-1300, and BlastX................

FIGURE 5. a). Exploded view of finite element model and b). grouttube detail..........11

FIGURE 6. Pressure time history distribution over the face of the barrier...................12

FIGURE 7. NIKE3D eigenvalue value analysis resulted in a fundamental frequency of $142.7 \mathrm{hz}$.

FIGURE 8. Strain gage locations for Bagpipe experiment conducted September 26, 1998.

FIGURE 9. Strain comparison between experimental values, computed values using Bagpipe model, and computed values using current model.

FIGURE 10. a). Strain comparison between experimental values, computed values using Bagpipe model, and computed values using current model; b). bar chart comparing peak strains.

FIGURE 11. Maximum stress locations for: a). faceplate and b). grillage .....................18

FIGURE 12. Maximum stress locations for concrete keyway and pedestal..................19

FIGURE 13. Maximum stress locations for shotcrete. ...............................................20

FIGURE 14. Maximum compressive stress for alluvium. .........................................21

FIGURE 15. Maximum von Mises stress locations for: a). 1" aluminum plate; b). grouttube; $c$ ). saddle plate; d). tubing; e). manway and f). optical port lid (assumed steel material)

FIGURE 16. Stress time histories for key structural components. The element which received the maximum stress was used for these time histories. (Note:

F.E.M. did not include damping). ....................................................22

FIGURE 17. Critical locations chosen for detailed weld analysis. ..............................25

FIGURE 18. a). Required membrane resultants; b.) required bending resultants; c.) fillet

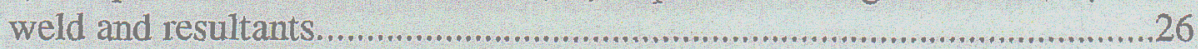




\subsection{Background}

The Lawrence Livermore National Laboratory's $\mathrm{N}$ Program has been fielding a number of subcritical experiments (SCE), which study the response of plutonium to high-explosive shock, at the Nevada Test Site over the last two years. The original methodology consisted of firing each subcritical experiment in a dedicated alcove mined 962 feet below Yucca Flat at the Nevada Test Site's U1A complex. Because each experiment had its own protective barrier, the cost and time associated with mining and equipping these alcoves resulted in a very slow turnaround between experiments. Three Livermore SCEs were conducted in this manner. HOLOG was the first LLNL SCE. The second was the Bagpipe SCE conducted on September 26, 1998, and the third was Clarinet conducted February 9,1999. All tests were extremely successful. The barriers were designed to withstand the explosive overpressure determined by the containment scientist. A great deal of structural analysis and model validation was conducted for the Bagpipe barrier, since this SCE had planned to use a larger quantity of HE than the other two. A series of modal analysis testing was conducted on the barrier to compare the fundamental frequency of the actual structure to that of the finite element model. In addition, the Bagpipe barrier was instrumented with a number of gages that measured the pressure loading, acceleration of the barrier, and strain during the subcritical experiment. This data was eventually compared to the finite element model. The finite element model strains correlated very well with the experimental results. A good portion of this data will be represented in this report to validate the current finite element model.

The current methodology for conducting SCEs consists of conducting smaller individual experiments within steel vessels located behind a structural barrier, similar to the Bagpipe barrier (see Figure 1). LLNL may conduct up to 12 SCEs in this manner for the Oboe series. The vessels allow the experiment to be precisely positioned at the optimum location for the fixed diagnostics array. Once the experiment is complete, the vessel is moved out of the way in the same alcove so that the next experiment may be conducted six to eight weeks later. The used vessels are entombed in grout in the experiment alcove to assure safety and security.

Once all of the vessels have been expended, a final "bare" experiment will be conducted before the alcove is abandoned. Since the final experiment has a different testing configuration with a different explosive weight and standoff distance than Bagpipe or Clarinet, a separate structural analysis is needed. This report will concentrate primarily on the final "bare" experiment for the U1A.102C alcove. 
a).

Elevation Looking

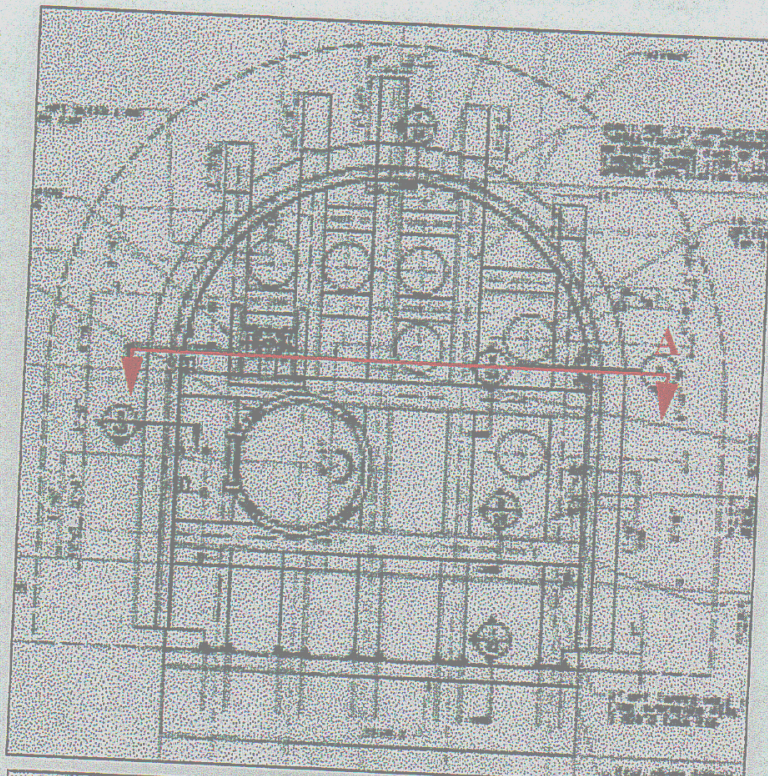

b). Elevation Looking

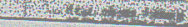
Towards Portal

c). Section $\mathbf{A}$
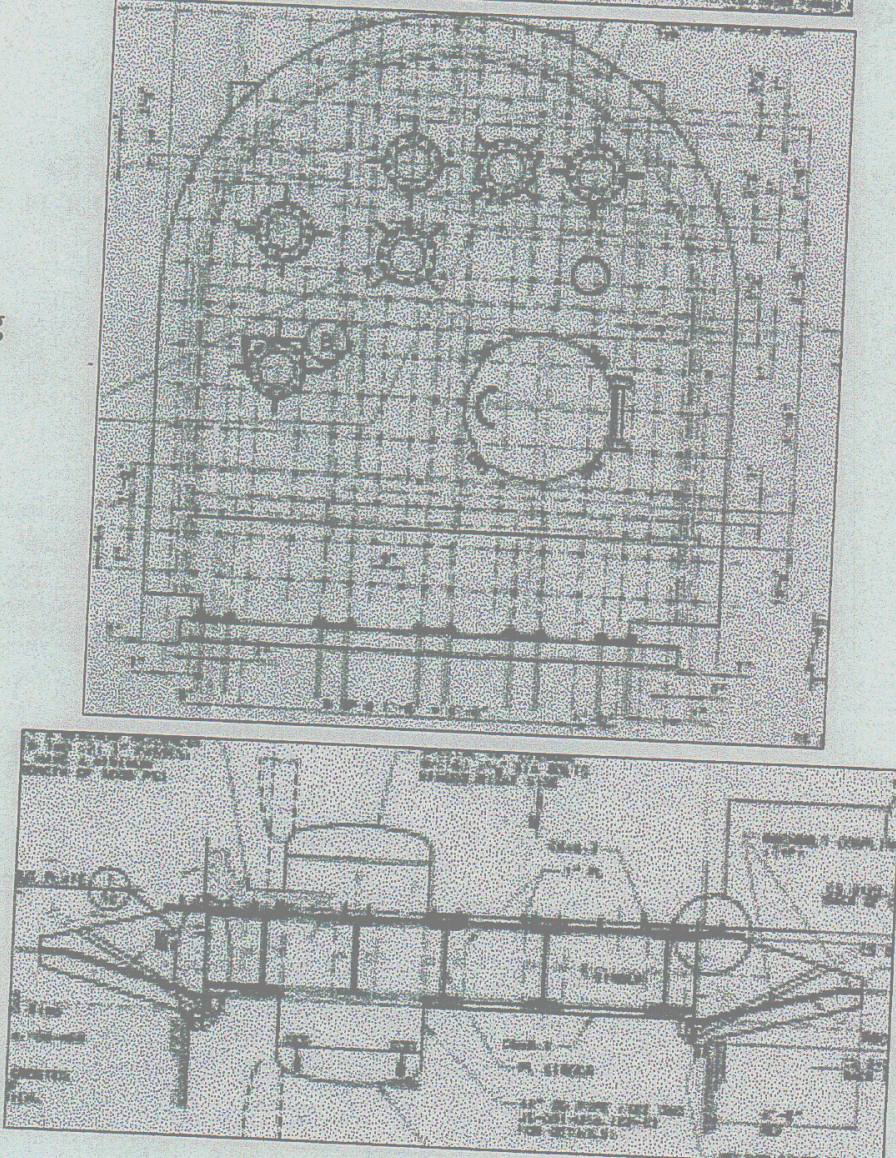

FIGURE 1. U1A,102C barrier configuration: a)

experiment side; b) elevation looking towards portal side or tunnel side; c) section A.

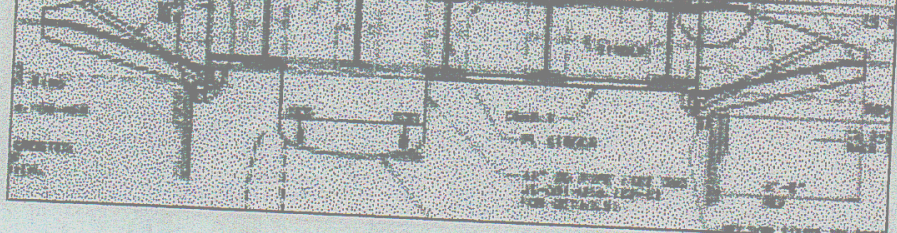




\subsection{Blast loading}

The blast loadings for the final experiment in the U1A.102C alcove were calculated using the code BlastX Version 4.0. The proposed loading for this analysis was considered to be 5 lbs of LX-14 placed $3 \mathrm{ft}$. off the ground at a distance of $11 \mathrm{ft}$ (Figure 2). Pressure time histories generated from BlastX were passed on to the analyst from Burkhard [Ref 1] for use in DYNA3D, a nonlinear explicit three-dimensional finite element code. Because the barrier currently being studied is similar to the Bagpipe containment barrier, it is instructive to report the Bagpipe design pressures and resulting stresses for comparison. Figure 2 shows a comparison between the U1A.102C barrier and Bagpipe predicted pressures. Note that the Bagpipe barrier, which is essentially the same as the one currently being studied, was designed to withstand a pressure load with a peak reflected pressure of 200 psi and a reflected impulse of $1.36 \mathrm{psi}$-sec. The predicted pressures for the U1A.102C barrier, on the other hand, have a peak reflected pressure of $100 \mathrm{psi}$ and a reflected impulse of $0.45 \mathrm{psi}-\mathrm{sec}$. Therefore, the peak pressures are a factor of two less than Bagpipe pressures, and the reflected impulse is a factor of three less than what was used to design Bagpipe. It should be noted that impulse, not peak pressure, is the parameter that is more likely to dominate the structural response.

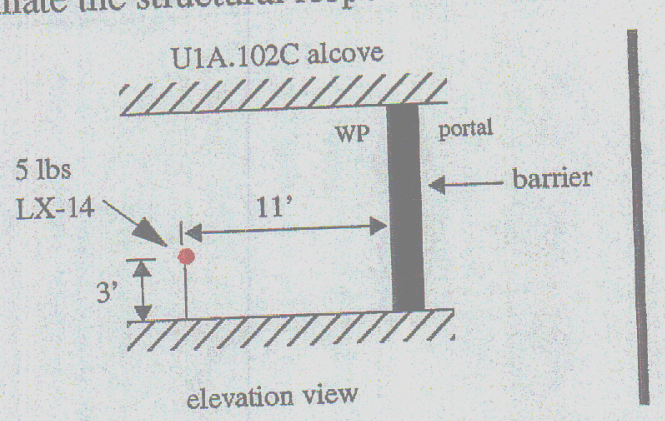

a)

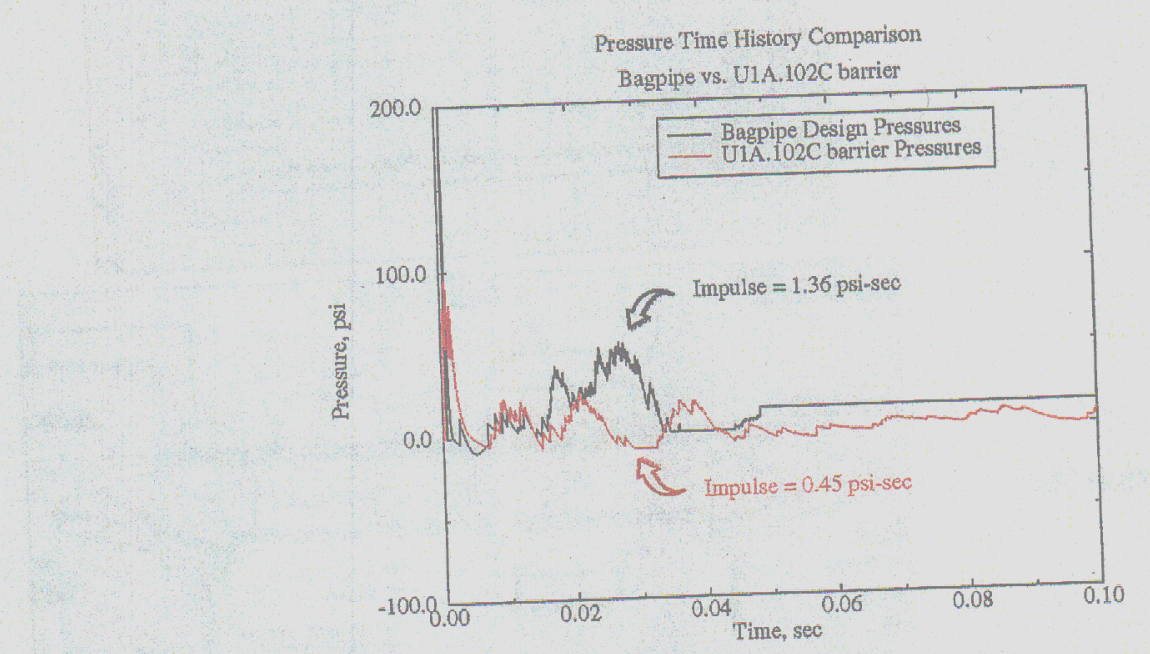

b)

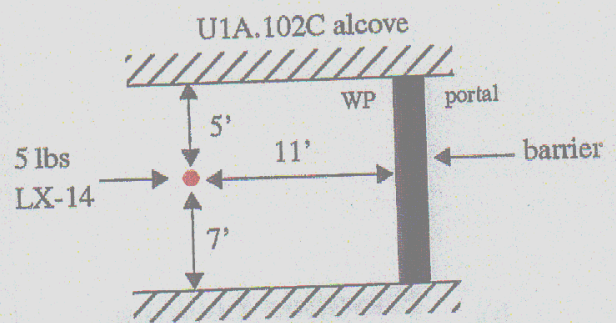

plan view

FIGURE 2. a). Experiment configuration for final experiment of U1A.102C alcove; b). pressure (U1A.102C barrier predicted pressures. 
The resulting Bagpipe predicted stresses and safety factors are summarized in Table 1. Since the peak reflected pressure and impulse are so much lower for the U1A.102C barrier, the stresses should be much smaller than the Bagpipe predicted stresses.

TABLE 1. Comparison of Barrier Safety Factors.

\begin{tabular}{|c|c|c|}
\hline $\begin{array}{l}\text { Structural } \\
\text { Component }\end{array}$ & $\begin{array}{l}\text { Maximum Stresses } \\
\text { for Bagpipe Barrier }\end{array}$ & $\begin{array}{c}\text { Safety Factors for } \\
\text { Bagpipe Barrier }\end{array}$ \\
\hline Faceplate/Groutplate & $12,900 \mathrm{psi} / 24,700 \mathrm{psi}$ & $4.33 / 2.7$ \\
\hline Grillage & $24,340 \mathrm{psi}$ & 2.73 \\
\hline $\begin{array}{l}\text { Grout Compressive } \\
\text { Stress }\end{array}$ & 1,670 psi & 3.0 \\
\hline Grout Tensile Stress & 2,080 psi & 0.2 \\
\hline $\begin{array}{c}\text { Alluvium Compres- } \\
\text { sive Stress }\end{array}$ & $523 \mathrm{psi}$ & 2.2 \\
\hline
\end{tabular}

Two other methods were used to check the results obtained by BlastX. Blast pressures were determined using both the military blast manual TM5-1300 and ALE3D, an Arbitrary Lagrangian-Eulerian three-dimensional hydrocode program developed at LLNL. The majority of the blast effects data in TM5-1300 pertains to the blast pressures output of bare spherical TNT explosive. However, the data can be extended to include other potentially mass-detonating materials by relating the explosive energy of the effective charge weight of the material in question to that of an equivalent weight of TNT. Using the correct TNT equivalency [Ref 4] for the experiment in question, the peak reflected pressure and reflected impulse was determined to be 90.18 psi and 0.06 psi-sec. TM5-1300, however, does not take into account the effects of confinement. For a confined explosion, such as the one being studied, the actual distribution of the blast loads is highly irregular because of the multiple reflections and time phasing that occurs. Therefore, one can only compare the data obtained by TM5-1300 with the first triangular pulse determined by BlastX, which has a peak reflected pressure of 100 psi and a reflected impulse of 0.13 psisec.

In order to properly capture the blast wave propagation through the alcove, the ALE3D hydrocode was also used for this study. ALE3D has the ability of modeling high explosives using equation of state formulas, the ability to model the propagation of shock waves in various media, and the ability to handle problems in which gross deformation of objects would normally tangle a lagrangian mesh. A finite element model of the alcove, barrier, air, and explosive were modeled in order to calculate the blast pressures imposed on the barrier (see Figure 3). Due to the difficulty of modeling the actual shape of the alcove in ALE3D, the model was simplified. In actuality, the room opens up to the left resulting in an alcove that is $\mathrm{L}$-shaped with a total volume of 12,366 cubic feet. The finite element model assumes it opens up on both the left and right sides with a total volume of 10,320 
cubic feet. In order to accurately model the blast wave propagation, a total of 860,000 brick elements were used in the simulation. The simulation was conducted on ASCI Blue using a total of 32 processors.

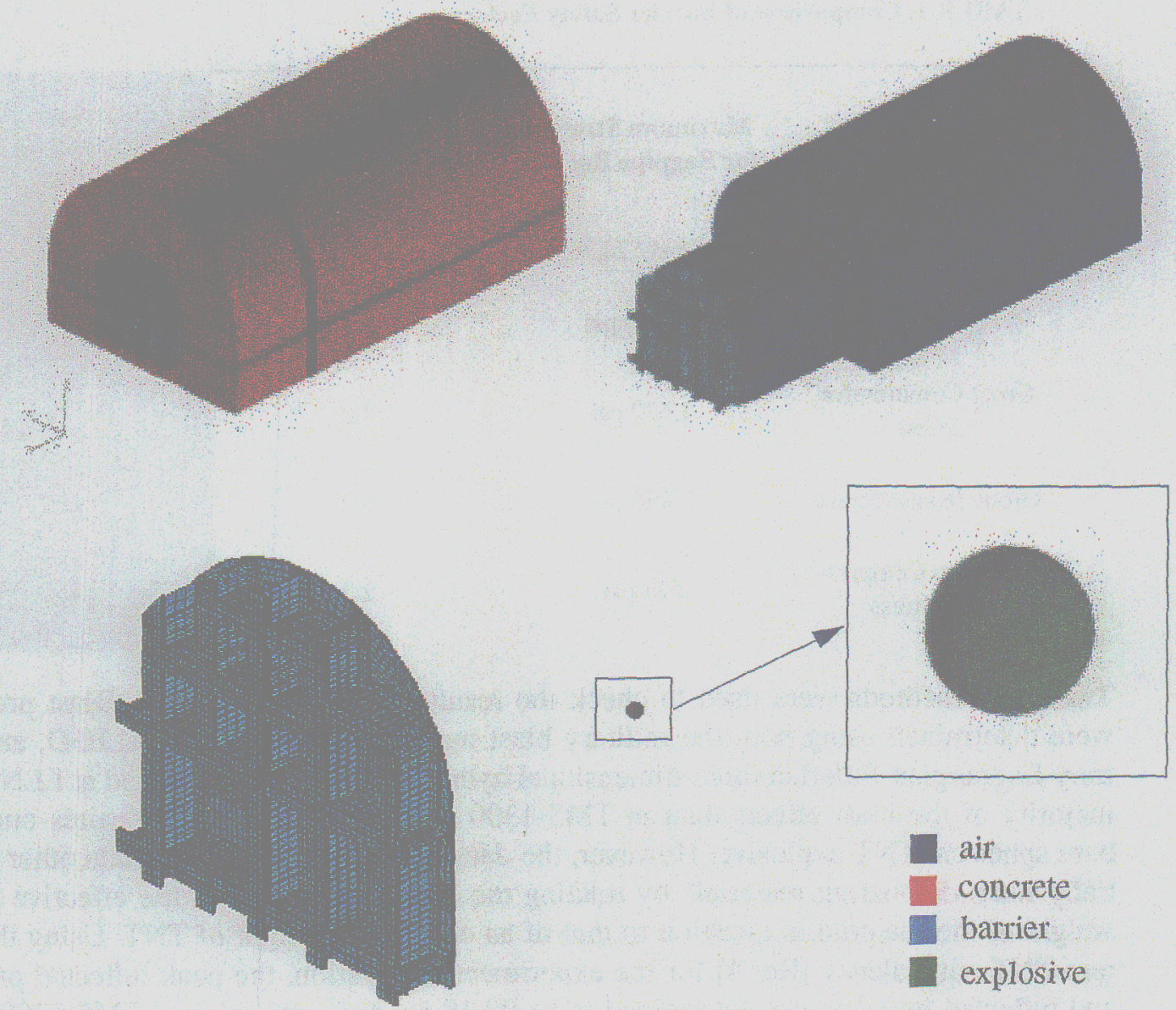

FIGURE 3. Finite element model used in hydrocode simulation.

The resulting ALE3D pressure load on the structure is shown in Figure 4. This plot also shows the TM5-1300 and BlastX predicted pressures for comparison. The ALE3D results correlated very well to the BlastX results. Although ALE3D has a smaller peak pressure, both loadings have the same overall shape. It should also be mentioned that a slightly larger amount of HE (approximately $1 \mathrm{lb}$. more than BlastX and TM5-1300 calculation) was used in the ALE3D calculation. Since TM5-1300 and ALE3D both have smaller impulses and peak pressures, one could make the judgment that BlastX calculates pressures that are a little conservative. In addition, since BlastX appears to give an upper bound to the predicted pressures, it seems reasonable to use the BlastX data for design and analysis of the subcritical barriers. 


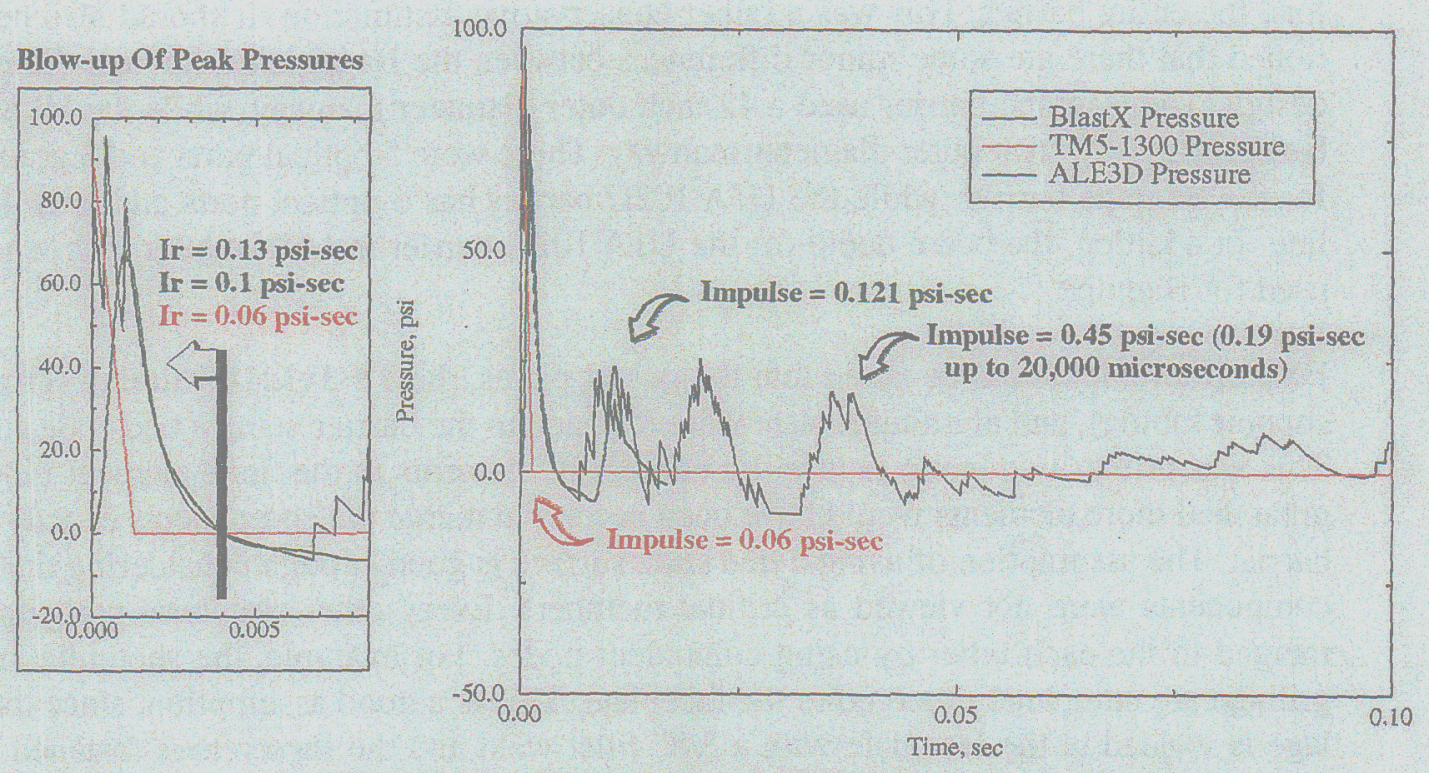

NOTE: Due to the expensive nature of the ALE3D calculation, the simulation was stopped by the user at 20,000 microseconds.

FIGURE 4. Pressure comparison between ALE3D, TM5-1300, and BlastX.

\subsection{Finite element model}

The DYNA3D finite element model of the U1A.102C barrier consisted of approximately 120,000 brick elements and 25,000 shell elements. The three-dimensional model is shown in Figure 5. A summary of all of the material properties used in the finite element models have also been provided in Table 2 . These material properties are the same as those used for the previous barriers. The primary model used to analyze the Bagpipe barrier was considerably more simple than the one being used in this study. The reasons behind using a higher fidelity model for this analysis was the following:

1. Although the final analysis of Bagpipe used a simple beam model, two other more detailed finite element models were used in conjunction with the beam model.

2. More accurate concrete and alluvium stresses can be determined using a more complex three-dimensional model. For Bagpipe, final concrete stresses were determined using a simple hand calculation based on beam forces.

3. By using a more complex model, the concrete and alluvium could be modeled exactly. This resulted in a better approximation for the boundary conditions than what was used in the Bagpipe beam model.

4. The computational speed of an SMP version of DYNA3D allowed for a higher fidelity model to be used in this study.

Because the pressure loading is not usually very uniform over the face of the barrier, 20 different pressure time histories calculated by BlastX were used as the loading in the anal- 
ysis (see Figure 6). The Bagpipe analysis, on the other hand, used the peak pressure to load the entire barrier. This was a rather conservative assumption. It should also be mentioned that there are some minor differences between the Bagpipe design and the current design. The Bagpipe barrier used a 42 inch outer diameter manway, while the U1A.102C barrier uses a 44 inch outer diameter manway. There were 5 optical ports and 2 grout lines for the Bagpipe barrier, while the U1A.102C barrier has 6 optical ports and only 1 grout line. In addition, the beam depth for the U1A.102C barrier is $1 / 8$ " smaller than what was used for Bagpipe.

Furthermore, it should be noted that the gusset plates, the TS $3 \times 3 \times 1 / 4$ " tubing (grouttube support tubing), and aluminum plate were fastened to the barrier using a tied slide surface. This was primarily done to reduce the number of elements in the finite element model. A great deal more elements would have been needed to merge the components exactly to the barrier. The assumption of using a tied slide surface is good enough considering that these components were not viewed as critical members. Every other structural component is merged to the each other by using coincident nodes. For example, the shotcrete and the grillage are completely merged to the faceplate. This is a good assumption, since the grillage is welded to the faceplate with a $3 / 8^{*}$ fillet weld and the shotcrete is fastened to the faceplate with the help of $1 / 2$ " diameter $\times 51 / 4$ " long nelson studs placed across the working point side of the faceplate (see drawings JS-001-U1a.102-S1 and S2).

TABLE 2. Material properties used for analysis

\begin{tabular}{|c|c|c|c|}
\hline Structural Component & $\begin{array}{c}\text { Mass } \\
\text { Density } \\
\left(\text { lbs-sec }{ }^{2}\right. \\
\left.\text { in. }{ }^{4}\right)\end{array}$ & $\begin{array}{l}\text { Elastic } \\
\text { Modulus } \\
\text { (psi) }\end{array}$ & $\begin{array}{l}\text { Poisson's } \\
\text { Ratio }\end{array}$ \\
\hline faceplate/groutplate & $7.324 \mathrm{E}-04$ & $29.0 \mathrm{E}+06$ & 0.29 \\
\hline grillage & $7.324 \mathrm{E}-04$ & $29.0 \mathrm{E}+06$ & 0.29 \\
\hline concrete & $2.122 \mathrm{e}-04$ & $4.03 \mathrm{E}+06$ & 0.19 \\
\hline alluvium & $1.940 \mathrm{E}-04$ & $2.0 \mathrm{E}+05$ & 0.25 \\
\hline shotcrete & $2.122 \mathrm{E}-04$ & $4.4 \mathrm{E}+06$ & 0.19 \\
\hline $\begin{array}{l}\text { optical ports/manway/gusset plates/grouttube } \\
\text { tubing and saddle plates }\end{array}$ & 7.324E-04 & $29.0 \mathrm{E}+06$ & 0.29 \\
\hline 4" SCH pipe with added valve mass & $4.61 \mathrm{E}-03$ & $29.0 \mathrm{E}+06$ & 0.29 \\
\hline aluminum grouttube plate & $2.54 \mathrm{E}-04$ & $10.0 \mathrm{E}+06$ & 0.29 \\
\hline
\end{tabular}




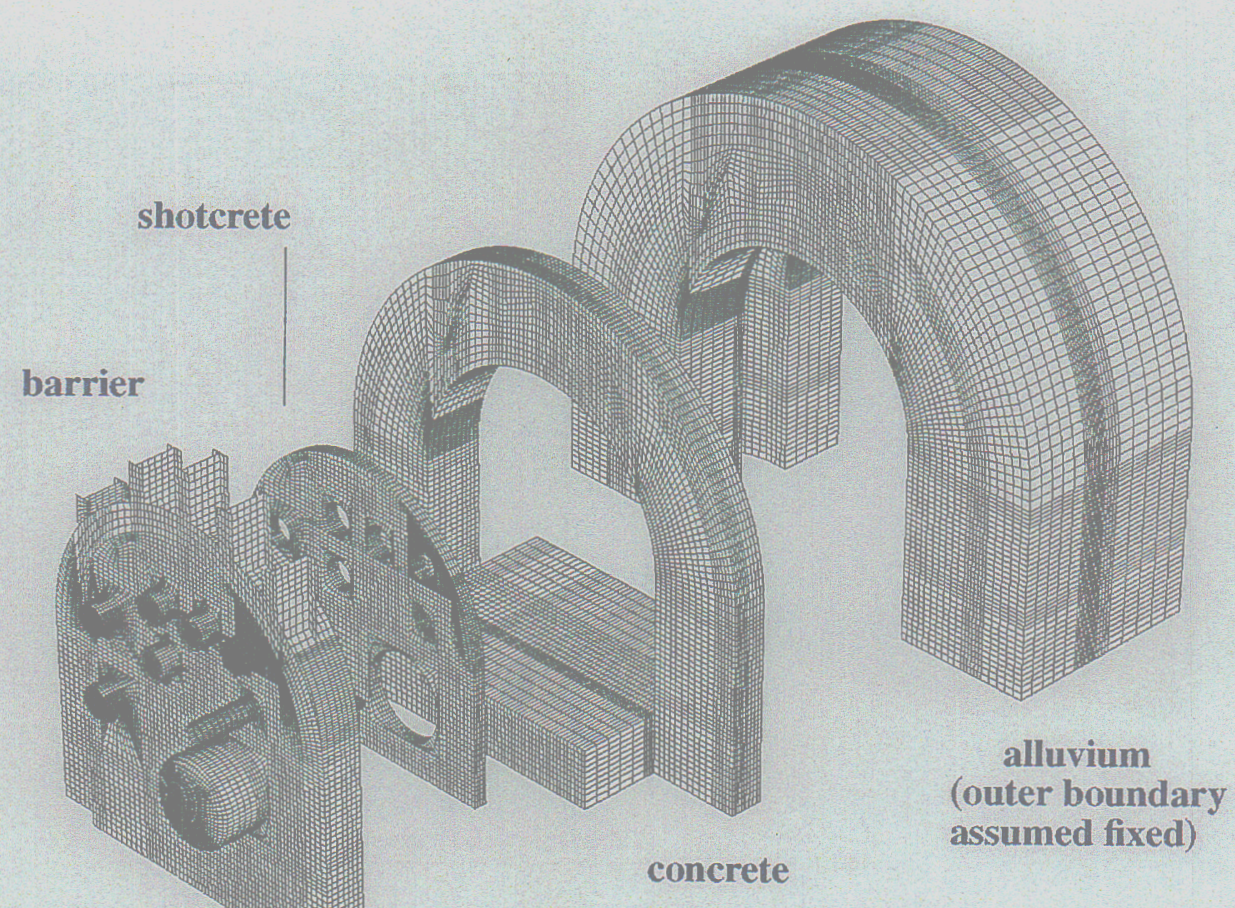

a).

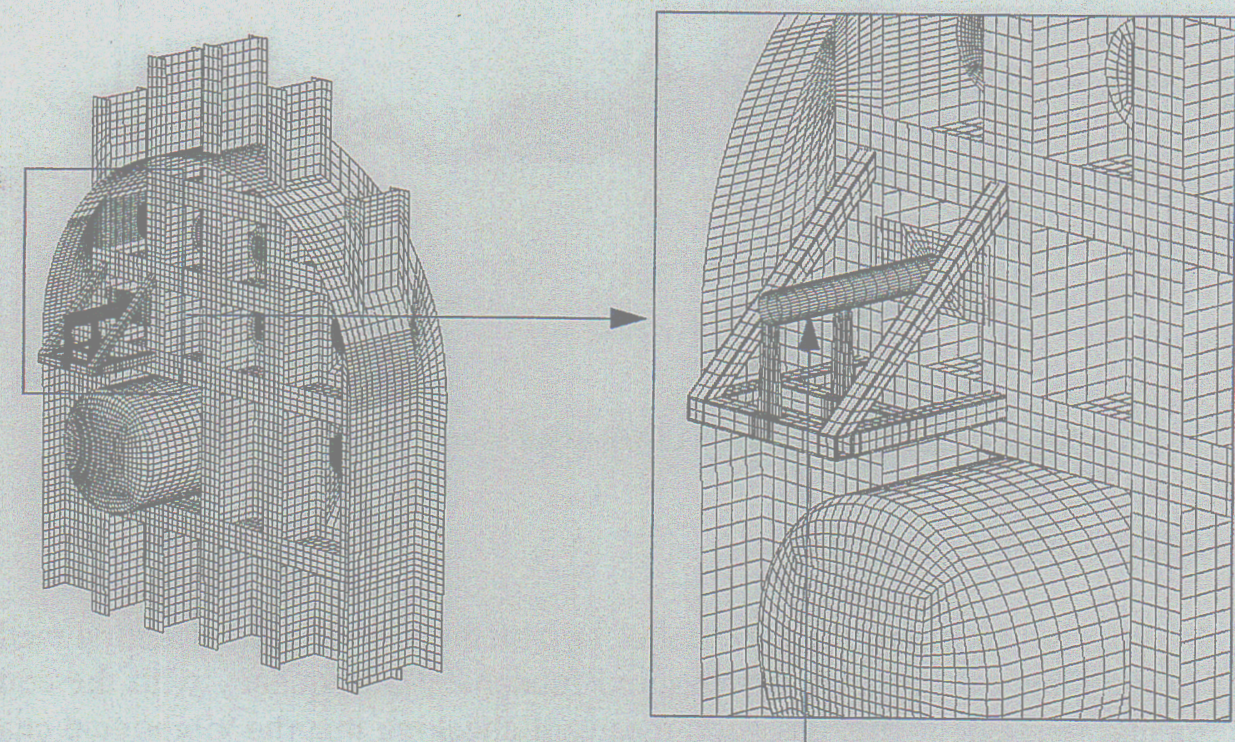

b). mass density increased to accommodate for two valves ( $W=90$ lbs approx. for each valve)

FIGURE 5. a). Exploded view of finite element model and b), grouttube detail. 


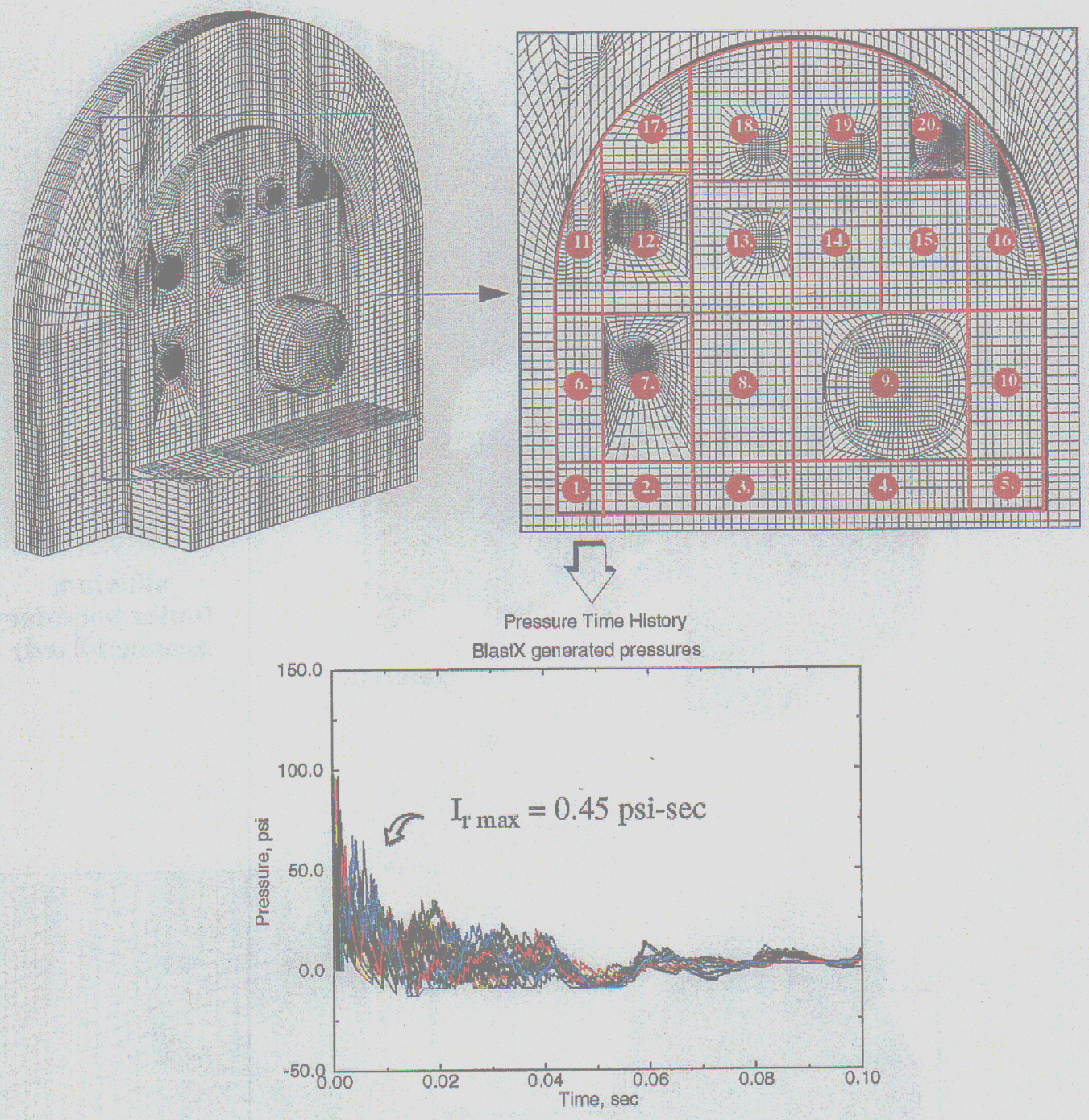

FIGURE 6. Pressure time history distribution over the face of the barrier.

\subsection{Model validation}

In order to validate the current model, two methods were used. The first method compared the Bagpipe experimentally measured fundamental frequency with the computed fundamental frequency. This is a good means of checking that the vibrational characteristics of the model are close to that of the real structure. The second method used to validate the computational model was to use the measured Bagpipe pressures to load the current model and compare the computationally determined strain data with the measured strain data. It should be noted that these methods would not be adequate if the Bagpipe barrier design was not so similar to the U1A.102C barrier design. 


\subsection{Eigenvalue analysis}

The finite element model and fundamental modes are shown in Figure 7 . The finite element model used in the eigenvalue analysis does not include the alluvium material. The alluvium was removed in this case because it is difficult for NIKE3D, an implicit finite element code, to solve a problem of this size. Therefore, instead of the alluvium, the concrete keyway and pedestal outer boundaries were assumed to be fixed. The resulting fundamental frequency matched very well to the experimental data. The computed value was $142.7 \mathrm{hz}$, while the experimentally determined frequency was $143.7 \mathrm{hz}$. Table 3 compares the data with the previous Bagpipe model.
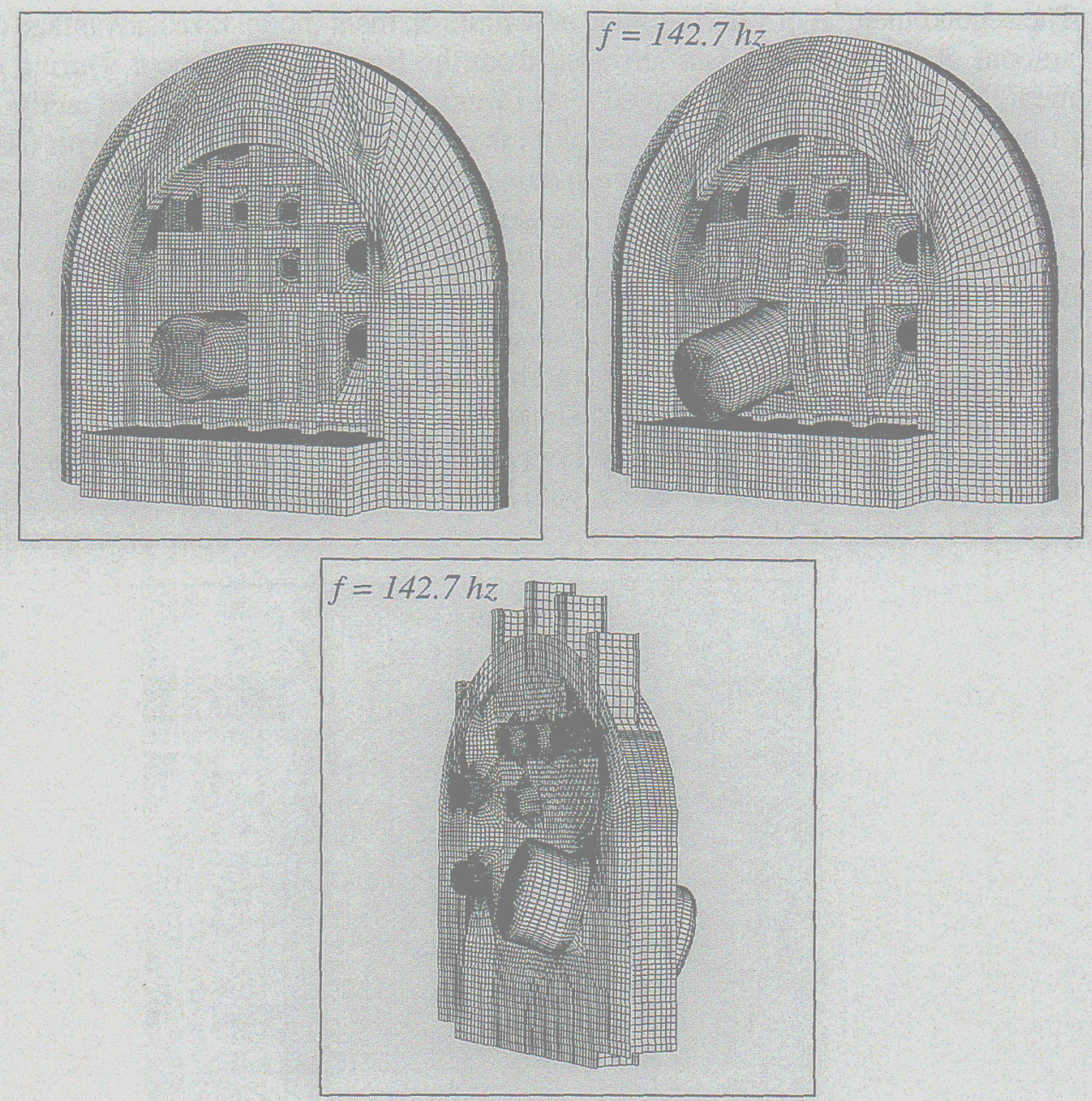

FIGURE 7. NIKE3D eigenvalue value analysis resulted in a fundamental frequency of $142.7 \mathrm{hr}$. 
TABLE 3. Fundamental frequency comparison.

\section{Computed Bagpipe \\ Frequency}

(hz)

150.3

\section{Experimental Bagpipe \\ Frequency}

(hz)

143.7

\author{
U1A.102C barrier Model \\ Frequency \\ (hz)
}

142.7

\subsection{Comparison between experiment and computational model}

The second method of validating the new finite element model takes advantage of the large amount of experimental data retrieved from the Bagpipe experiment. During the experiment, the barrier was instrumented with 11 uniaxial strain gages located on the portal side of the barrier (see Figure 8). In addition, the barrier was instrumented with triaxial strain gages, uniaxial and triaxial accelerometers, and a number of pressure transducers. Therefore, to validate the current model, the experimentally measured pressures from the Bagpipe experiment was used as the loading for the current model. Due to very minor differences between the pressures from the different transducers, only one pressure time history was used in the following analysis. Once the dynamic analysis was complete, a comparison was done between the experimentally measured uniaxial strains and the computed strains. The comparisons are shown in Figure 9 and Figure 10. The simple beam model strains used for the design of Bagpipe are shown as well. The computed and experimental strains correlate very nicely, with some of the data from the current model, such as gages 108,109 , and 111, matching much closer than the older finite element model.

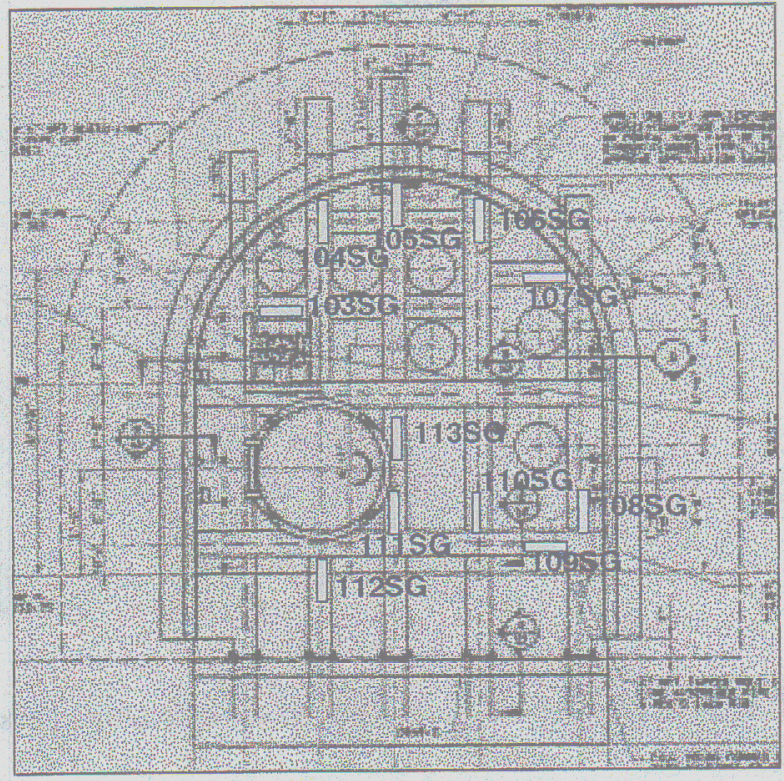

FIGURE 8. Strain gage locations for Bagpipe experiment conducted September 26, 1998. 

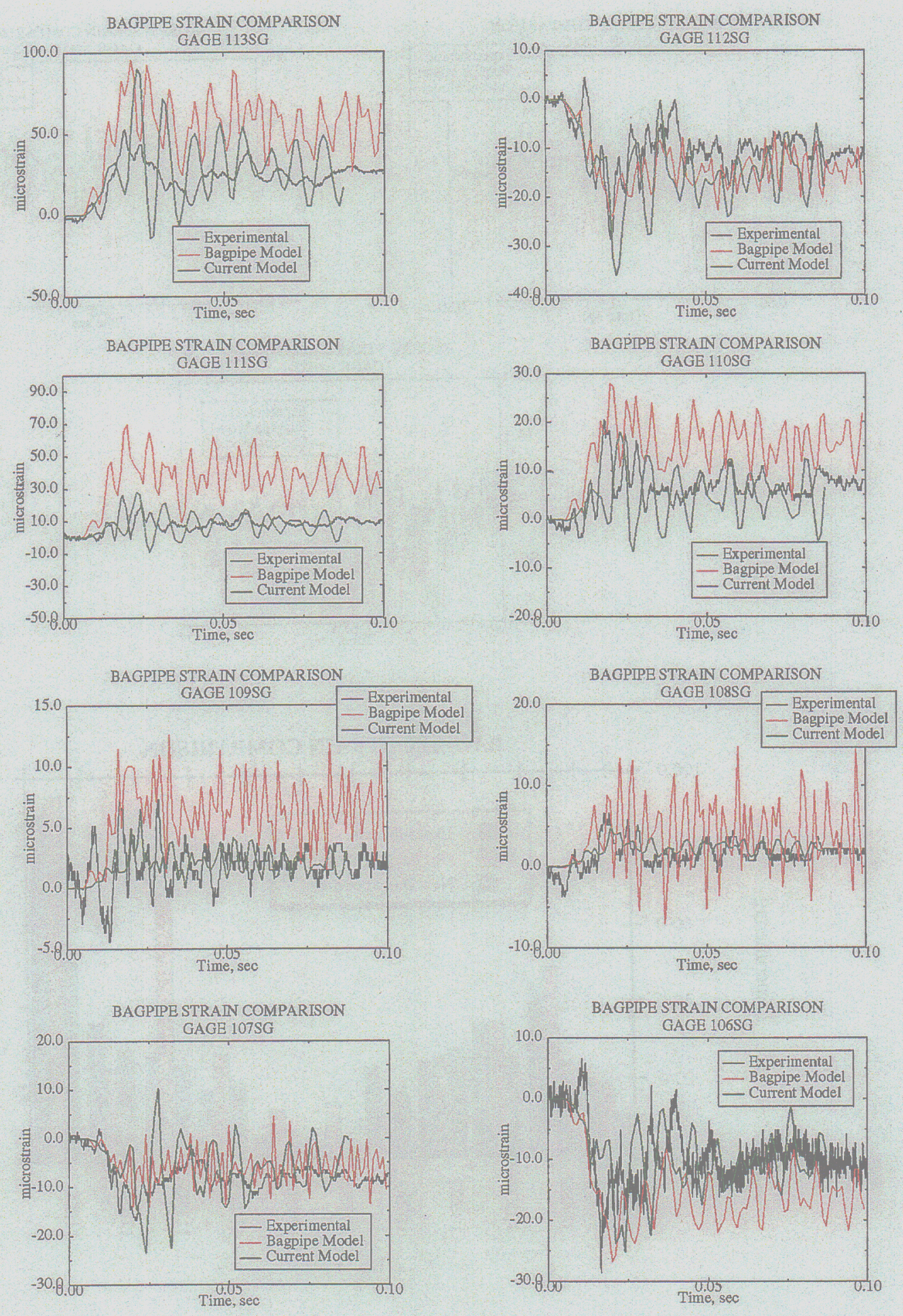

FIGURE 9. Strain comparison between experimental values, computed values using Bagpipe model, and computed values using current model. 

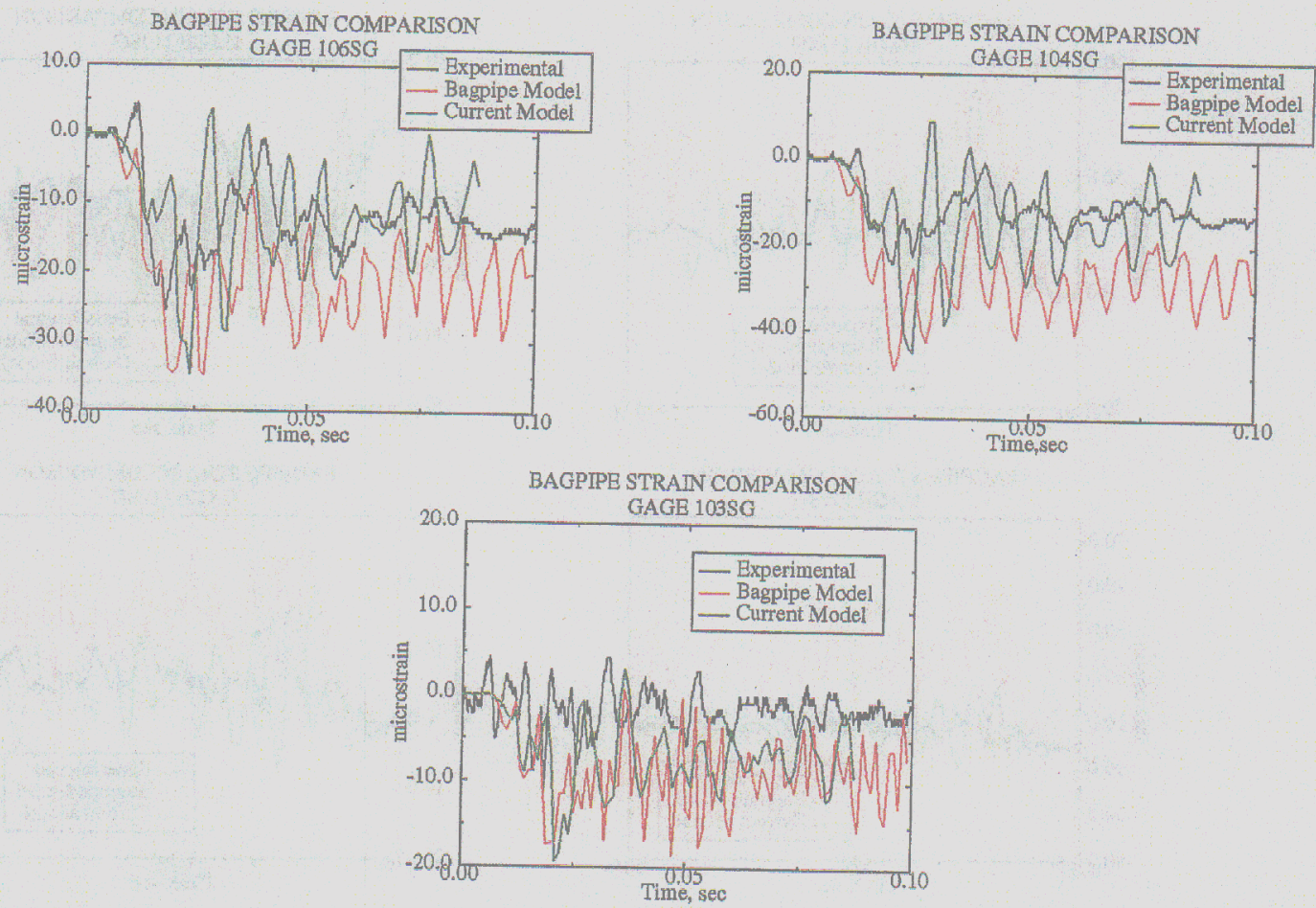

a).

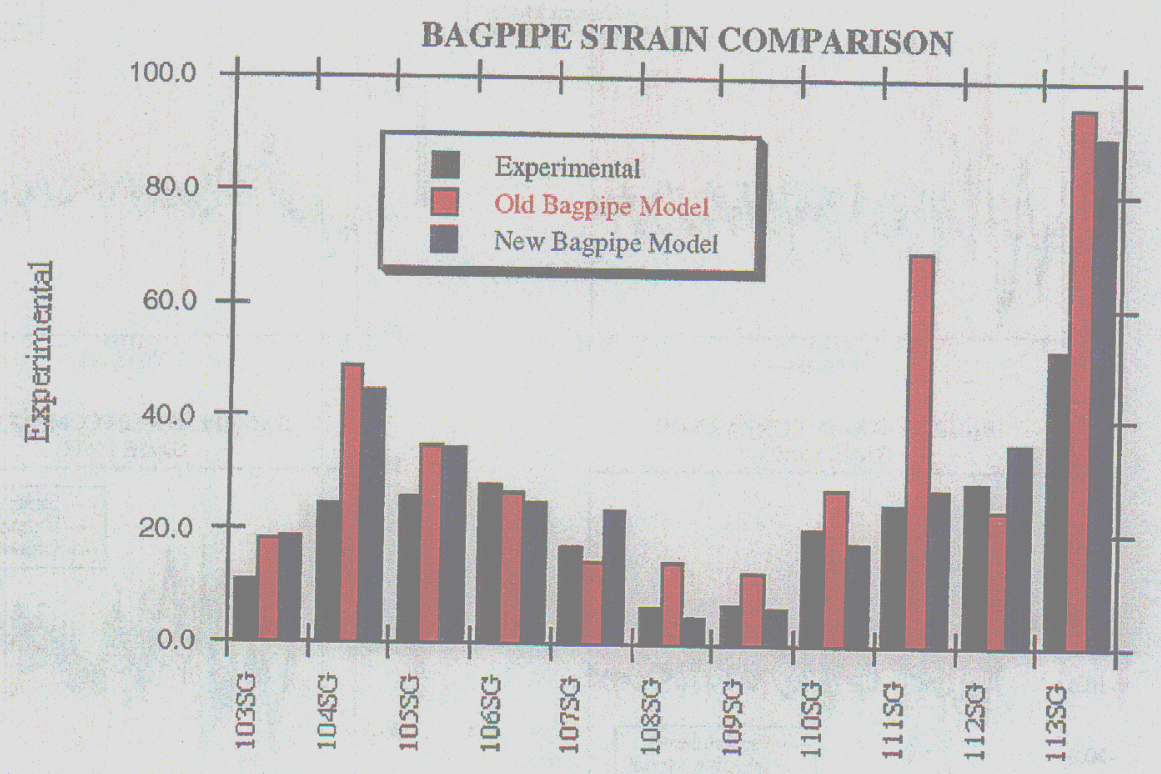

b).

FIGURE 10. a). Strain comparison between experimental values, computed values using Bagpipe model, and computed values using current model; b). bar chart comparing peak strains. 


\subsection{Finite element analysis}

A summary of the peak stresses and resulting safety factors for the U1A, 102C barrier are given in Table 4. To account for strain rate effects, the allowable stress has been increased by a third [Ref 3]. It should be noted that an allowable stress of 36,000 psi was chosen for all steel materials except for those materials which had material certifications. The allowable compressive stress values for the concrete, alluvium, and shotcrete were provided by Burkhard [Ref 1]. The tensile stress values for the concrete and shotcrete were determined using the $\mathrm{ACI}$ Code equation

$$
f_{t}=6 \sqrt{f_{c}^{\prime}}
$$

This is a conservative approach since the shotcrete has significantly greater strength due to the fact that it is fiber-reinforced. The requirements allow for a minimum safety factor for steel based on dynamic yield of 2.0 [Ref 3]. All of the safety factors for the ductile materials are greater than the allowable value, with the grouttube having the lowest safety factor of 3.0. The only materials that do not achieve the allowed safety factor is the concrete pedestal and shotcrete. The concrete pedestal peak tensile stress occurs on the portal side at the pedestal-barrier interface (see Figure 12). This high stress is not viewed to be of great concern due to the fact that this stress occurs in a very localized region on a very short time scale (see Figure 16). Furthermore, the model does not account for strain rate effects, which can significantly increase the concrete tensile strength. Figure 11 through Figure 15 show the locations of the maximum stresses for the different barrier components. In addition, stress time histories for the elements which had the maximum stress are included in Figure 16.

TABLE 4. Summary of peak stresses and safety factors.

\begin{tabular}{|c|c|c|c|}
\hline Barrier Component & Allowable Stress & $\begin{array}{l}\text { Maximum Stress and } \\
\text { Time of Peak Stress }\end{array}$ & $\begin{array}{c}\text { S.F. } \\
\text { (must be greater than } \\
2.0 \text { for steel) }\end{array}$ \\
\hline Faceplate/Groutplate $^{\dagger}$ & $81,795 \mathrm{psi}\left(\sigma_{y} x 1.33\right)$ & 8,000 psi $(t=0.03 \mathrm{sec})$ & 10.2 \\
\hline Grillage $^{t}$ & $81,795 \mathrm{psi}\left(\sigma_{y} x 1.33\right)$ & $8,980 \mathrm{psi}(t=0.003 \mathrm{sec})$ & 9.1 \\
\hline Concrete & $\begin{aligned} \text { Ten. Stress } & =425 \mathrm{psi} \\
\text { Comp. Stress } & =5,000 \mathrm{psi}\end{aligned}$ & $\begin{array}{l}\text { Ten. Stress }=564 \mathrm{psi}(t= \\
0.025 \mathrm{sec}) \\
\begin{array}{c}\text { Comp. Stress }=736 \mathrm{psi}(t \\
=0.003 \mathrm{sec})\end{array}\end{array}$ & $\begin{array}{l}\text { Ten. Stress }=0.75 \\
\text { Comp. Stress }=6.8\end{array}$ \\
\hline Alluvium & Comp. Stress $=1,160$ psi & $\begin{array}{c}\text { Comp. Stress }=80.3 \mathrm{psi}(t \\
=0.004 \mathrm{sec})\end{array}$ & Comp. Stress $=14.4$ \\
\hline Shotcrete & $\begin{aligned} \text { Ten. } \text { Stress } & =465 \text { psi } \\
\text { Comp. Stress } & =6,000 \text { psi }\end{aligned}$ & $\begin{array}{l}\text { Ten. Stress }=1,320 \mathrm{psi}(t \\
=0.03 \mathrm{sec}) \\
\text { Comp. Stress }=1,250 \mathrm{psi} \\
(t=0.005 \mathrm{sec})\end{array}$ & $\begin{array}{l}\text { Ten. Stiess }=0.35 \\
\text { Comp. Stress }=4.8\end{array}$ \\
\hline Optical Ports/ Manway ${ }^{\dagger}$ & $\begin{array}{c}47,880 \text { psi / } 93,100 \text { psi } \\
\left(\sigma_{y} \times 1.33\right)\end{array}$ & $\begin{array}{l}11,300 \mathrm{psi}(t=0.001 \mathrm{sec}) \\
/ 7,240 \mathrm{psi}(t=0.005 \mathrm{sec})\end{array}$ & $4.23 / 12.9$ \\
\hline Grouttube & $47,880 \mathrm{psi}\left(\sigma_{3} x 1.33\right)$ & $15,900 \mathrm{psi}(t=0.018 \mathrm{sec})$ & 3.0 \\
\hline 1"Aluminum Plate & $50,540\left(\sigma_{y} \times 1.33\right)$ & $3,260 \mathrm{psi}(t=0.005 \mathrm{sec})$ & 15.5 \\
\hline TS $3 \times 3 \times 1 / 4 "$ tubing & $47,880 \mathrm{psi}\left(\sigma_{y} x 1.33\right)$ & $8,070 \mathrm{psi}(t=0.019 \mathrm{sec})$ & 5.9 \\
\hline $1 / 2$ " saddle plate & $47,880 \mathrm{psi}\left(\sigma_{y} \times 1.33\right)$ & 13,300 psi $(t=0.023 \mathrm{sec})$ & 3.6 \\
\hline
\end{tabular}



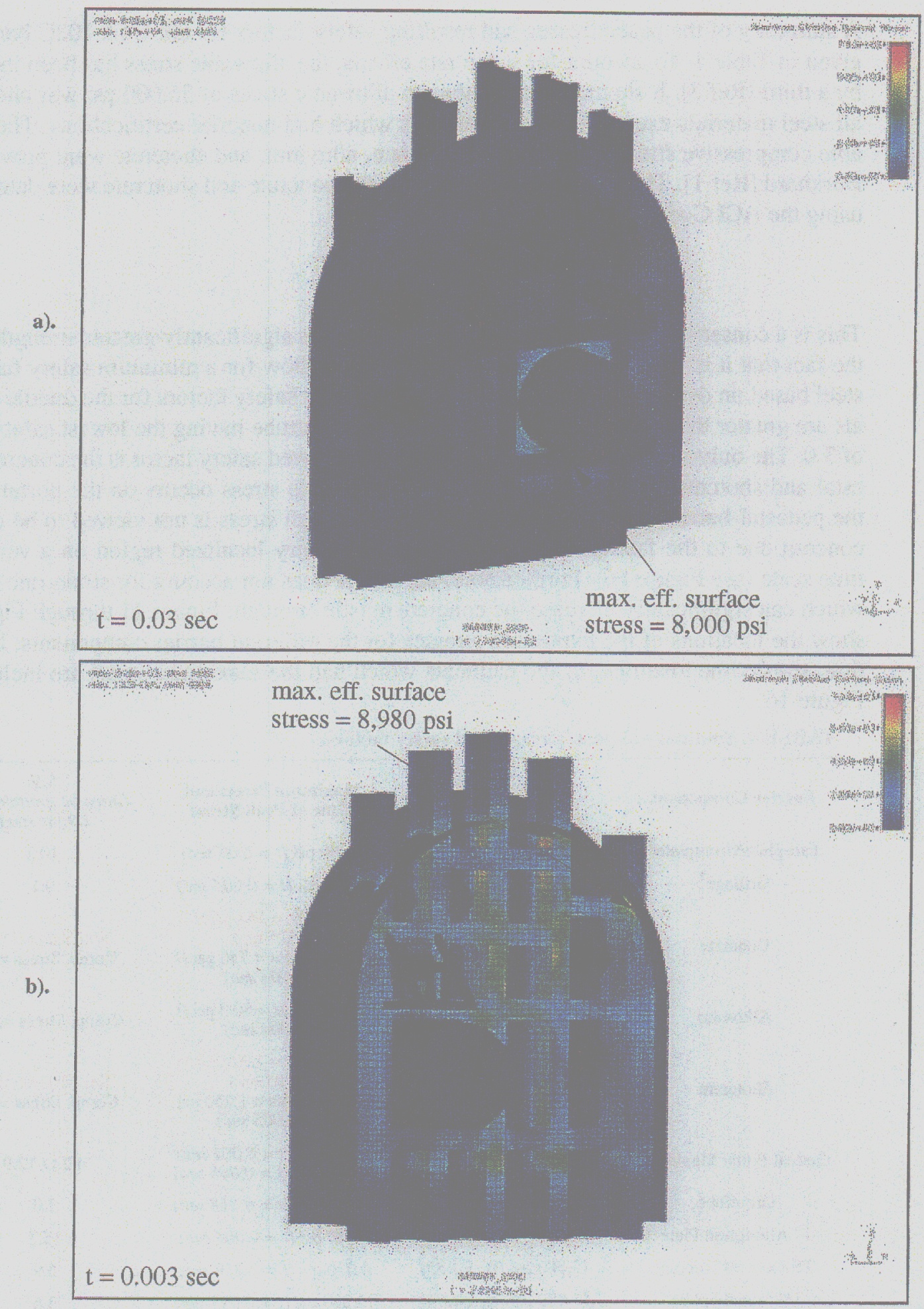

FIGURE 11. Maximum stress locations for: a), faceplate and b). grillage. 

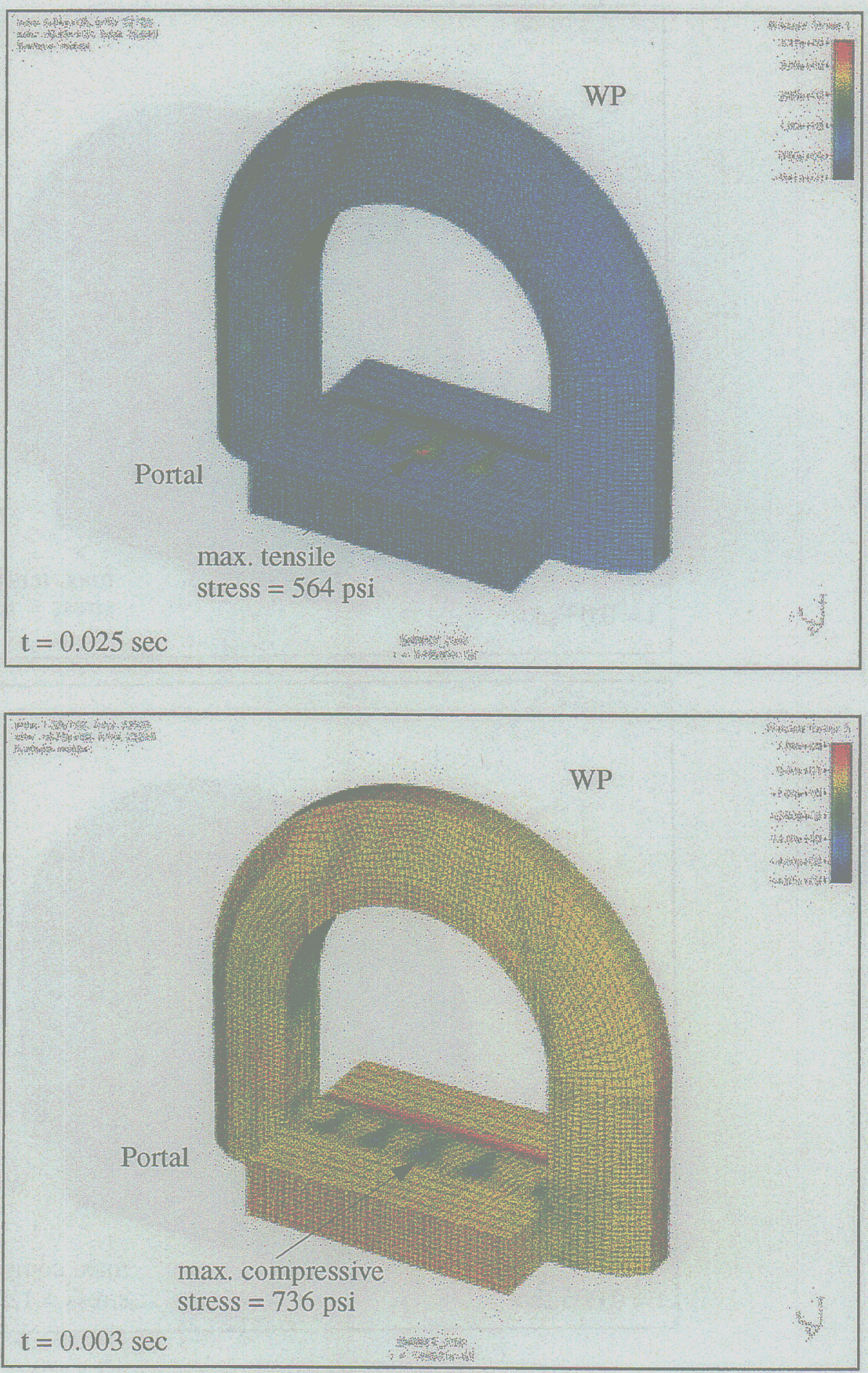

FIGURE 12. Maximum stress locations for concrete keyway and pedestal. 

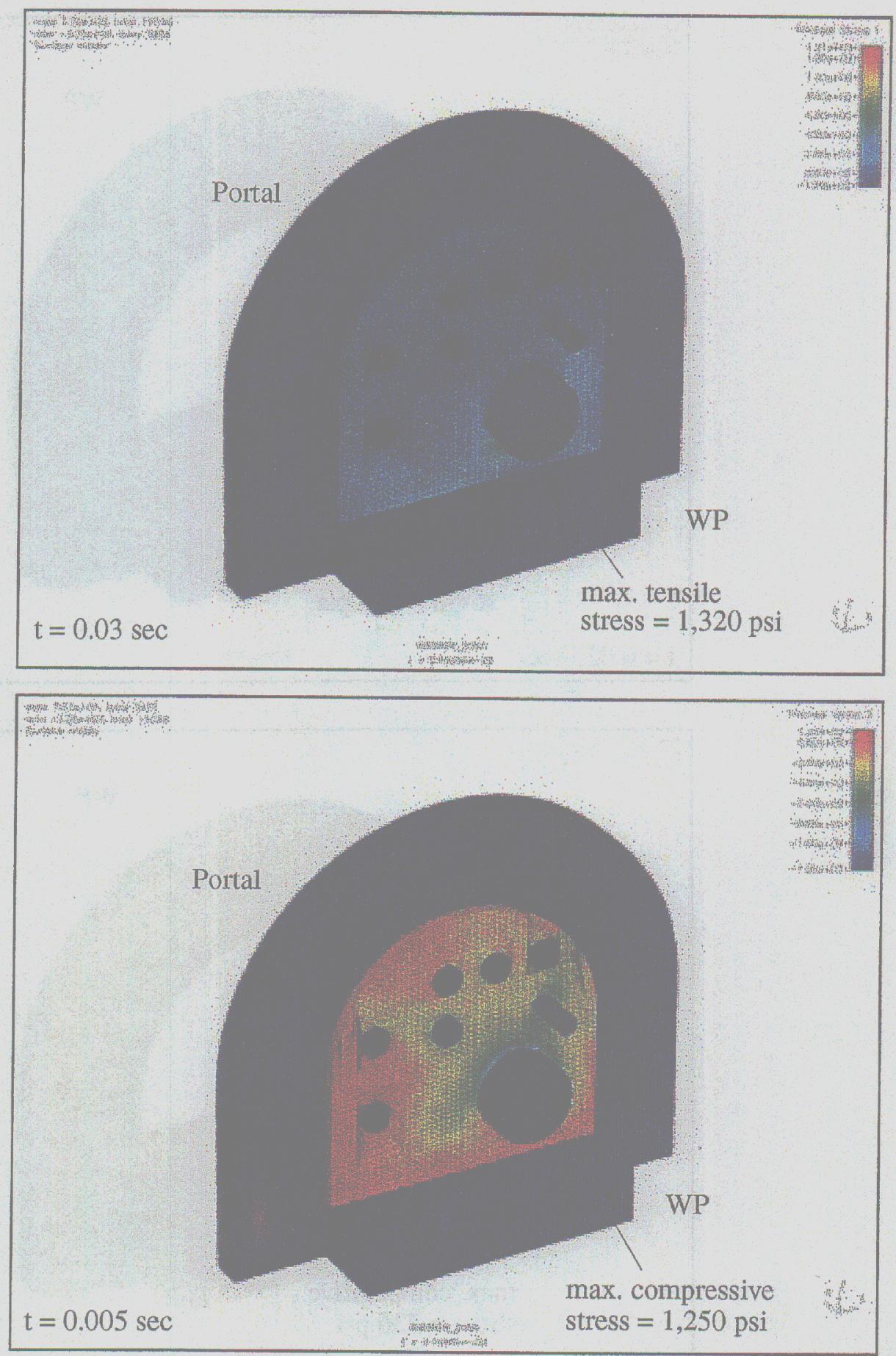

FIGURE 13. Maximum stress locations for shotcrete. 


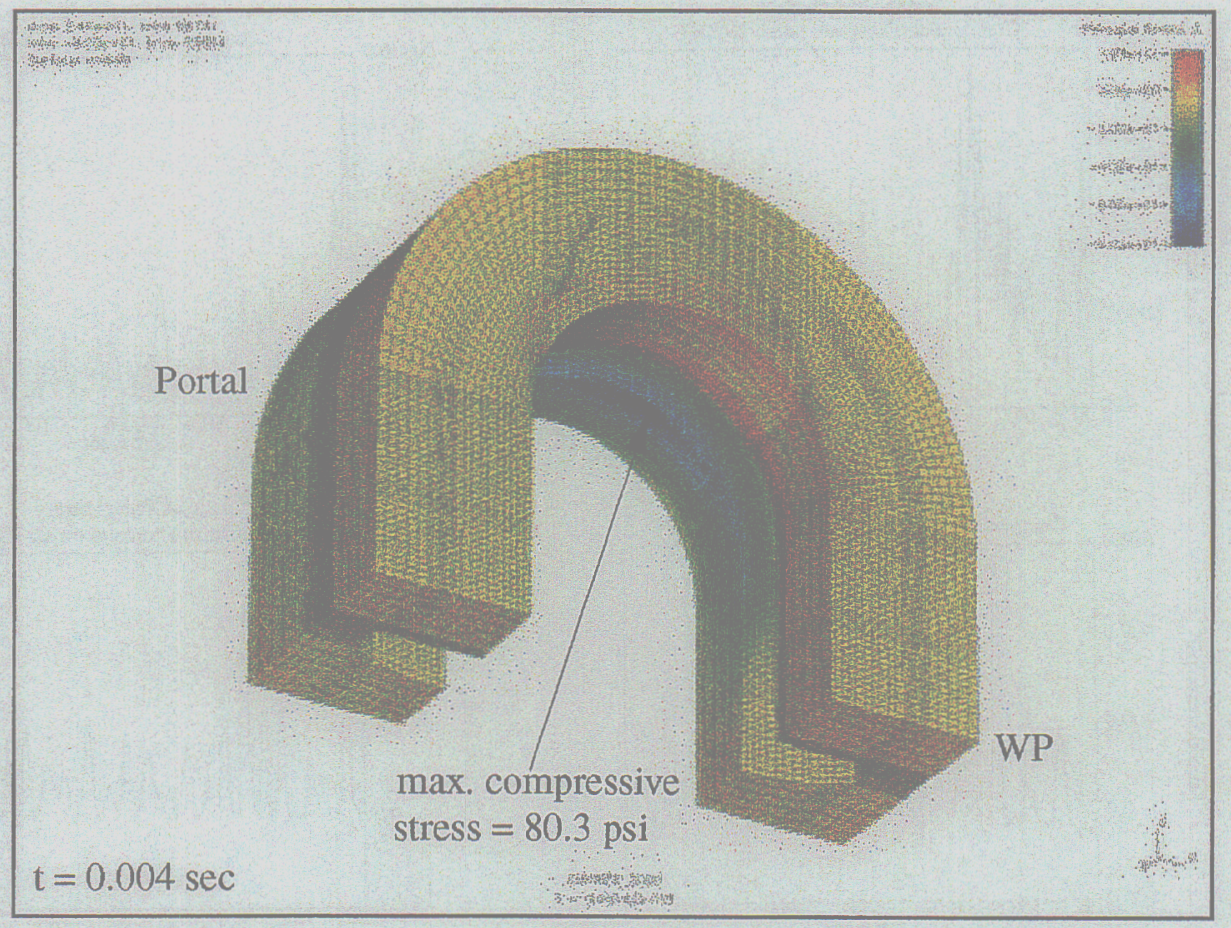

FIGURE 14. Maximum compressive stress for alluvium.
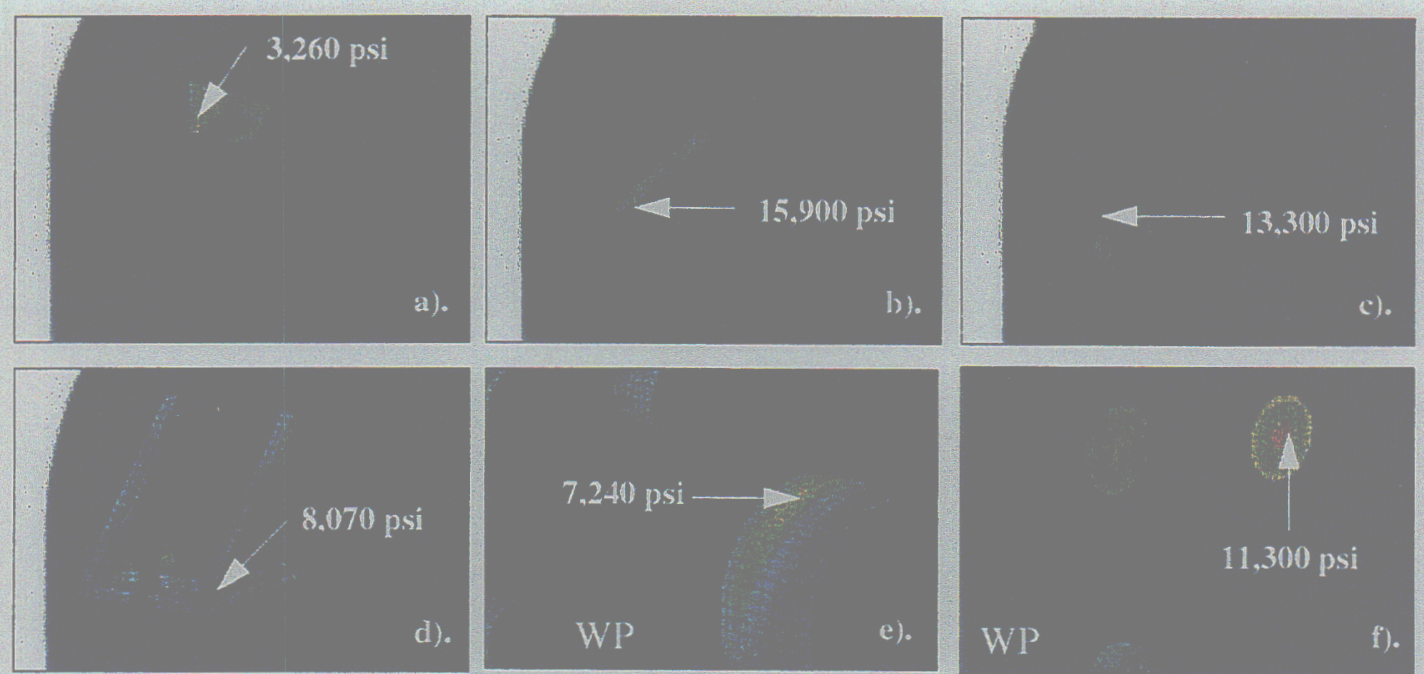

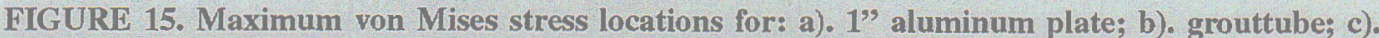
saddle plate; d). tubing; e). manway and f). optical port lid (assumed steel material). 

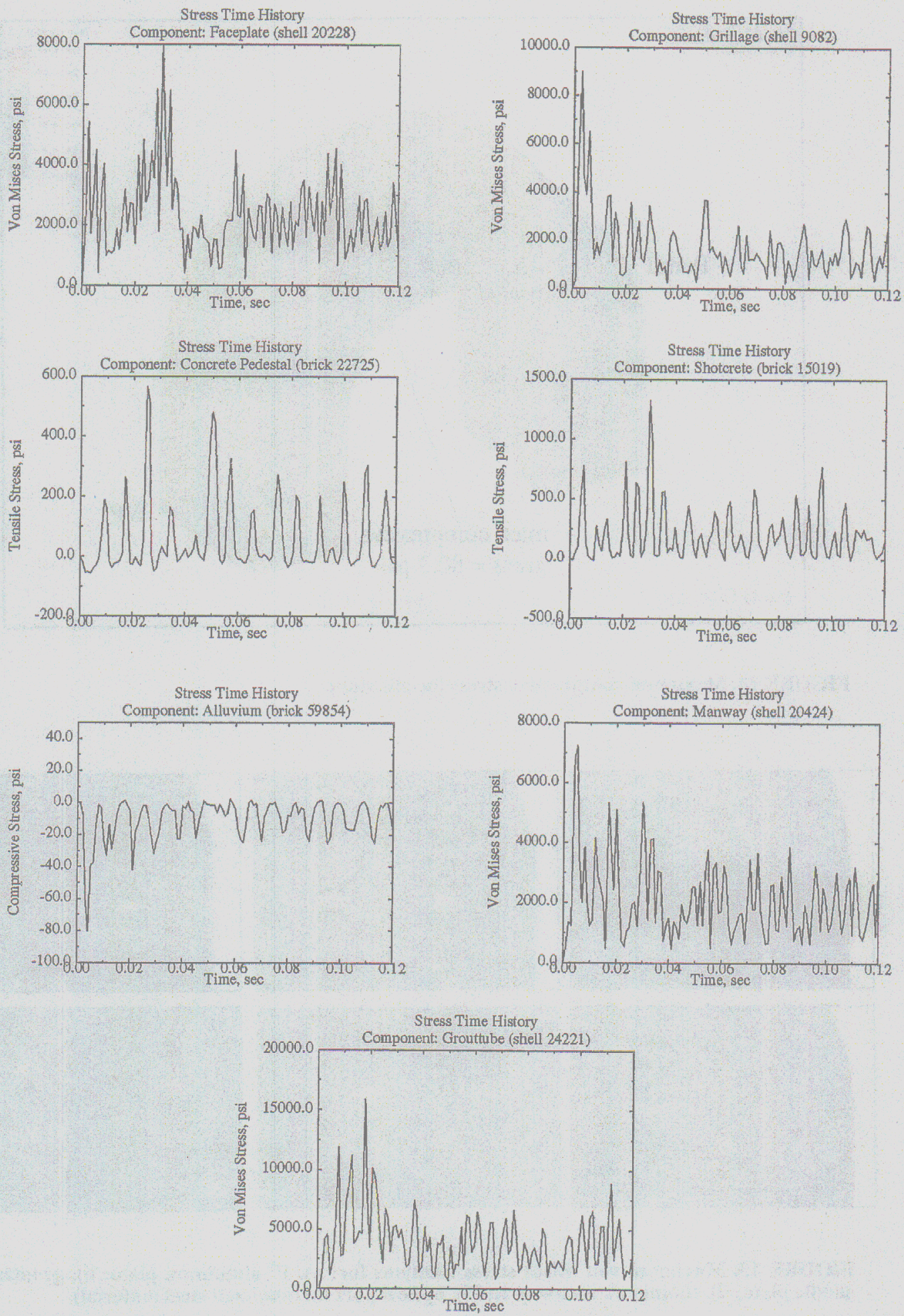

FIGURE 16. Stress time histories for key structural components. The element which received the maximum stress was used for these time histories. (Note: F.E.M. did not include damping). 


\subsection{Weld analysis}

The weld stresses for critical sections, or those interfaces that would be stressed the greatest, were also analyzed. The critical locations studied are shown in Figure 17 . The methodology for analyzing the welds consists of first extracting the shell resultants at the location of the weld from the post-processor. For the weld at the grouttube-faceplate interface, for example, the shell elements at the interface were selected and time histories were gathered for each membrane resultant described in Figure 18. Once the resultants at the weld location were extracted, the forces are combined by vectorially adding all the forces that occur at the same position in the welded joint. For instance, if there are three forces, each at right angles to each other, the resultant is equal to the square root of the sum of the squares of the three forces:

$$
f_{r}=\sqrt{\left(f_{1}\right)^{2}+\left(f_{2}\right)^{2}+\left(f_{3}\right)^{2}}
$$

For ease of computing and to make sure that the maximum force was calculated, four different calculations were completed for each selected element at every time step:

$$
\begin{aligned}
& f_{r}=\sqrt{\left(N_{x x}\right)^{2}+\left(Q_{x x}\right)^{2}+\left(N_{z z}\right)^{2}} \\
& f_{r}=\sqrt{\left(N_{y y}\right)^{2}+\left(Q_{x x}\right)^{2}+\left(N_{z z}\right)^{2}} \\
& f_{r}=\sqrt{\left(N_{x x}\right)^{2}+\left(Q_{y y}\right)^{2}+\left(N_{z z}\right)^{2}} \\
& f_{r}=\sqrt{\left(N_{y y}\right)^{2}+\left(Q_{y y}\right)^{2}+\left(N_{z z}\right)^{2}}
\end{aligned}
$$

After this calculation is complete, the maximum $f_{r}$ value is determined, which is the maximum load on the fillet weld in units of lbs/in. This value must be less than the allowable load recommended by AWS:

$$
f_{r} \leq f_{r w}=0.3 \times t_{e} \times F_{E X X}
$$

where $t_{e}$ is the effective throat dimension of the weld and $F_{E X X}$ is the nominal tensile strength of the weld metal assumed to be $70 \mathrm{ksi}$. The maximum and allowable loads for critical weld joints are given in Table 5. The maximum loads are all less than the allowable values. 
TABLE 5. Maximum and allowable loads for critical weld joints

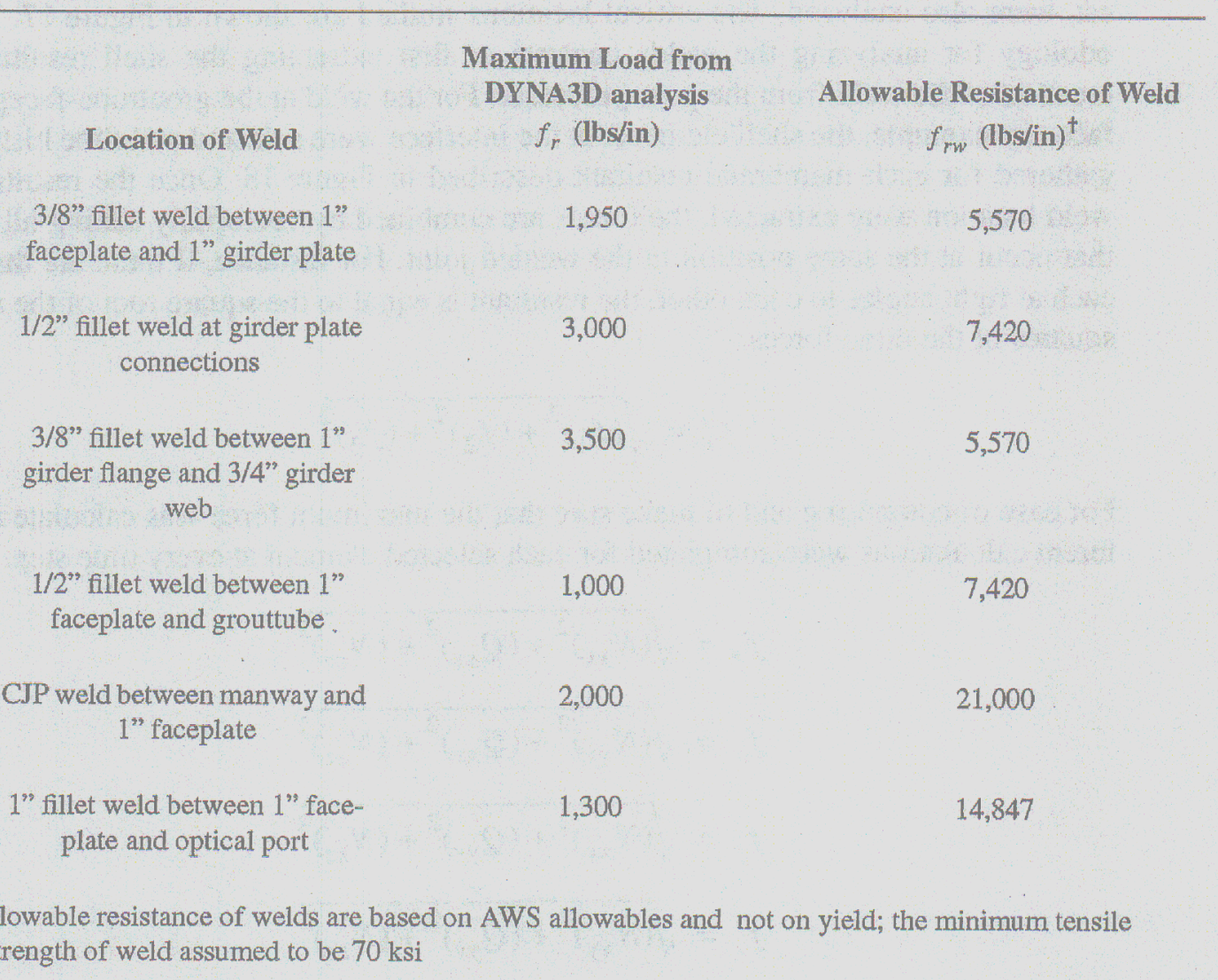




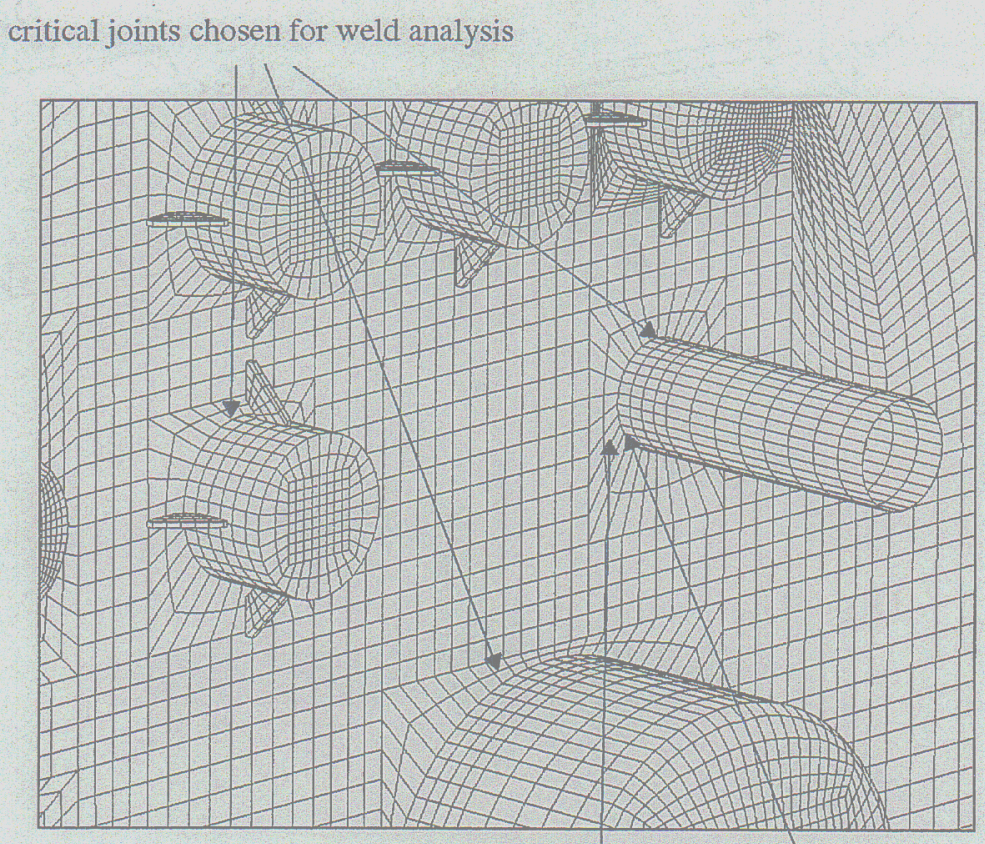

shell element resultants gathered from rows of elements near weld joint

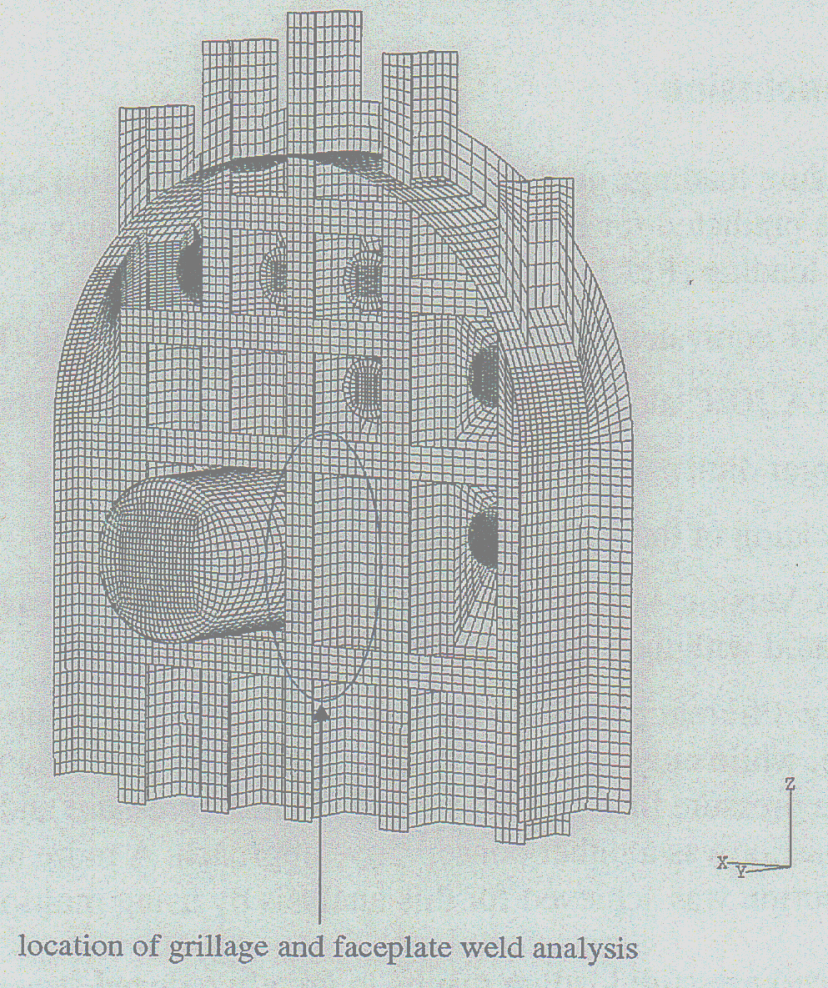

FIGURE 17. Critical locations chosen for detailed weld analysis. 


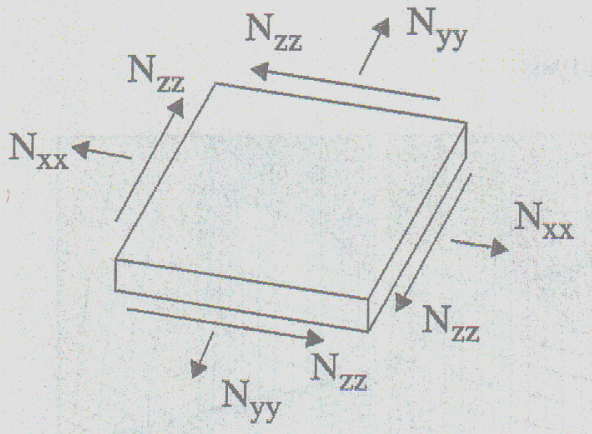

a).

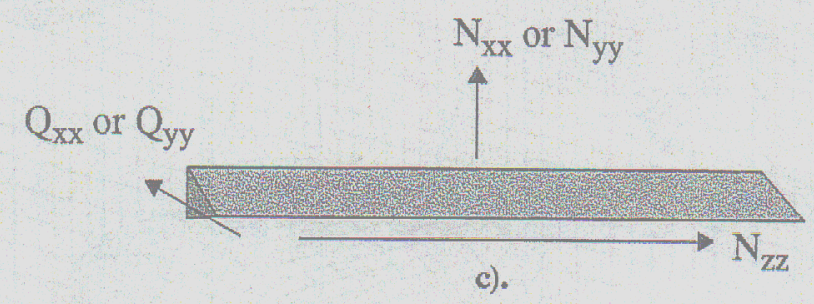

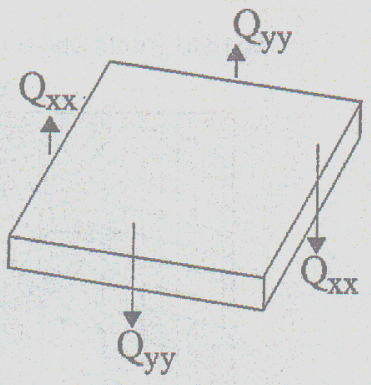

b).

FIGURE 18. a). Required membrane resultants; b.) required bending resultants; $c$.) fillet weld and resultants.

\subsection{Conclusion}

The pressure loadings on the barrier for the expected final experiment are much lower than what was predicted for Bagpipe. There are several factors which contribute to the reduced pressure loading [Ref 1$]$ :

1. the TNT equivalency factor used in BlastX was reduced [Ref 4].

2. the U1A.102C alcove has four times the volume of the Bagpipe alcove.

3. the larger dimensions of the alcove help reduce reflected shock pressures.

4. the location of the HE relative to the barrier is different.

5. BlastX Version 4.0 used for this calculation has an improved shock reflection model as compared with the version of BlastX used for Bagpipe.

6. Twenty different pressure time histories were used for the analysis of the U1A.102C alcove, while only one pressure time history was used for the Bagpipe analysis. Utilizing the pressure time history with the highest pressure and impulse for the entire Bagpipe bartier was a rather conservative approach. A more accurate pressure load distribution was achieved for this analysis by using multiple time histories.

The reduced pressure loading results in greatly reduced stresses in the barrier compared to Bagpipe. Every structural component, except the shotcrete and concrete in tension, has a safety factor equal to or greater than 3.0, which is the "General Purpose" Safety Factor recommended in the ME Design Safety Standards. Moreover, the weld loads are well 
below the allowable resistance set by the American Welding Society (AWS). It should be noted that for the steel materials, the dynamic yield was used to calculate the safety factor. Furthermore, in previous subcritical experiments, a safety factor of 1.5 was allowed A lower safety factor was allowed because materials were certified and detailed calculations were used. The shotcrete on the front of the barrier is expected to be damaged during an event such as this and it is intended to absorb some of the energy from the blast; therefore, a high tensile stress is not of great concern. Moreover, the high tensile stress in the grout is not of great concern because it occurs on a short time scale in a very localized region. The region at which the high stress occurs is on the portal side of the manway at the girderconcrete interface. Some local tensile cracking at this location will not effect the load carrying capability of the structure. Furthermore, an elastic property was used to model the concrete. If a more sophisticated concrete material model, such as one that included strain rate effects, were to be used, it is likely that no damage would be predicted in the concrete. This is because at high strain rates, the tensile strength of concrete can increase by a factor ranging from 1 to 6 . In addition, the finite element model correlated well with experimental values for both the Bagpipe experiment and the modal testing, which gives us increased confidence that the finite element can predict or simulate the structural response with good accuracy.

\subsection{Acknowledgements}

This work was performed at the Lawrence Livermore National Laboratory under the auspices of the United States Department of Energy, contract W-7405-Eng-48.

\subsection{References}

1. Personal communication between C. Noble (LLNL) and N. Burkhard (LLNL).

2. Structures to Resist the Effects of Accidental Explosions (with Addenda), Department of the Army Technical Manual (TM5-1300), Department of the Navy Publication (NAVFAC P-397), Department of the Air Force Manual (AFM 88-22), Washington, D.C., June 1990.

3. Structural Design Criteria for the BAGPIPE Containment Barrier, EME 97-031, December 1997.

4. J. Pastrnak, TNT Equivalency for BlastX Calculations, Interdepartmental Letterhead, August 9, 2000.

5. J. Pastrnak, Update Status of LX-14/TNT Equivalency for BlastX Calculations, Interdepartmental Letterhead, September 25, 2000. 
Appendix 3

Update Status of LX-14/TNT Equivalency for BLASTX Calculations 
Mail Station L-125

Ext: 28403

To: Distribution

From: John Pastrnak

Subject: $\quad$ Update status of LX-14/TNT Equivalency for BlastX Calculations

While looking over the BlastX Manual (written for version 3) I noticed an unusually large TNT equivalency for LX-14. The value given was 1.8. Normal structural and blast calculations that I have been involved with in the past normally use an upper bounding equivalency of 1,3. This is usually conservative since most of the explosives tested at Site 300 in terms of their effects on structures are considered to have a lower blast equivalency, nominally in the 1.1 to 1.21 range.

Attached for reference are TNT equivalent tables from 2 references I normally use, hereto referred in shorthand as the DOETIC and TM5 manuals respectively:

1) "A Manual For the Prediction of Blast and Fragment Loadings on Structures", DOE Albuequerque Operations Office, July 1992 w/9/93 addendum, DOE/TIC-11268.

2) "Structures to Resist the Effects of Accidental Explosions", Departments of the Army, Nayy, and the Air Force. November 1990. Army TM5-1300/Navy NAVFAC P-387/AIR FORCE AFR 88-22.

The DOETIC gives a LX-14 equivalency of 1.117 whereas TM5 gives heats of detonation that can be ratio-ed $(2.2 \mathrm{E}+06 / 1.97 \mathrm{E}+06)$ to give an equivalency of 1.117 as well.

I have contacted the BlastX folks (the ARMY at Waterways Experiment Station) and was referred to one of their contracting experts ; Bob Britt (601) 634-4238 of SAIC, also an author of the BlastX 4.0 Users Manual. He suggested that an equivalency of 1.8 might be valid in certain regimes, particularly for the higher pressure regions. (I take this to mean very close-in to a charge, typically $\mathrm{Z}<1 \mathrm{ft} / \mathrm{lb} \mathrm{b}^{1 / 3}$ ). He suggested and offered to run a SAIC hydrocode (RAGE) calculation for LX-14 and TNT and plot out peak pressure and shock impulse as a function of distance. We could examine and if need be select an appropriate TNT equivalency based on our desired distance. In the interim, he sent me this attached email

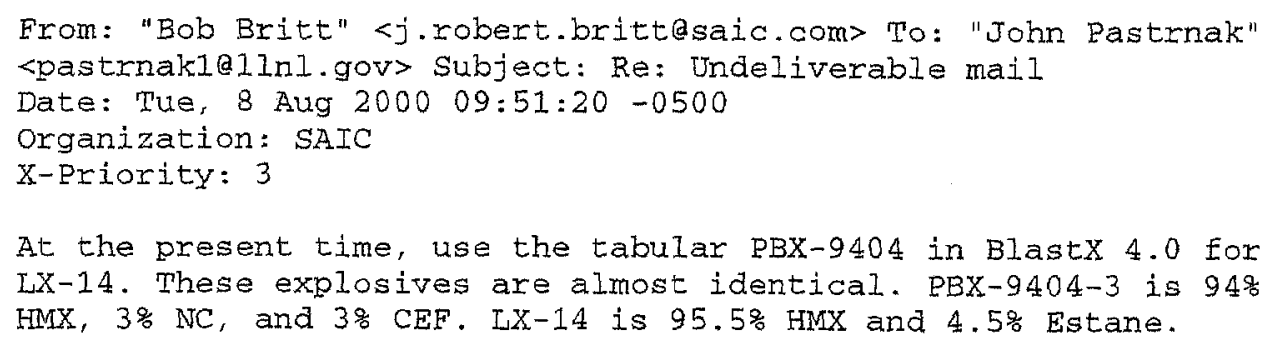

BlastX lists a TNT equivalency value for PBX-9404/TNT as 1.2 which is also consistent with my previous calculations. 
Bob Britt's subsequent RAGE hydrocode calculation (Fig.'s 1 \& 4) do appear to back up his earlier recommendation that the blast performance of LX-14 is very similar to that of PBX-9404 and that from a blast standpoint the use of PBX-9404 tabular values in BlastX may be more appropriate.

\section{PRESSURE}

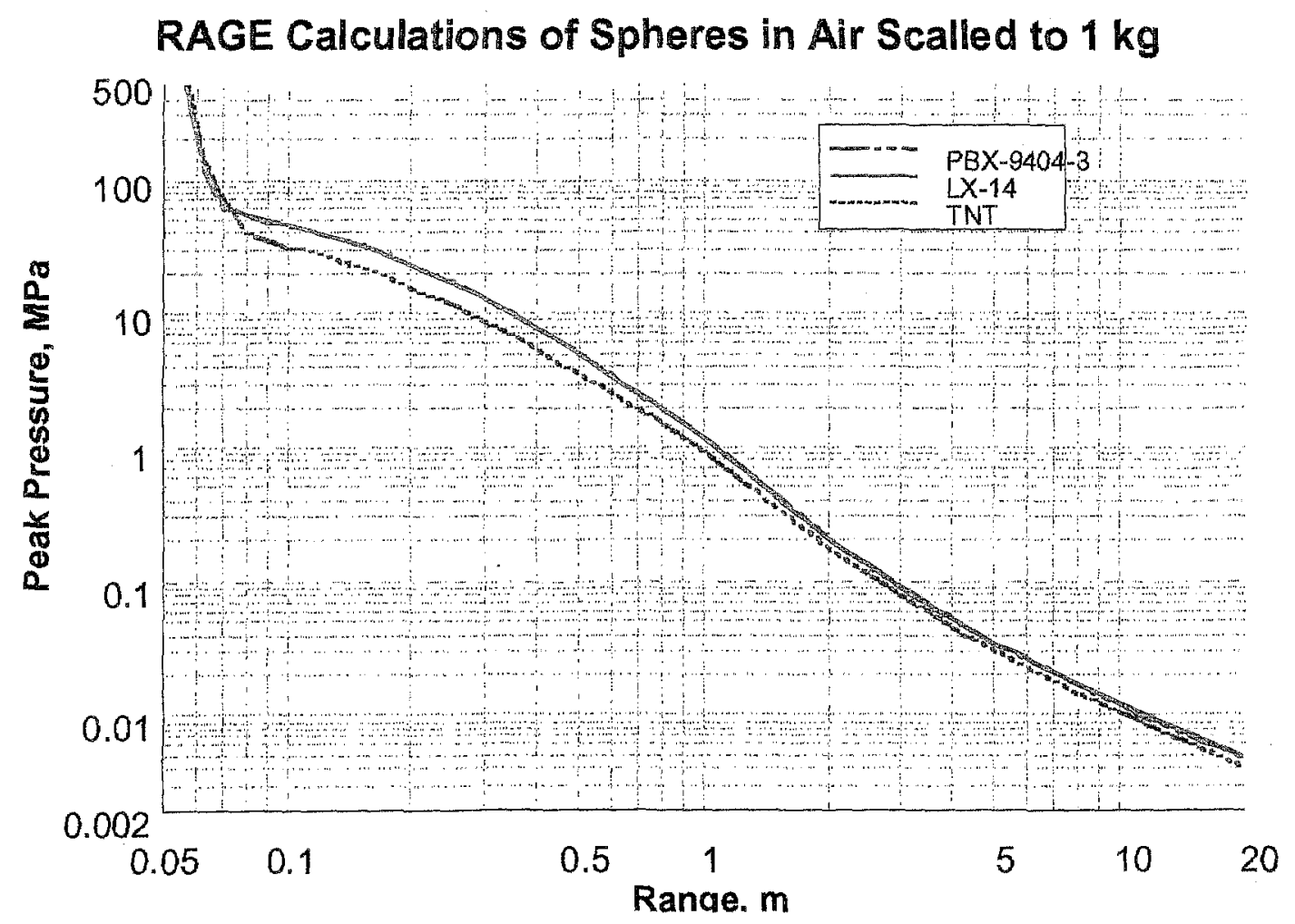

Figure 1

Plot courtesy SAIC, Bob Britt 8/9/2000

By reploting Bob Britts data the ratio of the peak pressures versus distance can be observed in Figure 2. Thus from a shock or blast standpoint, for $1 \mathrm{~kg}$ of LX-14, the TNT equivalency can be as high as 1.5 very close to the charge ( less than $0.5 \mathrm{~m}$ ) and falls off quickly to less than 1.2 for distances greater than $\sim 1.75 \mathrm{~m}$.

At present, this new data along with the DOETIC and TM5 manuals suggests that a less overly conservative TNT equivalency be used for shock pressure loadings when running the BlastX code. The value of the TNT equivalency for LX-14 previously published in the BlastX manual of 1.8 appears to be overly conservative. 


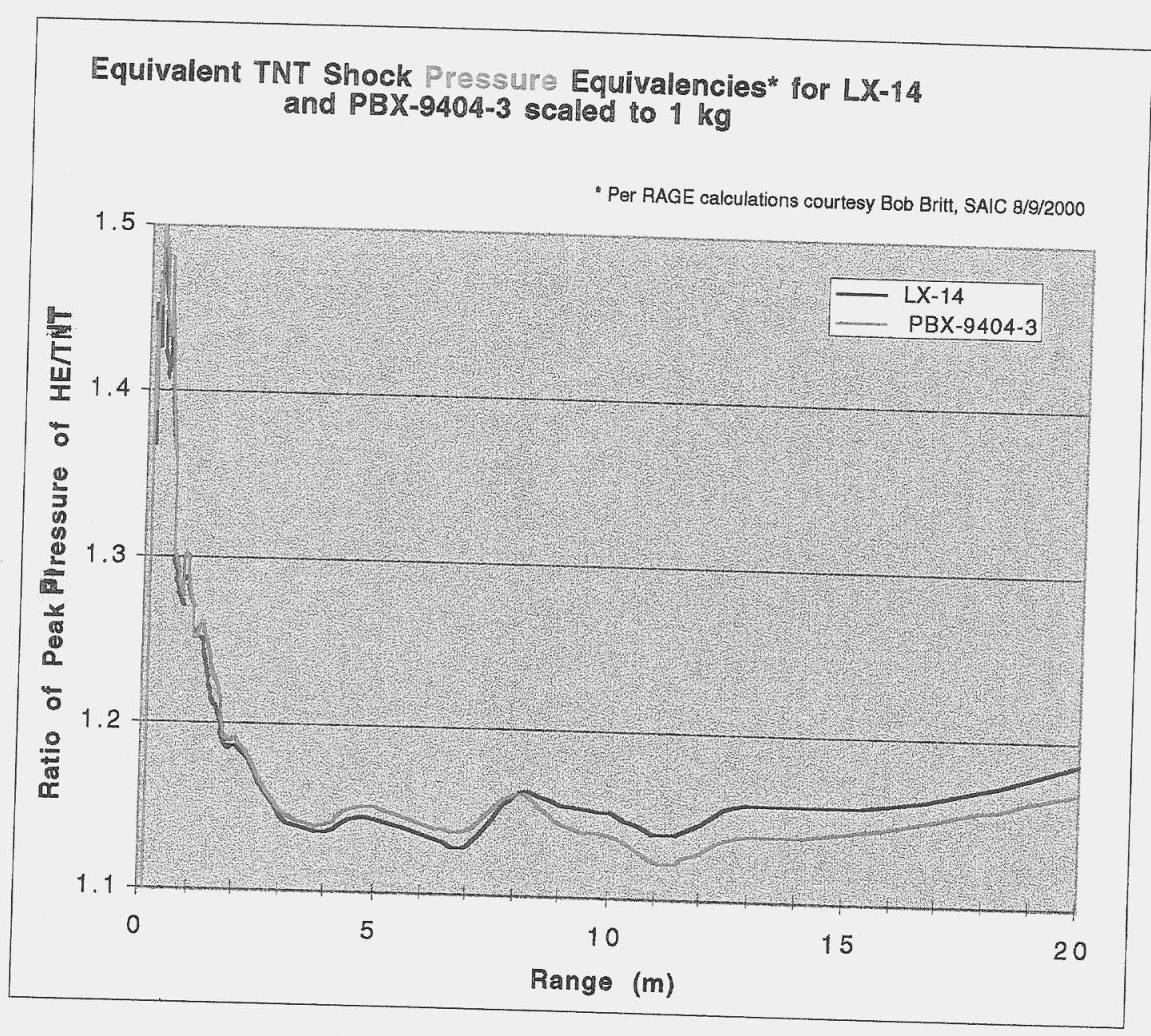

Figure 2

Data replotted from Figure 1 - data courtesy SAIC, Bob Britt 8/9/2000 


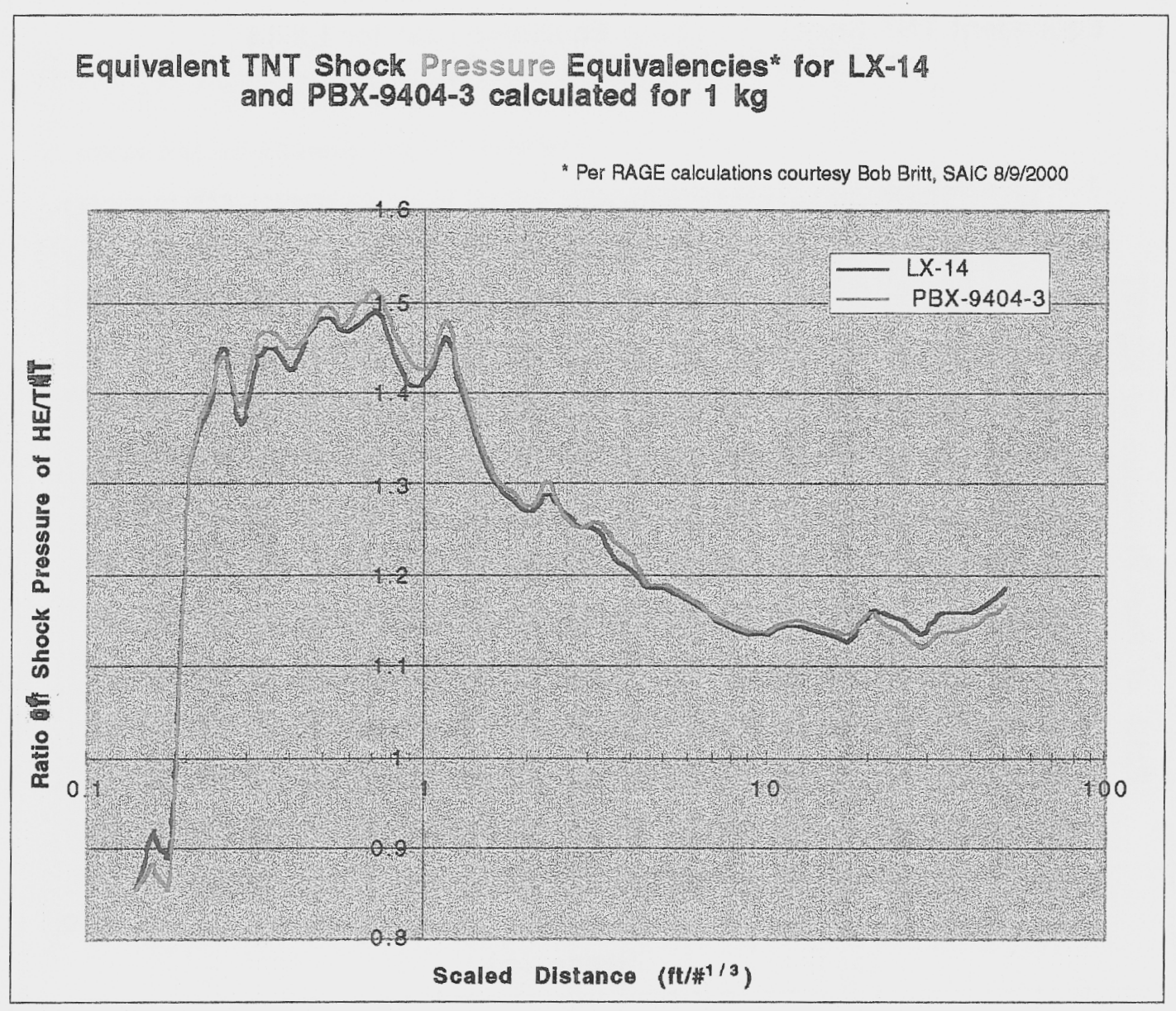

Figure 3

Data replotted from Figure 1 - data courtesy SAIC, Bob Britt 8/14/2000

From a pressure standpoint, for scaled distances greater than about $4 \mathrm{ft} / 1 \mathrm{~b}^{1 / 3}$ a safe TNT equivalency would be 1.2 for either LX-14 or PBX-9404. 


\section{IMPULSE}

Impulse in Air Scaled to $1 \mathrm{~kg}$ Sphere from RAGE Calculations

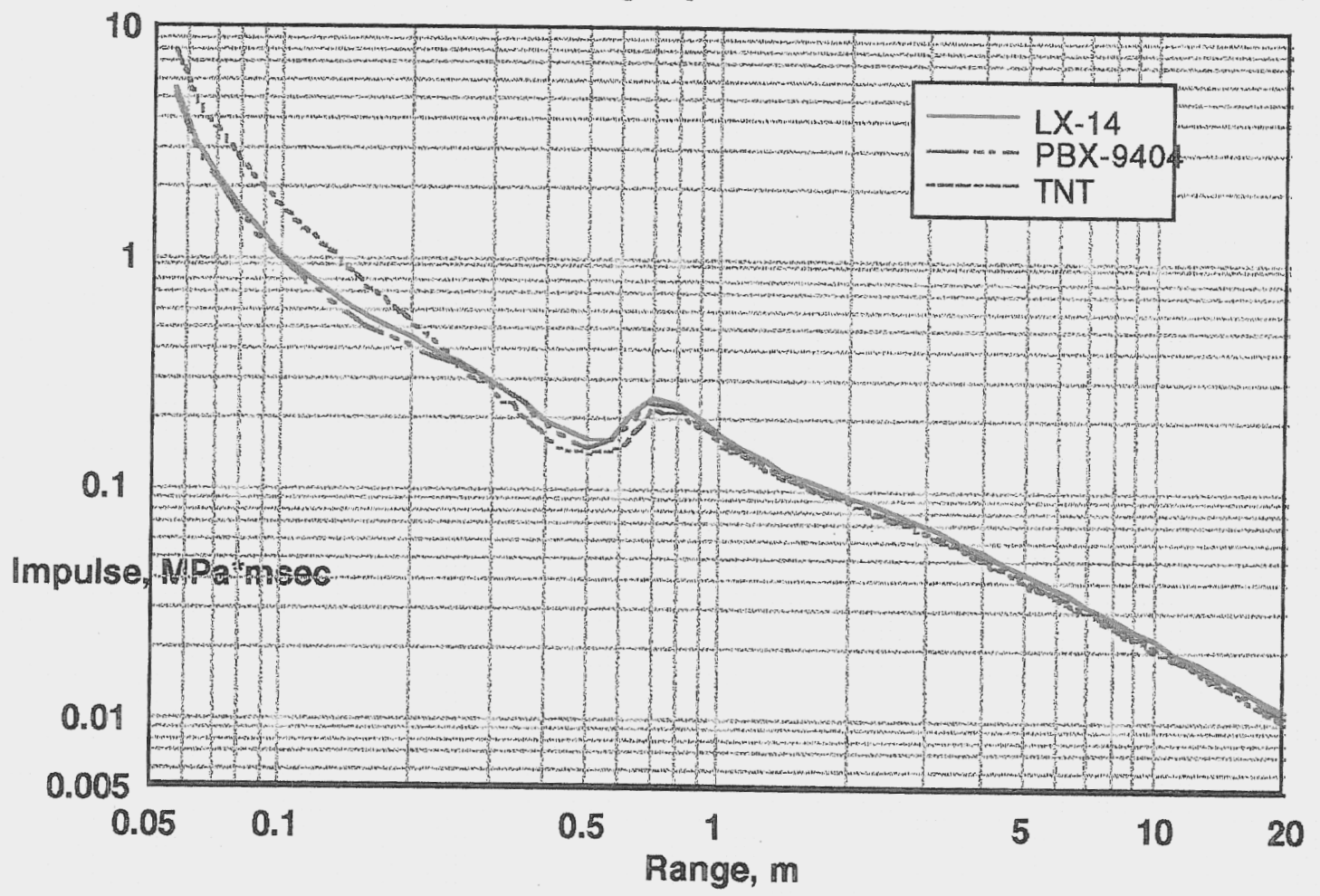

Figure 4

Plot courtesy SAIC, Bob Britt 8/14/2000 


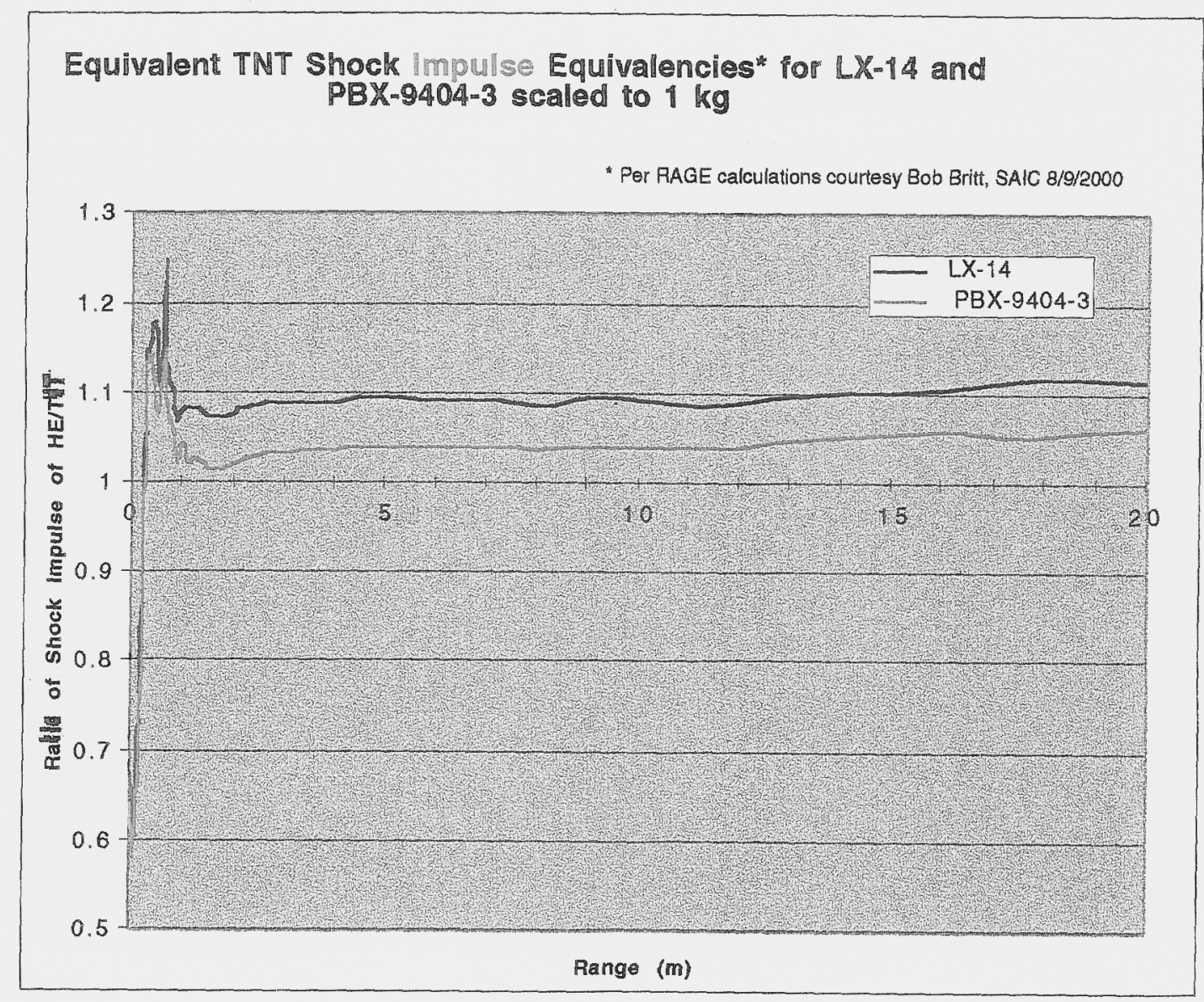

Figure 5

Data replotted from Figure 4 - data courtesy SAIC, Bob Britt 8/14/2000

Similar equivalencies based on impulse are also seen in Figure 5 where the ratio of the impulses versus distance can be observed. For LX-14 the TNT shock impulse equivalency peaks at about 1.25 but falls off faster; i.e., less than 1.1 at 1 meter. At distances between 15 to 20 meters the equivalency is limited to no more than 1.116 . This also very closely matches the DOETIC and TM5 equivalency of 1.117 . 


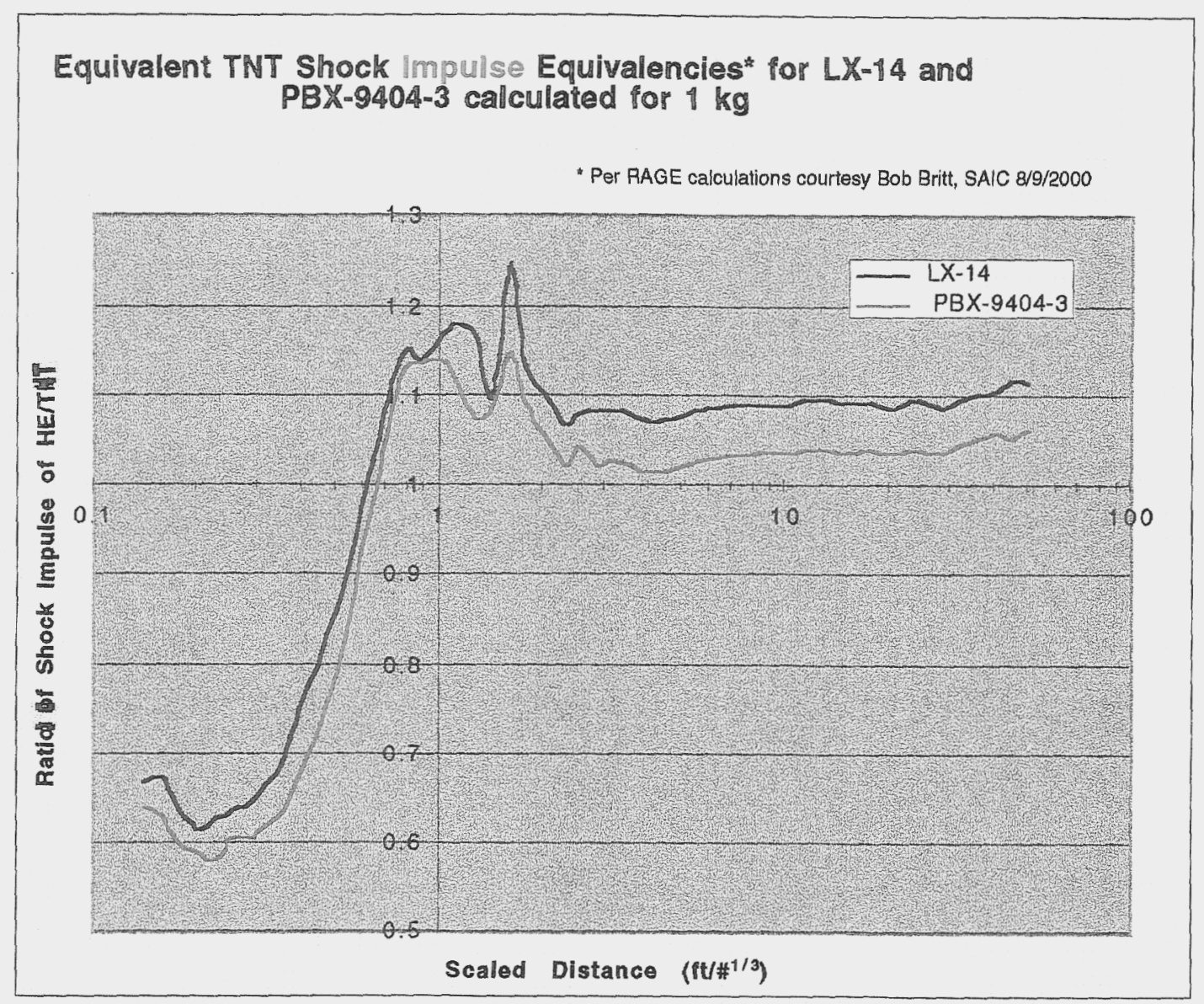

Figure 6

Data replotted from Figure 4 - data courtesy SAIC, Bob Britt 8/14/2000

From a shock impulse standpoint, for scaled distances greater than about $2 \mathrm{ft} / 1 \mathrm{~b}^{1 / 3}$ a safe TNT equivalency would be 1.1 for either LX-14 or PBX-9404. 


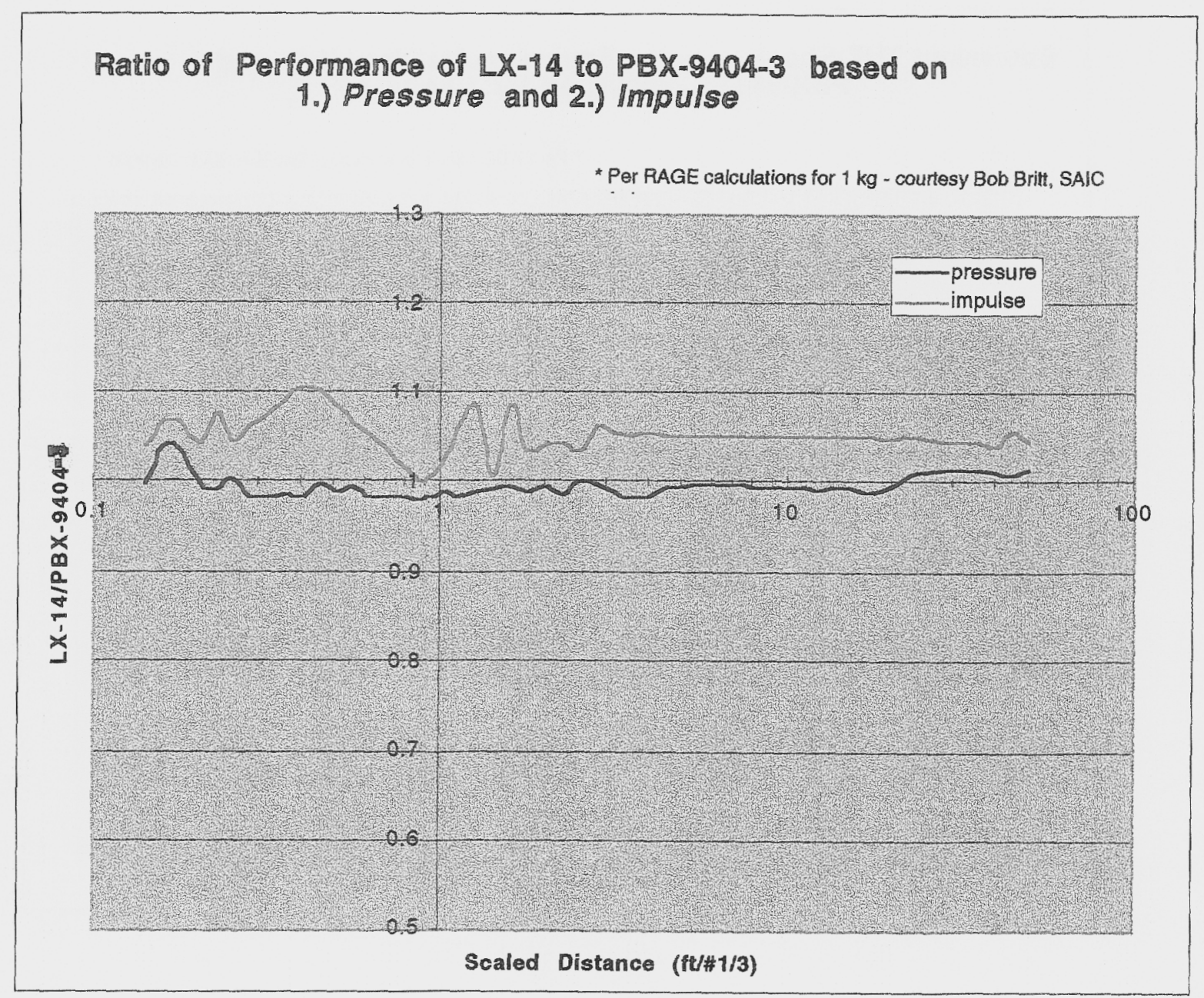

Figure 7

Data replotted from Figures 1 \& 4 - data courtesy SAIC, Bob Britt 8/14/2000

Bob Brit had made the preliminary recommendation when using BlastX with $\mathrm{LX}-14$ to use the tabular value model of PBX-9403-3 as a stand-in since the explosives are very similar in a chemical composition sense. To check the validity of this preliminary guidance, the ratio of LX14 divided by PBX-9404-3 was plotted first for pressure then for impulse as a function of scaled distance. The results of this ratio are shown in Figure 7. The conclusion based on $1 \mathrm{~kg}$ detonation is that for scaled distances greater than $1 \mathrm{ft} / 1 \mathrm{~b}^{1 / 3}$ (non close-in), pressure calcs using using the same amount of PBX-9404-3 would be valid since the ratio is essentially unity. However, BlastX impulse calcs based on PBX-9404-3 would under predict by about 5\%. The recommended procedure would then be to then increase the BlastX impulse results by a factor of 1.05 and use the peak pressure results without modification. Alternatively, one could go back to using the earlier BlastX procedure of a fixed TNT equivalency factor. A conservative TNT equivalency factor that conservatively envelopes both pressure and impulse results in this regime is 1.2 . 


\section{Tabular Data used in Figures 1-7}

HE Mass $=1 \mathrm{~kg}$ pressure and impulse yalues proyided courtesy of Bob Bnit, (SAIC) using RAGE Hydrocode.

\begin{tabular}{|c|c|c|c|c|c|c|c|c|c|c|c|c|c|c|c|}
\hline \begin{tabular}{|l}
$Z$ \\
scaled distance \\
ft//\# $n(1 / 3)$
\end{tabular} & $\begin{array}{l}\text { PBX,-9404-3 } \\
\text { range } \\
\text { m }\end{array}$ & $\begin{array}{l}\text { prassurs } \\
\text { psi }\end{array}$ & $\begin{array}{l}\text { impulse } \\
\text { psi-ms }\end{array}$ & $\begin{array}{l}\mathrm{LX}-14 \\
\text { rango } \\
\text { m }\end{array}$ & $\begin{array}{l}\text { pressure } \\
\text { psi }\end{array}$ & $\begin{array}{l}\text { impulse } \\
\text { psi-ms }\end{array}$ & $\begin{array}{l}\text { TNT } \\
\text { range } \\
m\end{array}$ & pressure & impulso & $\begin{array}{l}\begin{array}{l}\text { Dx. }+4 \pi N N T \\
\text { pressure }\end{array} \\
\end{array}$ & impulse & $\begin{array}{l}\text { PBX-9404/TN } \\
\text { pressurs }\end{array}$ & impulse & $\begin{array}{l}\overline{L X 14 / P B X-94} \\
\text { pressure }\end{array}$ & impulse \\
\hline 0.141727397 & 0.056198 & 619.72 & 5.082 & 0.0562 & 619.2 & 5.302 & 0.0502 & 724.9 & 7.94 & 0.8541868 & 6676 & 0.85490 & 635 & 0.9997609 & 1.0432 \\
\hline 0.15914132 & 0.063103 & 123.43 & 2.943 & 0.0631 & 128.6 & 3.148 & 0.0631 & 139.7 & 4.664 & & & & & & \\
\hline 0.176535068 & 0.07 & 60.188 & 2.175 & 0.07 & 62.59 & 2.326 & 0.07 & 70.11 & 3.6115 & 0.89274 & 0.6440537 & 0.8584795 & 28 & 1.0399083 & .0694 \\
\hline 0.201759408 & 80002 & 53.333 & 1.554 & 0.08 & 53.24 & 1.628 & 0.08 & 39.96 & 2.628 & 1.3323323 & 99 & 1.33 & 242 & 0.9982562 & 1.0444015 \\
\hline 0.226963672 & 9998 & 47.841 & 1.158 & 0.09 & 47.48 & 1.25 & 0.09 & 1.35 & 1.992 & & & 1.3927511 & 0. & 0.99 & 1.0794473 \\
\hline 0.252187911 & 099998 & 45.183 & 0.9794 & 0.1 & 45.49 & 1.025 & 0.1 & 1.35 & 1.612 & 67 & 83 & 1.44 & 0. & 1.006 & 1.0465591 \\
\hline 0.282456109 & 0.112 & 41.636 & 800 & 0.112 & 41.03 & 3.852 & 0.112 & 30 & 1.3214 & 1,3676667 & 0.645 & 1.3 & 0.6 & 453 & 1.0648345 \\
\hline .317763123 & 0.126 & 38.393 & 66 & 0.125 & 37.76 & 7204 & 0.126 & 26.23 & 1.0811 & 1.439573 & 0.666 & 1.4 & & 26 & 1.0774753 \\
\hline 0.355592066 & 0.141 & 34.049 & 0.5683 & 0.141 & 33.65 & 9 & 0.141 & 23.22 & 0.89383 & 1.44 & 0.6957699 & 652 & 0.6358032 & 316 & 1.0943164 \\
\hline 0.398464869 & 0.158 & 30.829 & 0.5008 & 0.158 & 30.3 & 44 & 0.158 & 21.25 & 0.74062 & 1.4258824 & 0.748562 & 1.4507765 & 0.6761902 & 0.98 & 1.1070288 \\
\hline 0.44890346 & 0.178 & 26.972 & 0.4481 & 0.178 & 26.94 & 46 & 0.178 & 18.33 & 0.61825 & 218 & & 1.4714675 & 0.7247877 & 0.9988136 & 1.1037715 \\
\hline 0.50438591 & 0.2 & 22.562 & 0.4053 & 0.2 & 22.39 & 11 & 0.2 & 5.07 & 0.51122 & 1.4857332 & 0.8628379 & 1.4971466 & 0.7928094 & 0.9923766 & 1.0883296 \\
\hline 0.564912219 & 0.224 & 19.605 & 0.3707 & 0.224 & 18.51 & 54 & 0.224 & 13.29 & 0.42337 & 1.4680211 & 0.9339349 & 1.4751693 & 0.8755935 & 0.9951543 & 1.0666307 \\
\hline 0.633004317 & 0.251 & 17.175 & 0.3385 & 0.251 & 16.9 & 0.356 & 0.251 & 11.44 & 0.35137 & 1.4772727 & 1.013177 & 1.5013112 & 0.9633719 & 0.9839884 & 1.0516987 \\
\hline 0.711184133 & 0.282 & 14.335 & 0.3055 & 0.282 & 14.14 & 0.3161 & 0.282 & 9.489 & 0.28822 & 1.4901465 & 1.0967317 & 1.5106966 & 1.0599542 & 0.9863969 & 1.0346972 \\
\hline 0.796929737 & 0.316 & 11.712 & 0.2689 & 0.316 & 11.53 & 0.2731 & 0.316 & 7.98 & 0.23772 & 1.4448622 & 1.1488306 & 1.4676692 & 1.1311627 & 0.9844604 & 1.0156192 \\
\hline 0.89528499 & 0.355 & 9.493 & 0.2288 & 0.355 & 0.316 & 0.2295 & 0.355 & 6.621 & 0.20116 & 1.4070382 & 1.1408829 & 1.4337713 & 1.1374031 & 0.9813547 & 1.0030 \\
\hline 1.008771819 & 0.4 & 7.5336 & 0.1918 & 0.4 & 7.476 & 0.1961 & 0.4 & 5.261 & 0.16797 & 1.4210226 & 1.1674704 & 1.4319711 & 1.1418706 & & 1.022 \\
\hline 1.127302508 & 0.447 & 6.2458 & 1651 & 0.447 & 6.164 & 0.1752 & 0.447 & 4.219 & 0.14843 & 1.4610097 & 1.1 & 1.48 & & & 1.061 \\
\hline 1.260964774 & 0.5 & 4.9981 & 0.1505 & 0.5 & 4.96 & 0.1637 & 0.5 & 3.536 & 0.14002 & 1.4027149 & 1.1691187 & 1.41 & 1.0 & 0.9 & 1.087707 \\
\hline 1.417324406 & 0.562 & 3.8964 & 0.1613 & 0.562 & 3.867 & 0.1628 & 0.562 & 2.873 & 0.14835 & 1.3459798 & & 1.3 & 1.0 & & 1.0076 \\
\hline 1.591337545 & 0.631 & 3.0278 & 0.1937 & 0.631 & 3.018 & 0.2106 & 0.631 & 2.312 & 0.16853 & 633 & 1.24 & 1.30 & 1.14 & 0.9 & 1.087248 \\
\hline 1.765350684 & 0.7 & 2.4395 & 0.2392 & 0.7 & $2.4 z$ & 0.248 & 0.7 & 1.887 & 0.21878 & & & & & & 1.036785 \\
\hline 2.017543639 & 0.8 & 1.8899 & 0.226 & 0.8 & 1.883 & 0.2 & 0.8 & 1.481 & 0.21 & & & & & & $\begin{array}{l}1.045 \\
1.04\end{array}$ \\
\hline 2.269 & 0.8 & 1.5095 & 0.1 & 0.9 & 1.493 & 0.15 & 0.9 & 1.158 & & & & & & & \\
\hline 2.52192954 & & 1.1808 & 0.16 & 1 & 1.184 & 0.17 & 1 & 0.9314 & & & & & & & \\
\hline 2.8298 & 1.122 & 0.89856 & & 122 & 0.8981 & & 122 & .7171 & & & & & & & \\
\hline & 1.259 & 0.68167 & & & 0.6761 & & & & & & & & & & \\
\hline & 1.413 & 0.50615 & & .413 & 0.4982 & & 1.413 & .4085 & & & & & & & \\
\hline & 1.585 & 0.37951 & & 85 & .3747 & & 1.8 & & 0. & & & 09 & 1.0 & 0.9873258 & 1.056038 \\
\hline 4.4 & 1.778 & 0.28302 & & .778 & 0.2819 & & 1.778 & 376 & & 78 & & 10 & 1.0 & 0.996 & 1.0554282 \\
\hline & & 0.27369 & & & 31 & & & 794 & & & & & & 0.98 & 1.05501 \\
\hline 5.64 & 239 & 4 & & 39 & 49 & & 39 & 99 & & & & 46 & & 0.998 & 1.055562 \\
\hline & & & & & 33 & & 12 & 01 & & & & 449 & & 0.9980552 & 1.053611 \\
\hline 7.10 & & & & & & & 2 & & & & & 99 & & 0.9983197 & 1.052813 \\
\hline & & 0.08 & & & & & & & & & & 16 & 1.03 & 0.996688 & 1.0528651 \\
\hline & 3 & 00 & & 48 & & & 3.548 & & & & & & & 0.9964534 & 1.0521983 \\
\hline & & 0.0 & & & & & 4 & & & & & 1.1414172 & 1.036 & 0.9961222 & 1.052652 \\
\hline & 4.467 & & & 67 & & & 4.467 & & & & & $1.149529 z$ & 1.040 & 0.995132 & 1.051668 \\
\hline & & & & & & & & & & 887 & & 1.1574183 & 1.0409859 & 0.9933737 & 1.0515217 \\
\hline & 5.623 & & & 5. & & & 5.623 & 538 & & 1.1398739 & 1.093 & 1.1450749 & 1.03942 & 0.995456 & 1.051728 \\
\hline & 6.31 & & & 6.31 & & & 6.31 & 0.02123 & 0.032178 & 1.1328309 & 1.092672 & 1.1395667 & 1.0395301 & 0.9940892 & 1.0511211 \\
\hline & $T$ & & & 7 & 2043 & 0. & 7 & 0.01808 & 0.02909 & 1.1299779 & 1.0935029 & 1.1386615 & 1.0405638 & 0.9923738 & 1.0508755 \\
\hline 20 & 8 & 0.016768 & & 8 & 0.01676 & 0.02791 & 8 & 0.01444 & 0.025661 & 1.1606648 & 1.0876427 & 1.7612188 & 1.035 & 0.9995229 & 1.0504328 \\
\hline 28 & 9 & 0.01398 & 23 & 9 & 0.01412 & 0.02477 & 9 & 0.01222 & 0.022628 & 1.1554828 & 1.0946615 & 1.1440262 & 1.0416298 & 1.0100143 & $\begin{array}{r}1.0509122 \\
\end{array}$ \\
\hline & 10 & 0.012011 & 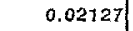 & 10 & 0.01216 & 0.02 & 10 & 0.07056 & 0.02045 & 1.1575152 & 1.0910315 & 1.7374053 & 1.040097 & 1.0124053 & 1.0498354 \\
\hline 28 & 11.22 & 0.010213 & 011 & 31.22 & 0.01036 & 0.0199 & 11.22 & 0.0091 & 0.018275 & 1.1384615 & 1.0889193 & 1.1223077 & 1.039124 & 1.0143934 & 1.0479 \\
\hline 31.75109301 & 12.59 & 0.0087168 & 0.016 & 12.59 & 0.00886 & 0.01768 & 12.59 & $0.007 a 6$ & 0.01616 & 1.156658 & 1.0940594 & 1.1379634 & 1.045 & 1.016428 & 1.046 \\
\hline 35.609645 & 14.12 & 0.0074689 & 0.015 & 14.12 & 0.00759 & & 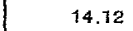 & .00655 & & & & 1.140290 & & & \\
\hline & 15.85 & $0 \tilde{4342}$ & & & & & 15. & & & & & & & & \\
\hline & & & & & & & & & & & & & & & \\
\hline & 20 & & & & & & & & 45 & & 466 & 3596 & 7.0 & 0152498 & \\
\hline
\end{tabular}


Table 2-1 Hoat of Detonation and Heat of Combustion

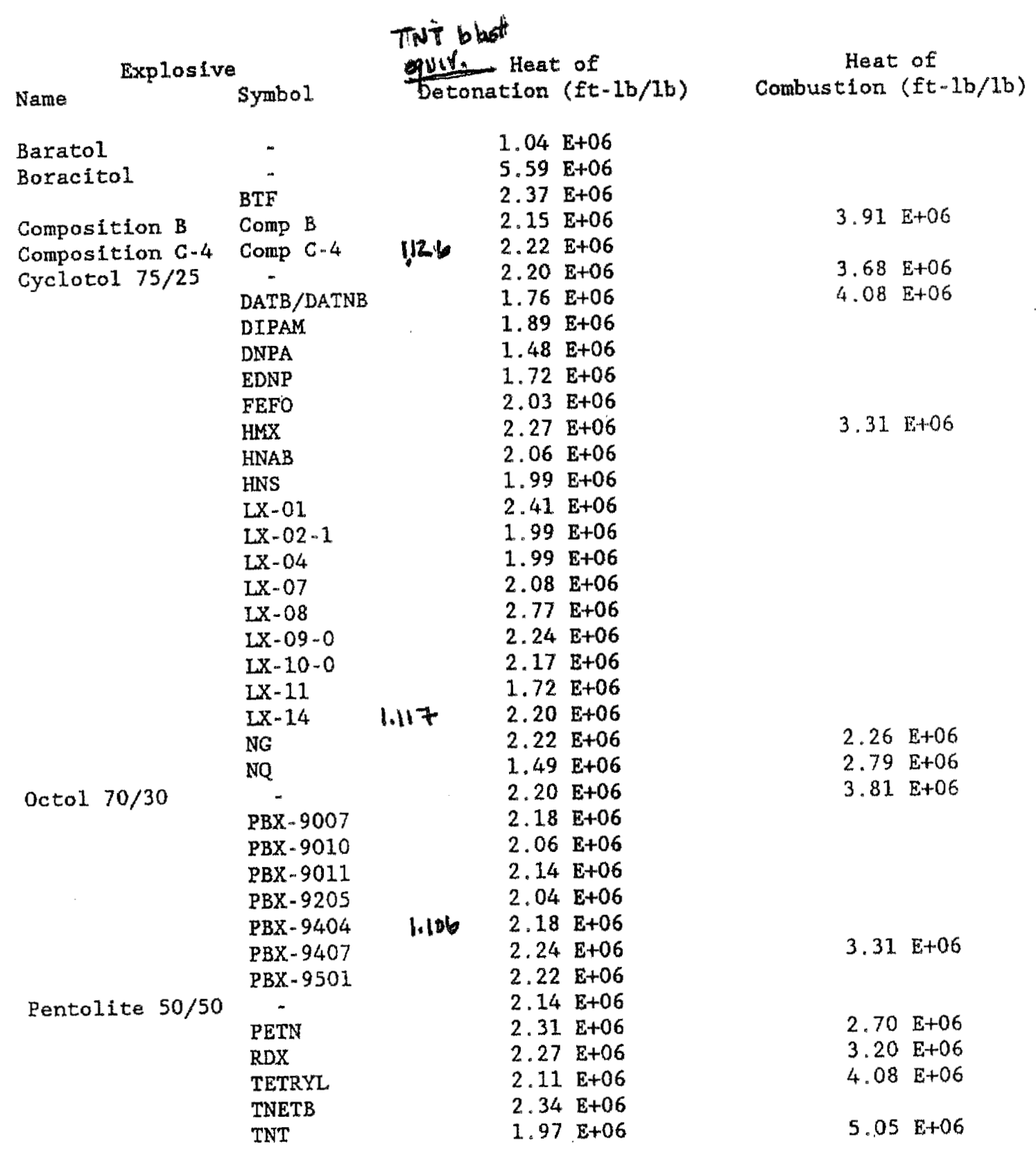


Table 6. Performance of Explosives" (continued)

\begin{tabular}{|c|c|c|c|c|c|c|c|}
\hline \multirow[t]{2}{*}{ COMMON NAME } & \multicolumn{2}{|c|}{$\begin{array}{l}\text { MEASURED DETRNATION VEA,OCITY } \\
\text { (nominal deasity, ambiens temperature) }\end{array}$} & \multicolumn{2}{|c|}{$\begin{array}{l}\text { MEASUKFN } \\
\text { CIMAPMAN-JOUGUET } \\
\text { DETONATION } \\
\text { PRFSSURE }\end{array}$} & \multirow[t]{2}{*}{$\begin{array}{l}\text { TNT } \\
\text { EQuIVALENT } \\
\text { WEIGHTt }\end{array}$} & \multicolumn{2}{|c|}{$\begin{array}{l}\text { CRITICAL FNFRFY FOR } \\
\text { SHOCK INITIATION }\end{array}$} \\
\hline & Nsec & $\mathrm{km} / \mathrm{sec}$ & $\mathrm{Ib} / \mathrm{in}^{\mathrm{t}}$ & MPa & & $\mathrm{n}-\mathrm{db} / \mathrm{m}^{2}$ & $y / \pi^{2}$ \\
\hline $1 \times-08$ & 21.522 & 6.56 & & & 1.402 & & \\
\hline $1 \times-09$ & 28,904 & 8.81 & $5.47 \times 10^{6}$ & $3.77 \times 10^{4}$ & 1.134 & $6.59 \times 10^{4}$ & $9.62 \times 10^{5}$ \\
\hline LX -10 & 28,937 & 8.82 & $5.44 \times 10^{6}$ & $3.75 \times 10^{4}$ & 1.100 & & \\
\hline$(L X-1)$ & 27,297 & 8.32 & $4.50 \times 10^{6}$ & $3.10 \times 10^{4}$ & .978 & & \\
\hline $1 x-14$ & 28,970 & 8.83 & $5.37 \times 10^{6}$ & $3.70 \times 10^{4}$ & 1.117 & & \\
\hline NG & 25,262 & 7.70 & $3.67 \times 10^{6}$ & $2.53 \times 10^{4}$ & 1.127 & & \\
\hline NQ & 25,098 & 7.65 & & & .753 & & \\
\hline OCTOL 75R5 & 27.822 & 8.48 & $4.96 \times 10^{6}$ & $3,42 \times 10^{4}$ & 1.114 & & \\
\hline$P B \times-9007$ & 26,542 & 8.09 & $3.84 \times 10^{6}$ & $2.65 \times 10^{4}$ & 1.107 & & \\
\hline PBX-9010 & 27,461 & 8.37 & $4.76 \times 10^{6}$ & $3.28 \times 10^{4}$ & 1.042 & & \\
\hline$P 8 x-9011$ & 27,887 & 8.50 & $4.70 \times 10^{\circ}$ & $3.24 \times 10^{4}$ & 1.085 & & \\
\hline$P B X-9205$ & 26,804 & 8.17 & $4.18 \times 10^{6}$ & $2.88 \times 10^{k}$ & 1.036 & & \\
\hline PBX-9404 & 28,871 & 8.80 & $5.44 \times 10^{6}$ & $3.75 \times 10^{5}$ & 1.107 & $4.32 \times 10^{4}$ & $6.30 \times 10^{3}$ \\
\hline PBX.9407 & 25,951 & 7.91 & $4.16 \times 10^{6}$ & $2.87 \times 10^{8}$ & 1.134 & & \\
\hline PBX-9501 & 28,970 & 8.83 & & & 1.127 & & \\
\hline PENTOLTE 5050 & 24,704 & 7.53 & $3.70 \times 10^{6}$ & $2.55 \times 10^{4}$ & 1.085 & & \\
\hline PETN & 27,099 & 8.26 & $4.86 \times 10^{6}$ & $3.35 \times 10^{4}$ & 1.169 & $-1.14 \times 10^{4}$ & $-1.67 \times 10^{3}$ \\
\hline $\mathrm{ROX}$ & 28,543 & 8.70 & $4.90 \times 10^{6}$ & $3.38 \times 10^{4}$ & 1.149 & $4.66 \times 10^{4}$ & $6.80 \times 10^{3}$ \\
\hline TATB & 25,459 & 7.76 & $4.22 \times 10^{6}$ & $2.91 \times 10^{6}$ & & $6.10 \times 10^{3}$ & $9.50 \times 10^{6}$ \\
\hline
\end{tabular}


Table 6. Performance of Explosives"

(continued)

\begin{tabular}{|c|c|c|c|c|c|c|c|}
\hline \multirow[t]{2}{*}{ COMMON NAME } & \multicolumn{2}{|c|}{$\begin{array}{l}\text { MFASURFD DFTUNATION VFI, K:ITY } \\
\text { (nomianat density, ambient temperature) }\end{array}$} & \multicolumn{2}{|c|}{$\begin{array}{l}\text { MFASURED } \\
\text { CIAPMAN-JOULUTT } \\
\text { DETONATION } \\
\text { PRESSURE }\end{array}$} & \multirow[t]{2}{*}{$\begin{array}{l}\text { TNT } \\
\text { WQWVALENT } \\
\text { WEIGHTY }\end{array}$} & \multicolumn{2}{|c|}{ 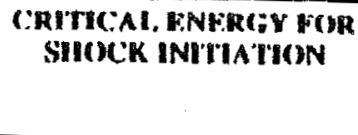 } \\
\hline & N/sec & $\mathrm{km} / \mathrm{sec}$ & $\mathrm{B} / \mathrm{in}^{2}$ & $\mathrm{MPa}$ & & $n-m / n^{2}$ & $\mathrm{~J} / \mathrm{m}^{2}$ \\
\hline $\begin{array}{l}\text { TETRYL } \\
\text { TNETB }\end{array}$ & $\begin{array}{l}25,754 \\
22,736\end{array}$ & $\begin{array}{l}7.85 \\
8.29\end{array}$ & $\begin{array}{l}3.77 \times 10^{6} \\
2.76 \times 10^{8}\end{array}$ & $\begin{array}{l}2.60 \times 10^{\circ} \\
1.90 \times 10^{4}\end{array}$ & 1.071 & $\begin{array}{l}2.88 \times 10^{4} \\
@ p=1.655\end{array}$ & $4.20 \times 10^{5}$ \\
\hline TNT $\underset{\text { (cressed) }}{\text { (cost) }}$ & $\begin{array}{l}27,198 \\
22,080\end{array}$ & $\begin{array}{l}6.93 \\
6.73\end{array}$ & $3.05 \times 10^{6}$ & $2.10 \times 10^{4}$ & 1.0 & $\begin{array}{l}9.73 \times 10^{4} \\
2.88 \times 10^{4}\end{array}$ & $\begin{array}{l}1.42 \times 10^{6} \\
4.20 \times 10^{6}\end{array}$ \\
\hline
\end{tabular}

a. See Table I

- Calculated

t Values are based on calculated maximum heals of detonation 
Appendix 4

Primary Barrier Drawings 


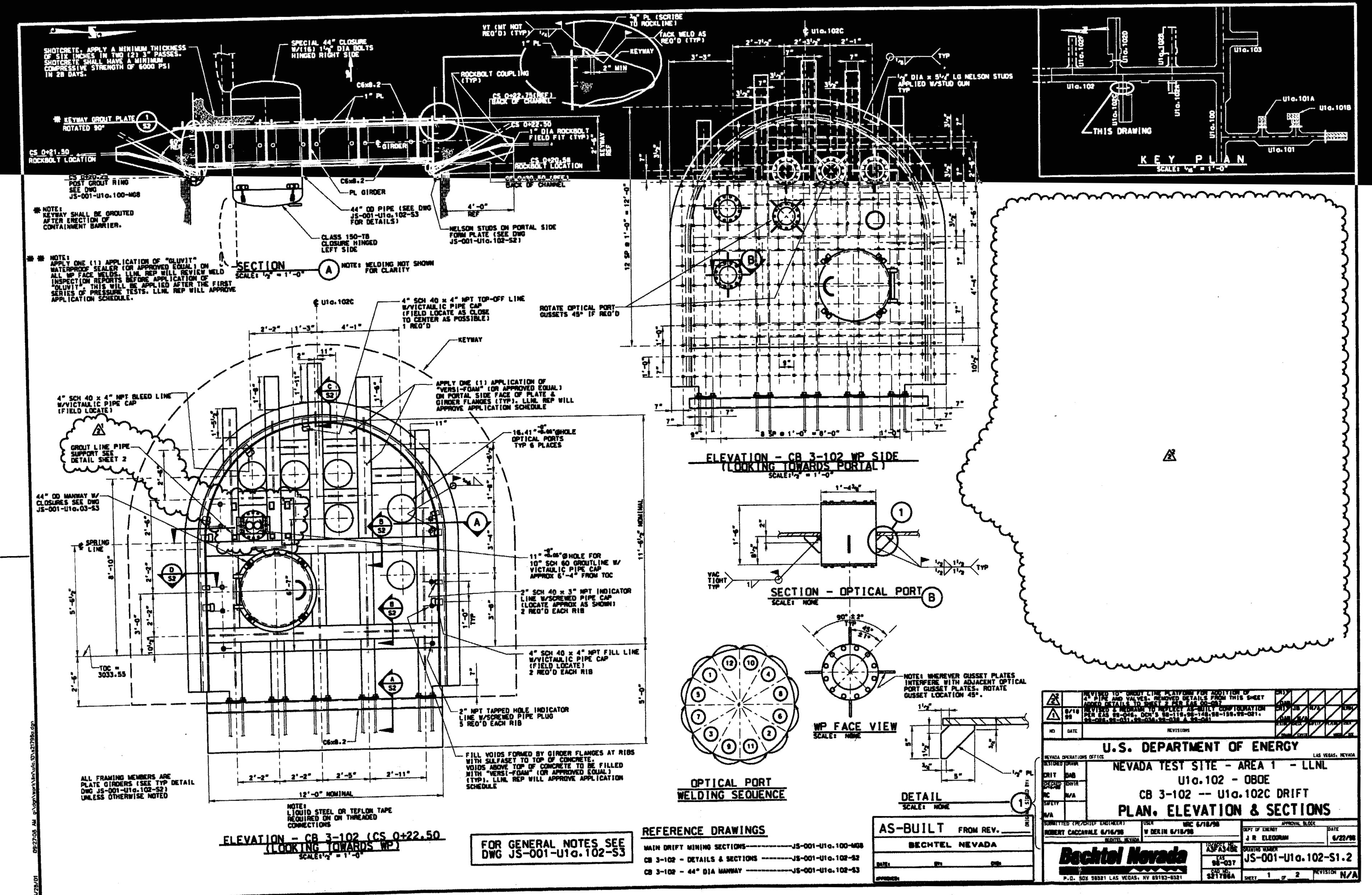




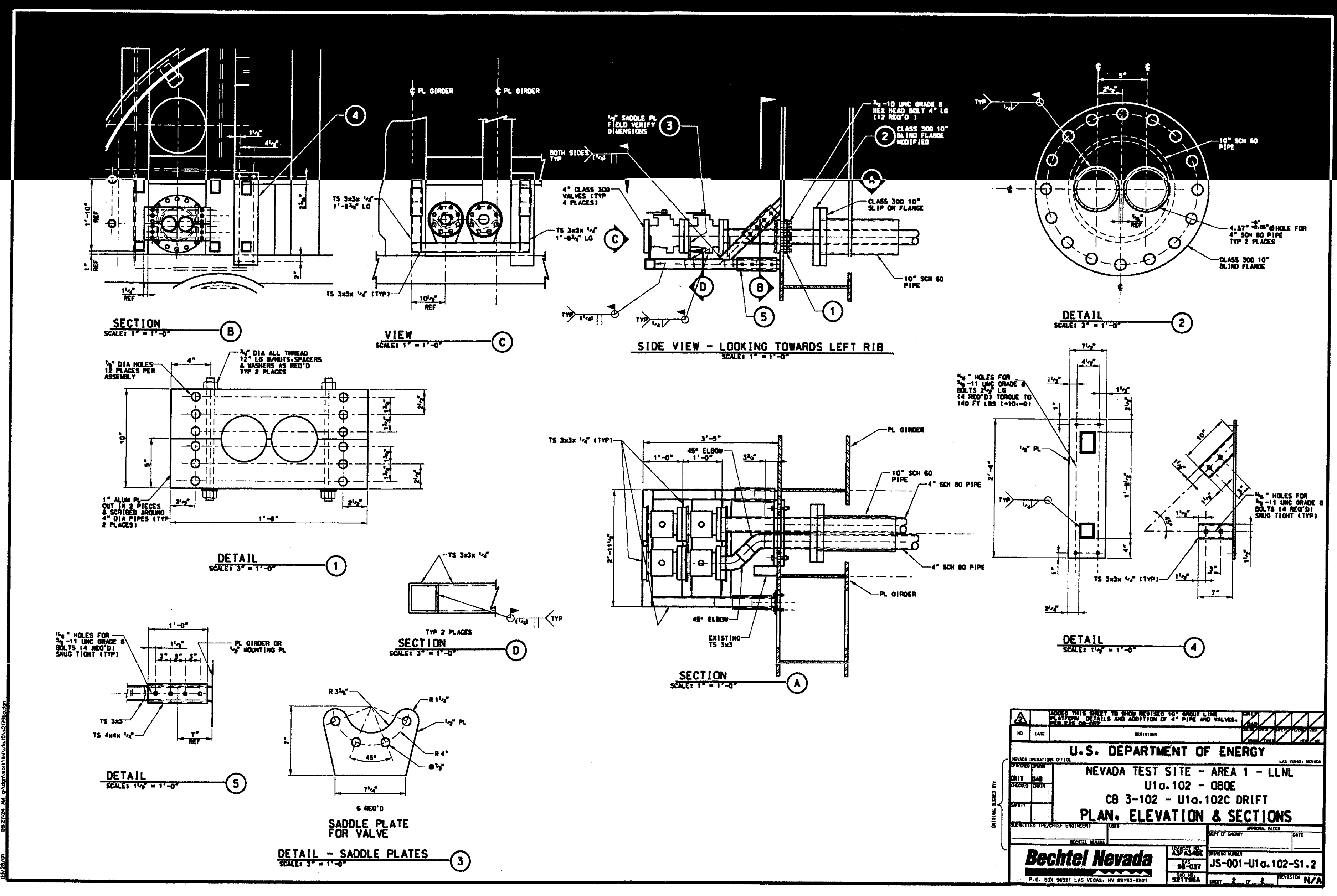




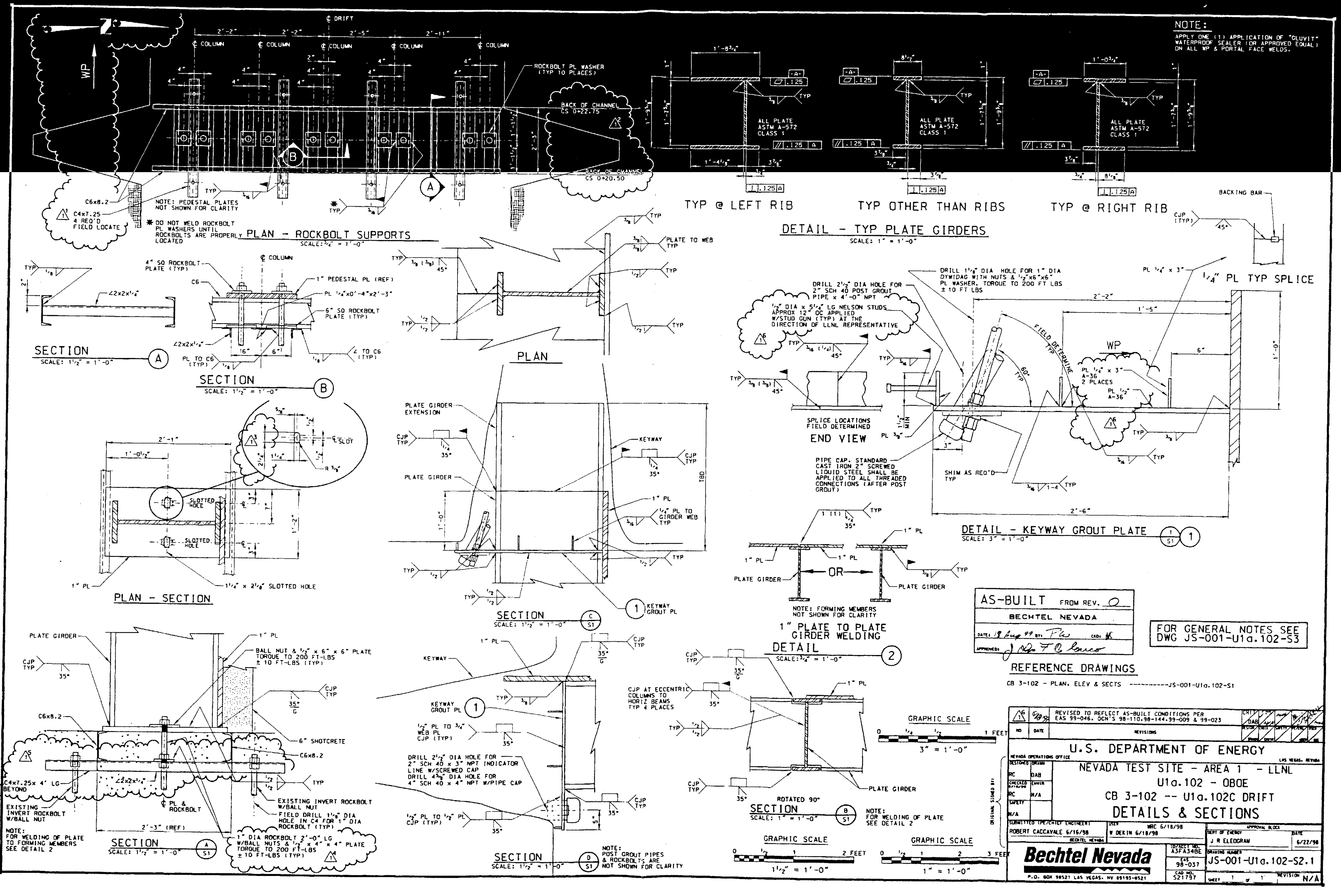


MANWAY NOTES:

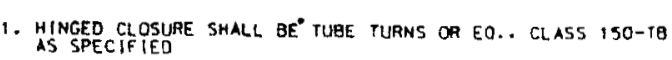

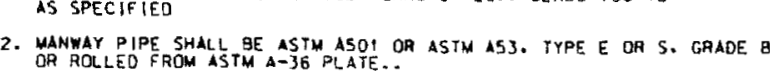<smiles>CCCCCCCC</smiles>

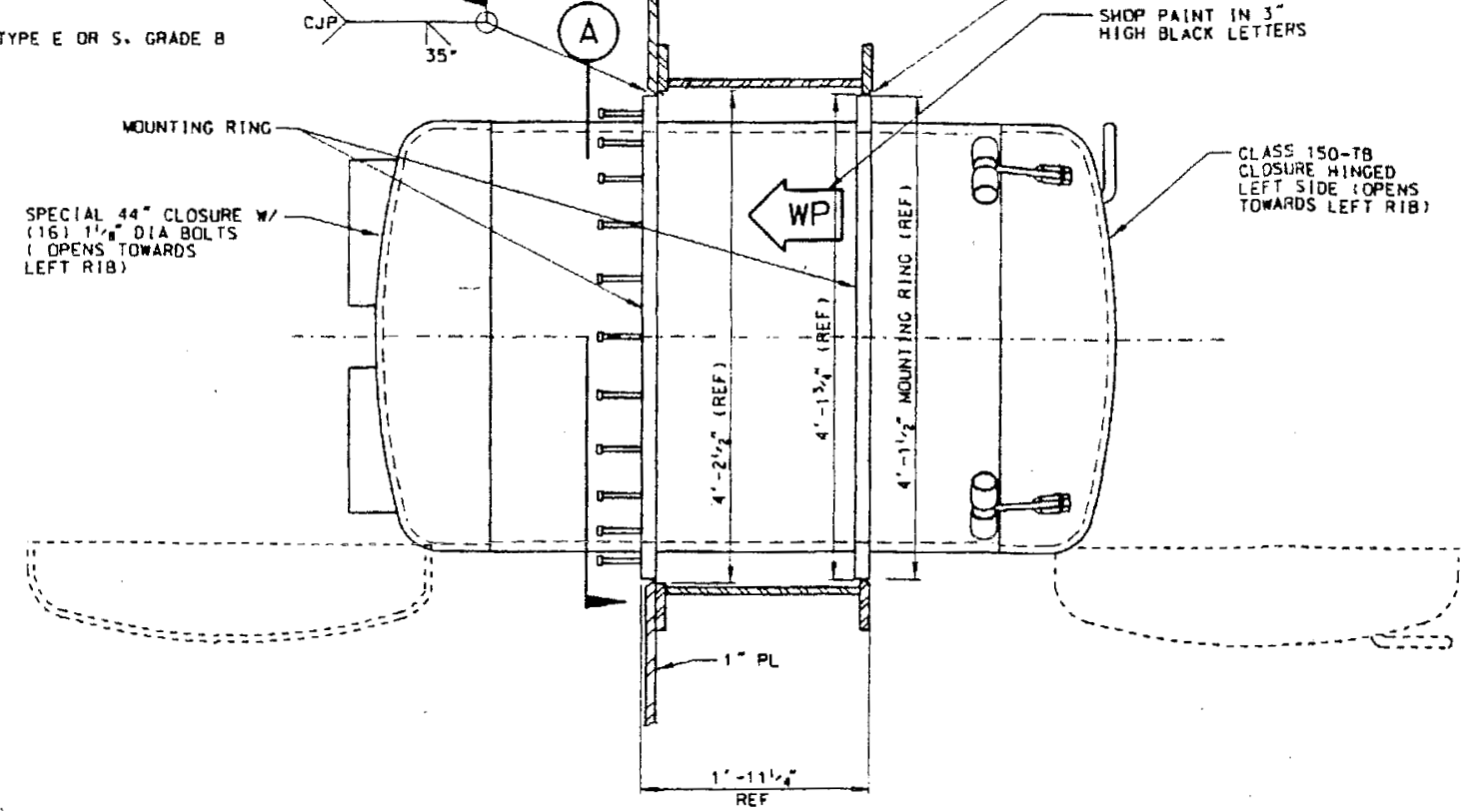

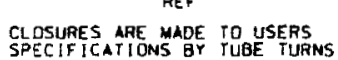

$\frac{44^{\prime \prime} \text { OD MANWAY - PLAN }}{\text { SCME: } 1^{*}=1^{\circ}-0^{*}}$
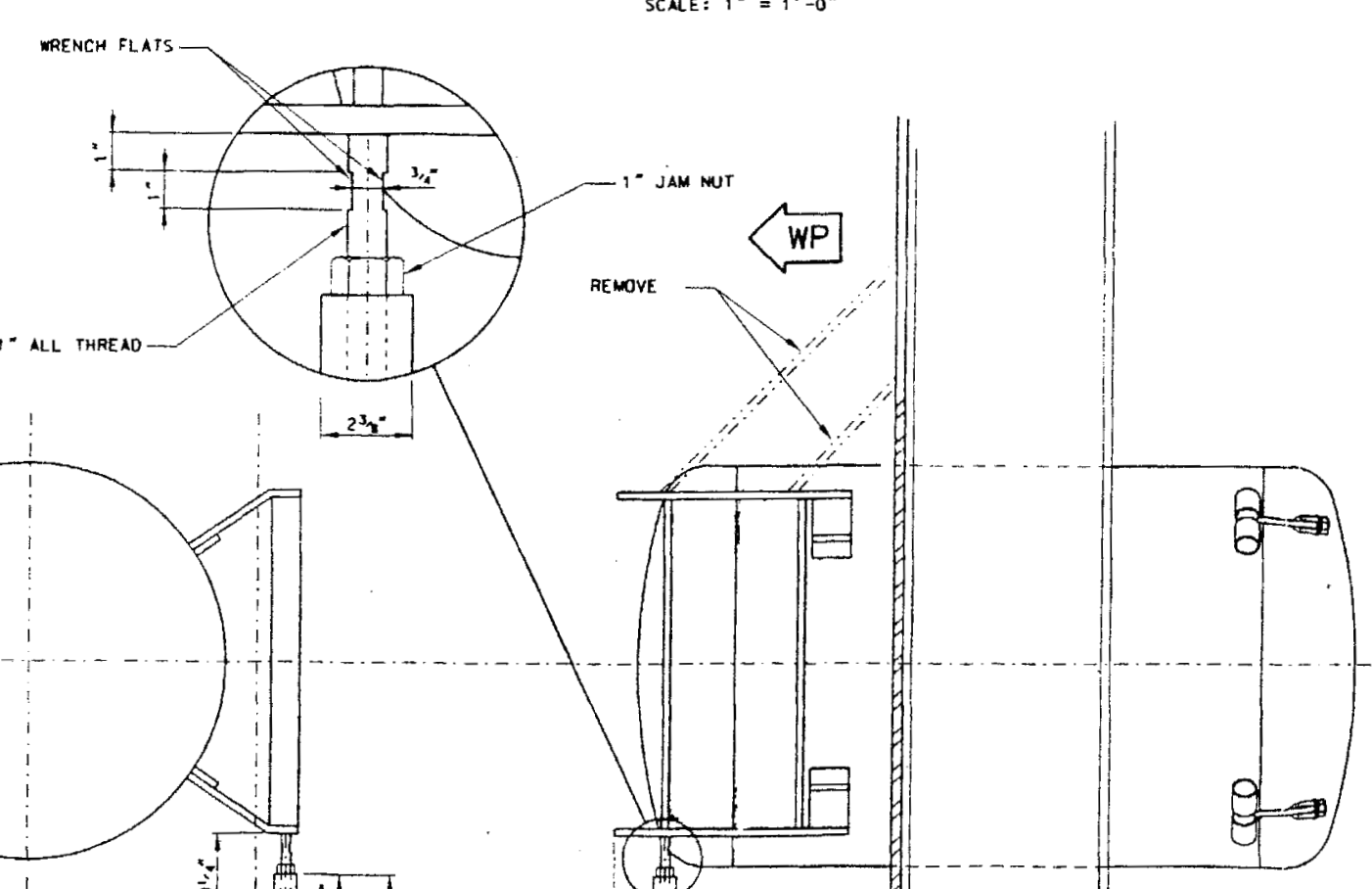

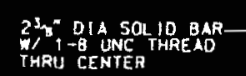
CENTER UNOER HINCE ARY -
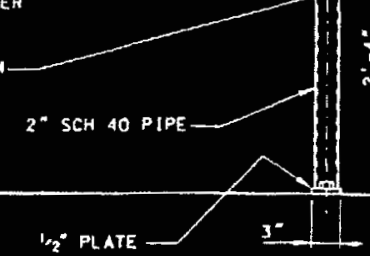

$-11$

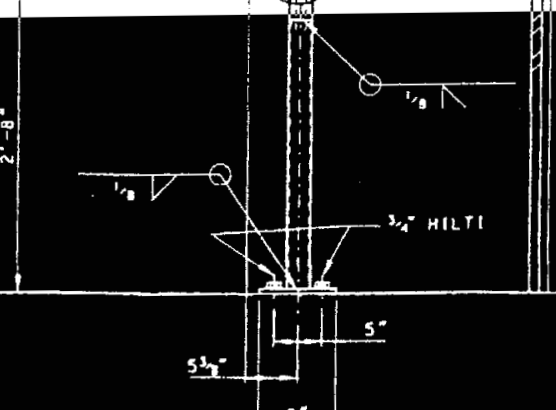

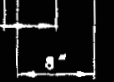

MANWAY WP SIDE CLOSURE SUPPORT
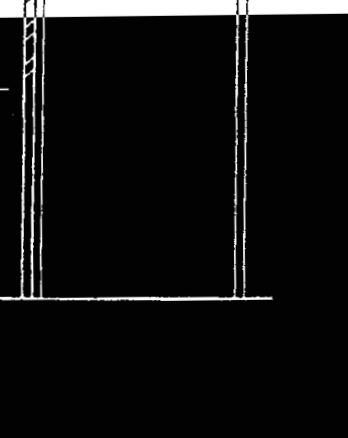

$\frac{\text { GENERAL NOTES }}{1.0 \text { MATERIAL }}$

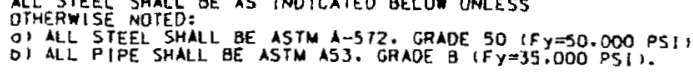

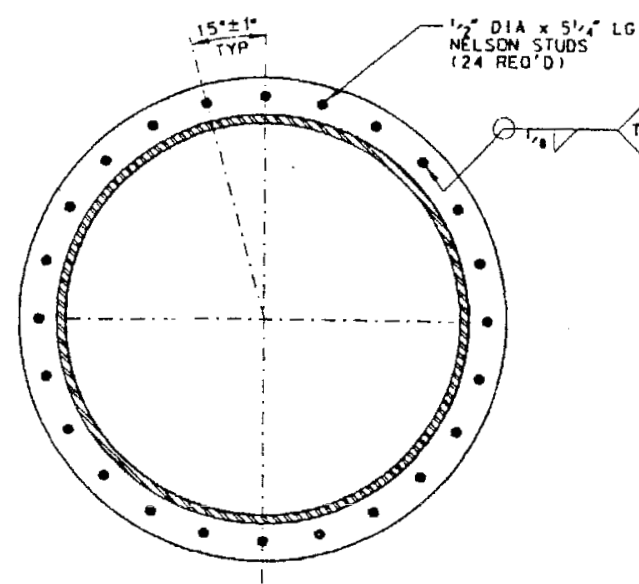

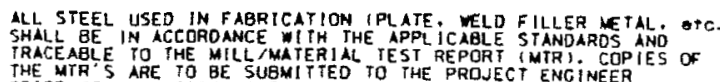

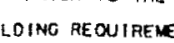

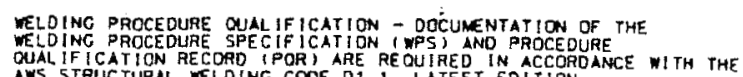

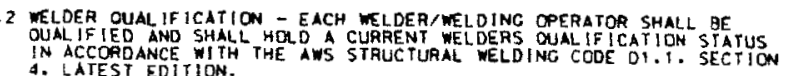

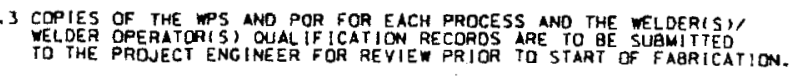

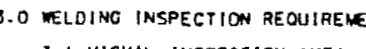

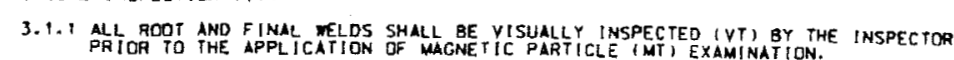

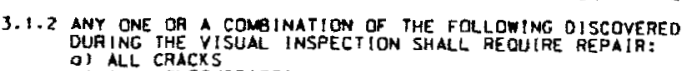

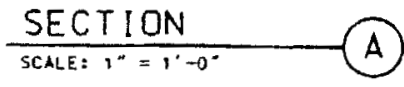

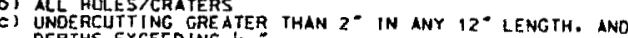

3.2 MAGNETIC PARTIILLE EX

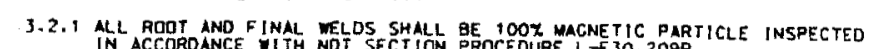

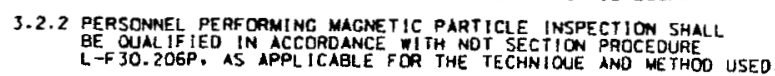

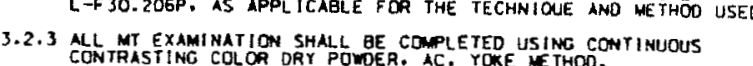

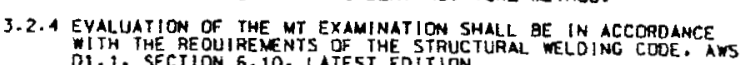

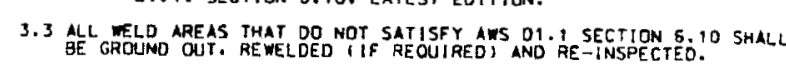

4.0 INSSEEction

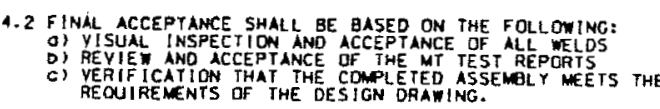

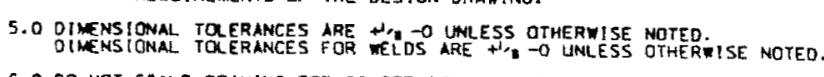

6.0 OO NOT SCALE DRANINC FOR CONSTRUCTION PURPOSES.

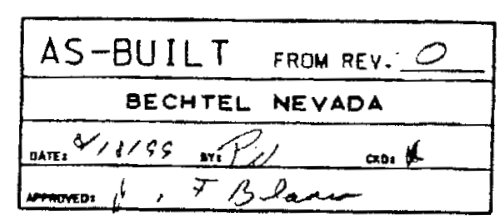

REFERENCE DRAWINGS

$=-\frac{2}{1^{\prime \prime}=1^{\prime}-0^{n}}$

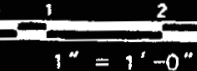


Appendix 5

Secondary Barrier Drawings 


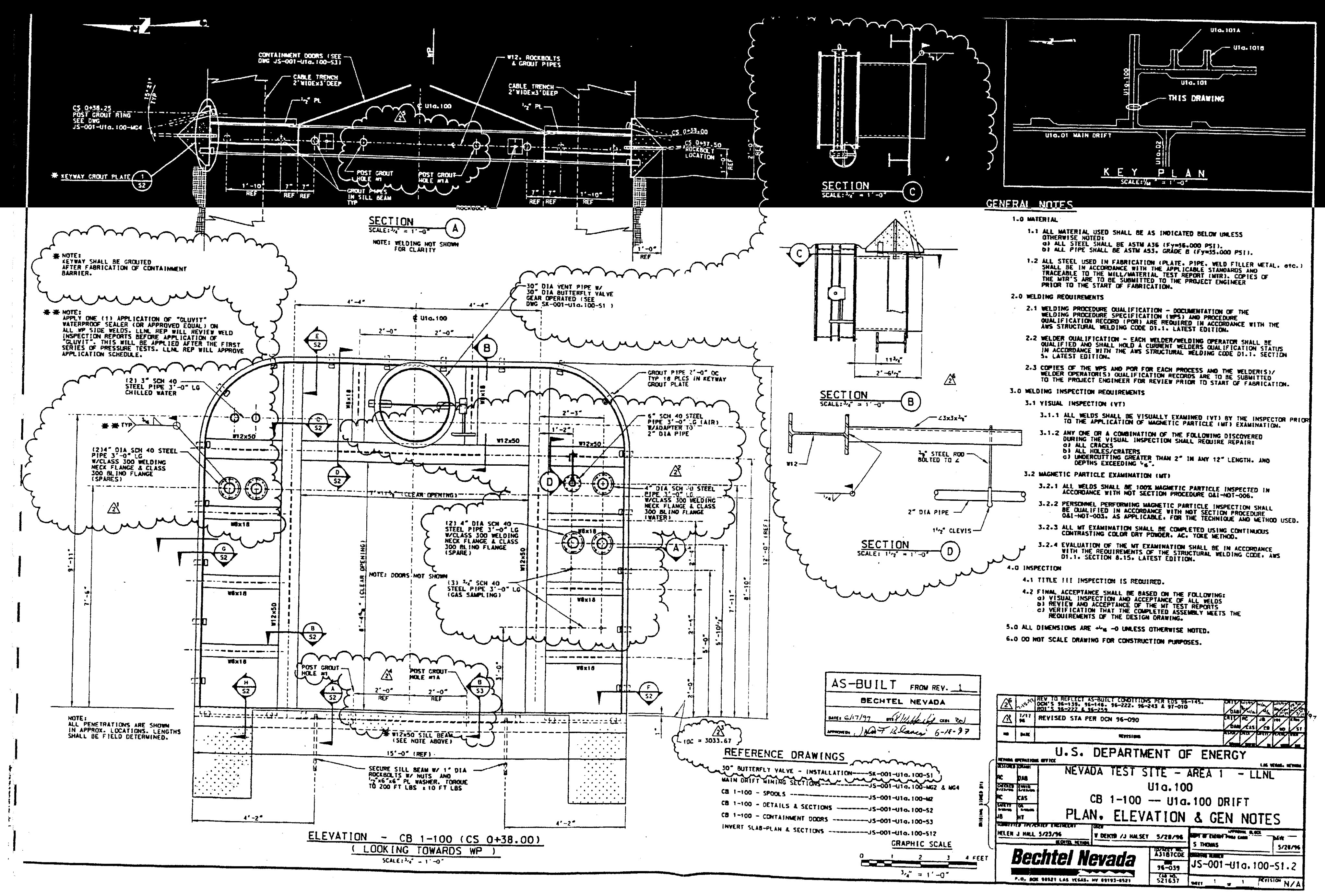




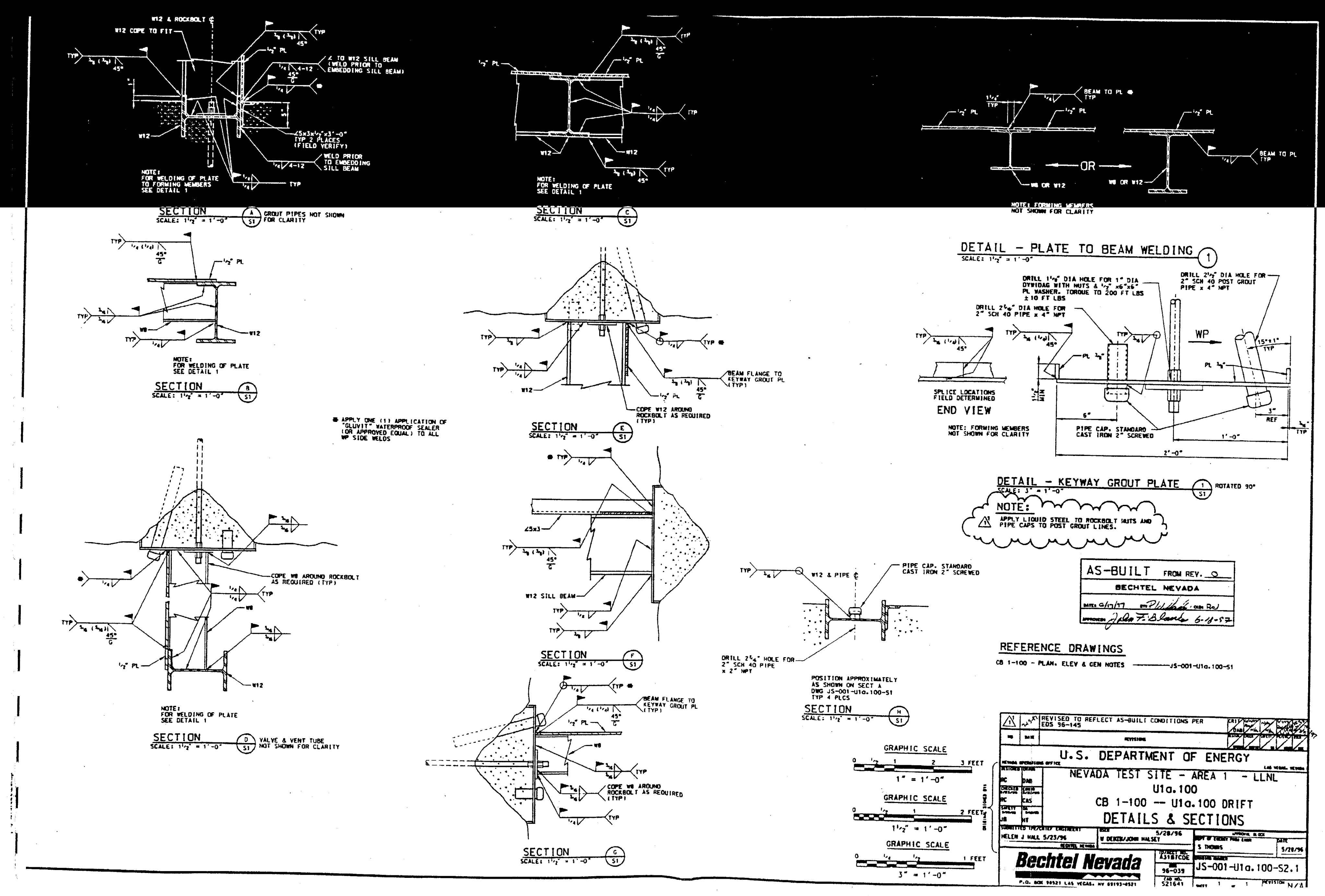




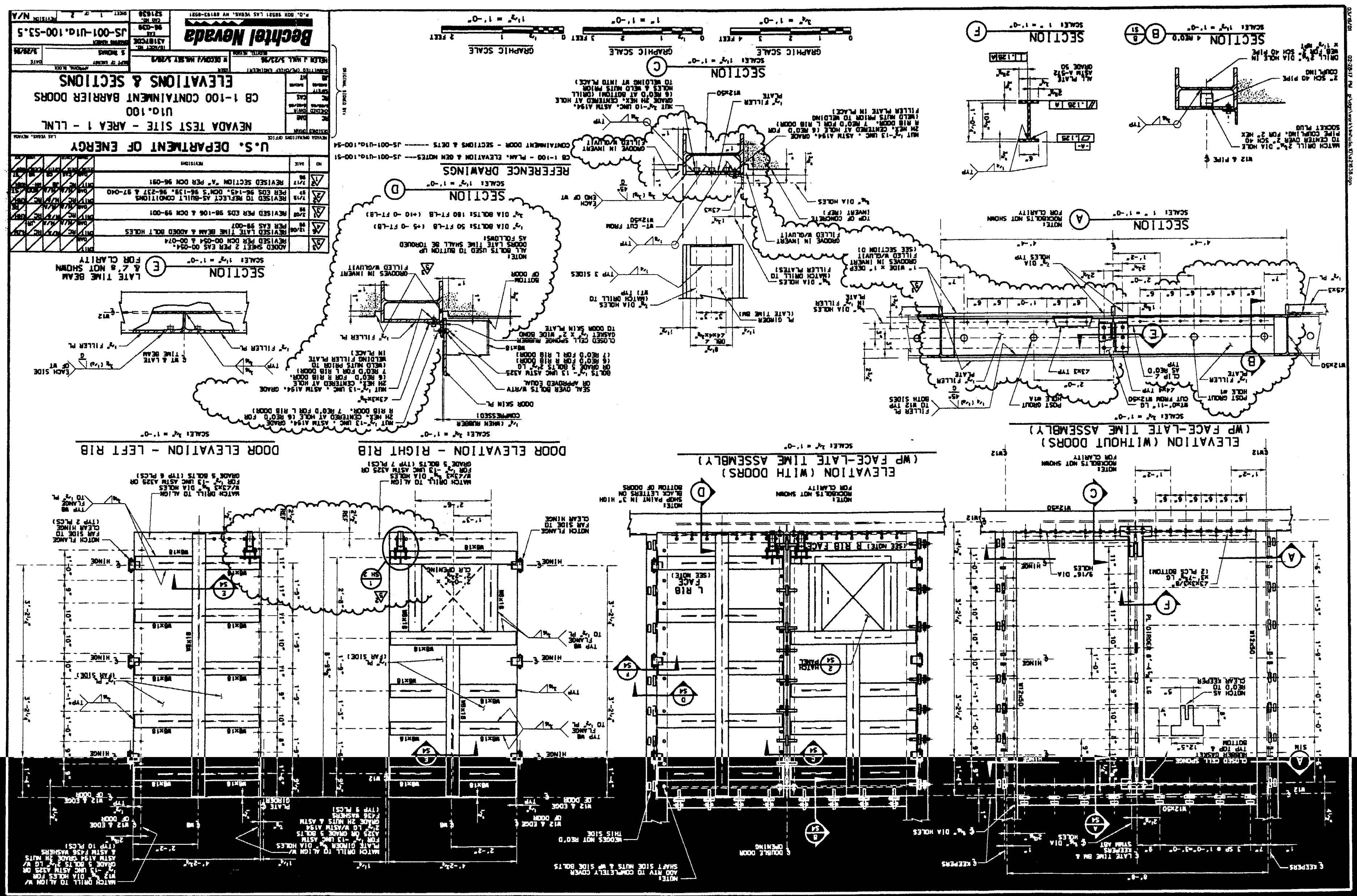




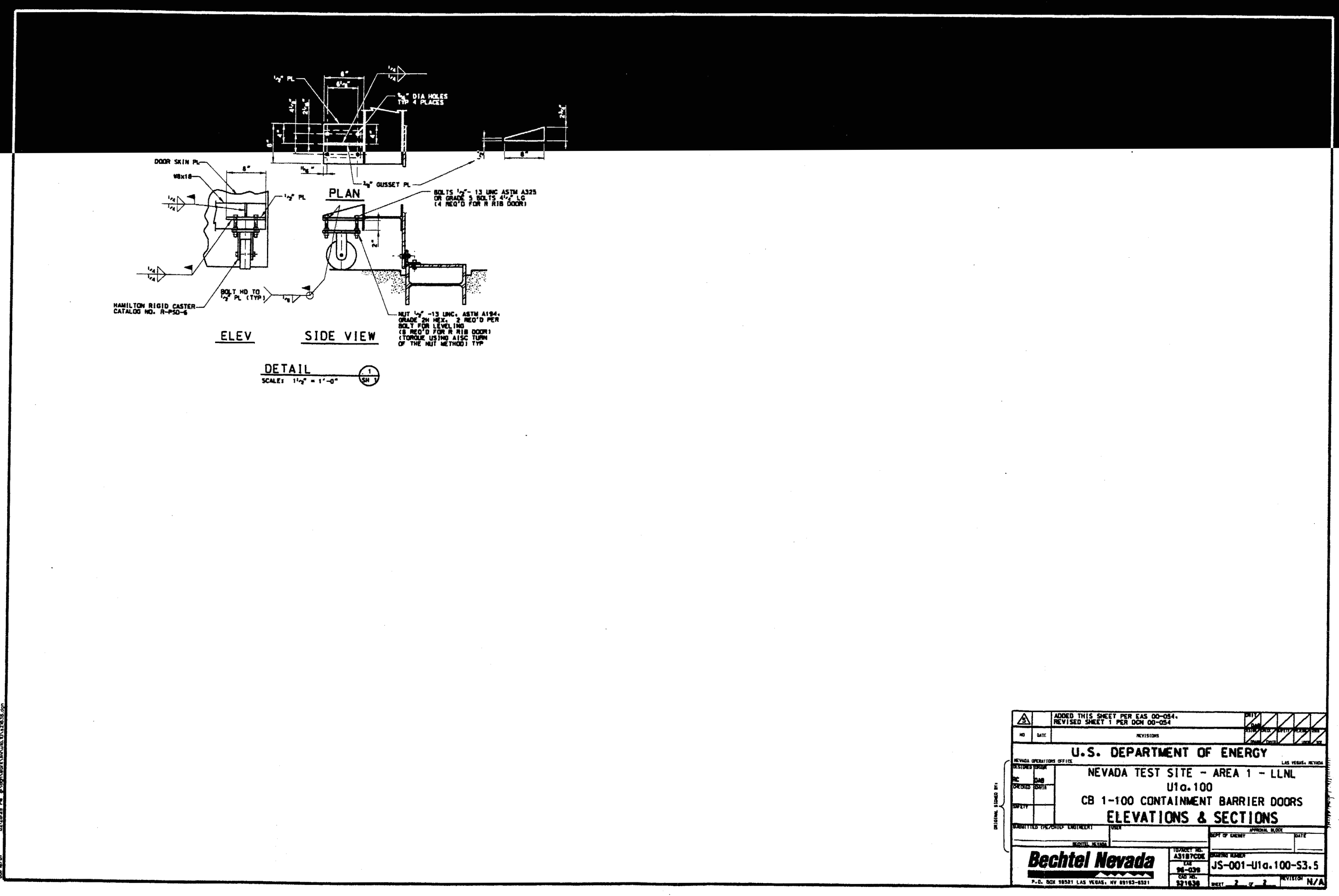




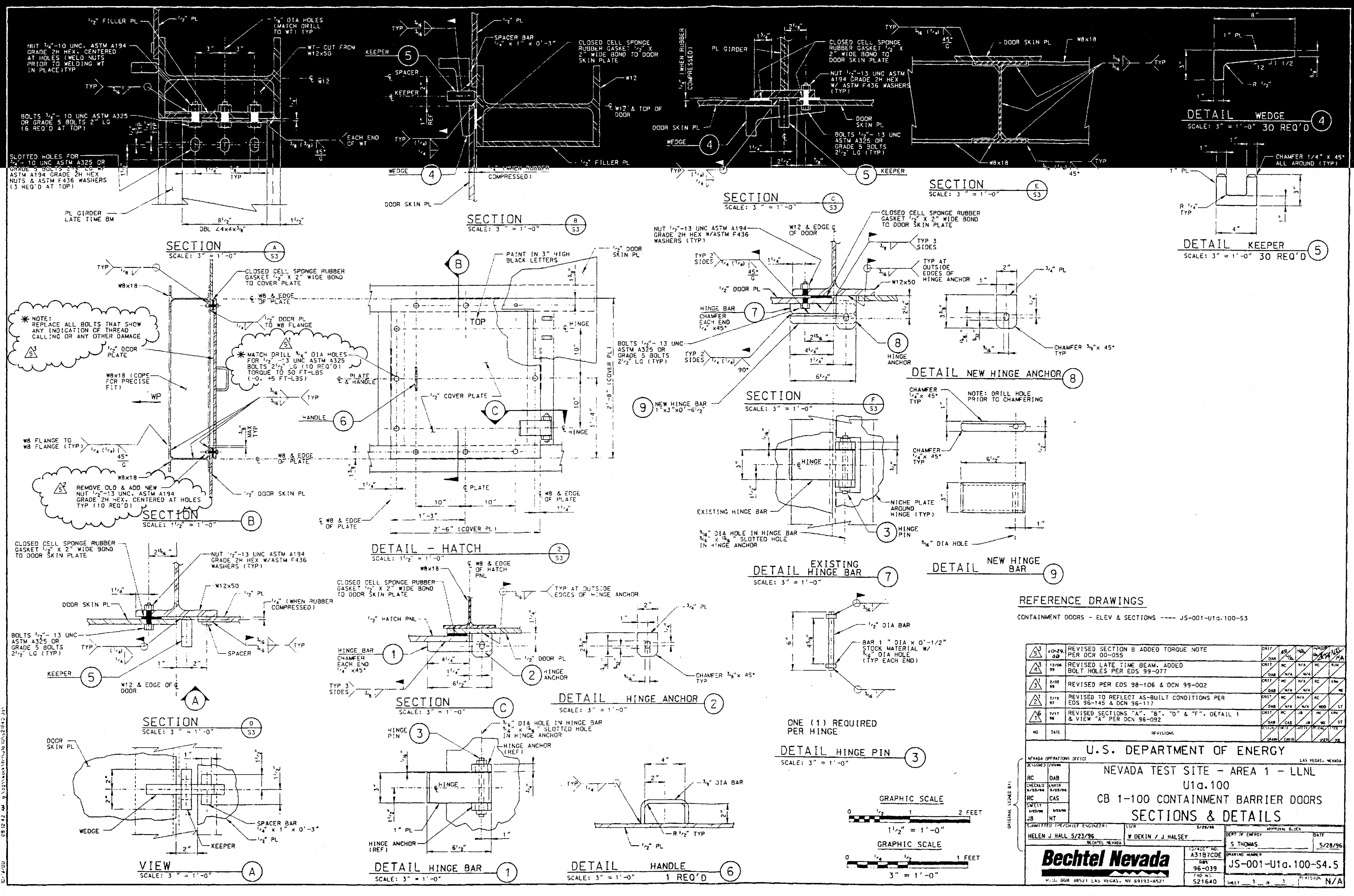


Appendix 6

Optical Port Drawings 


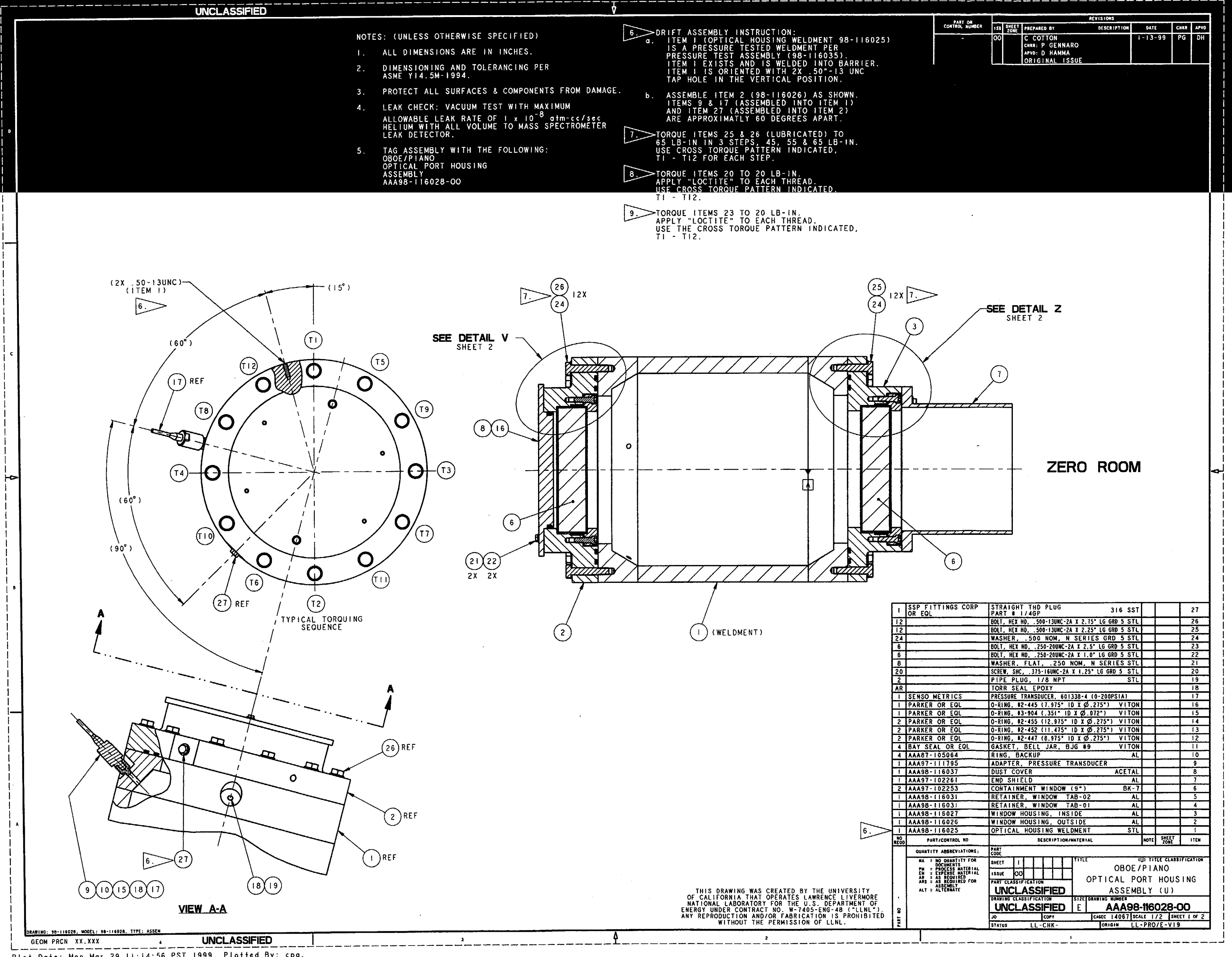




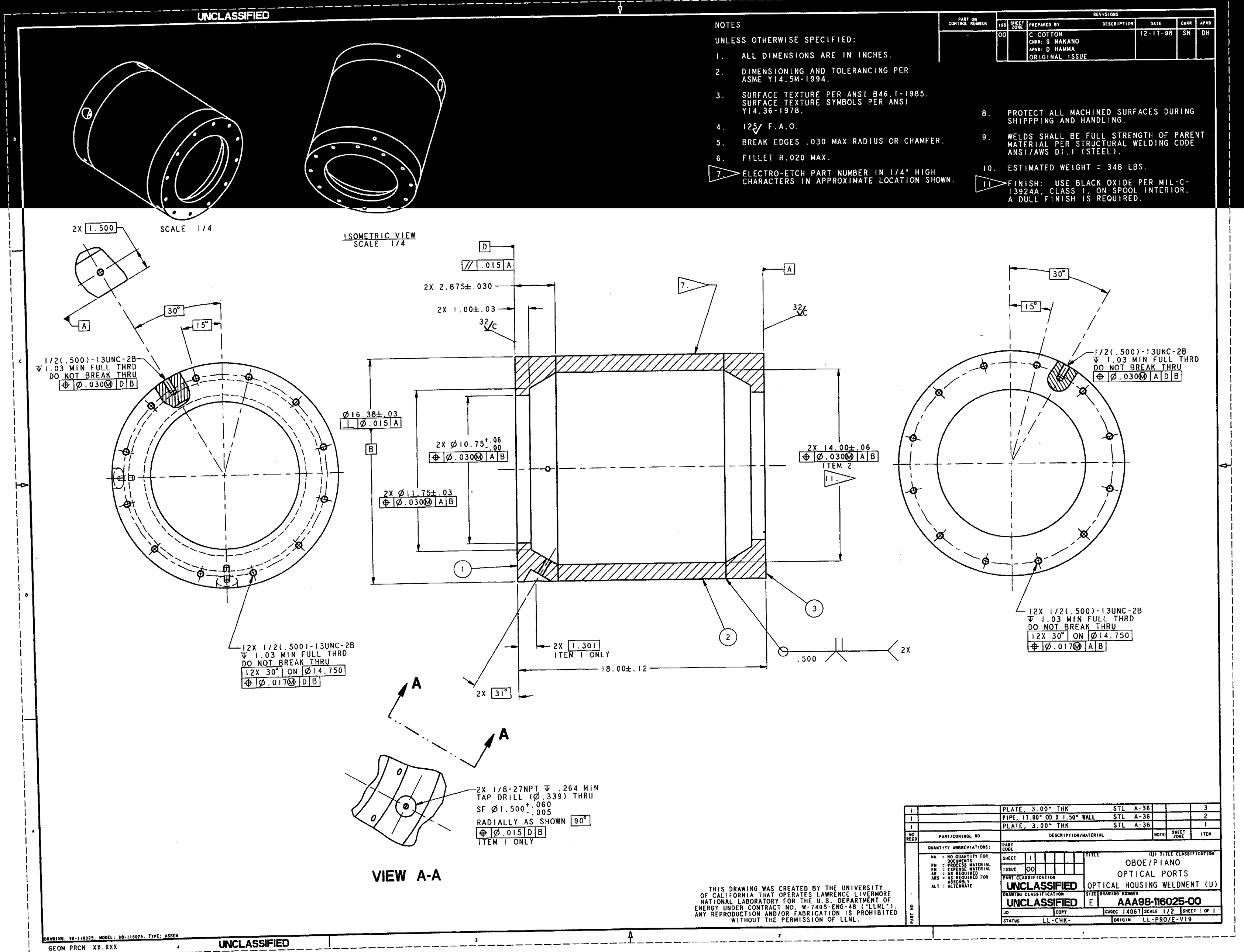

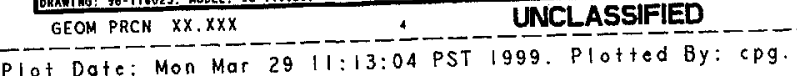




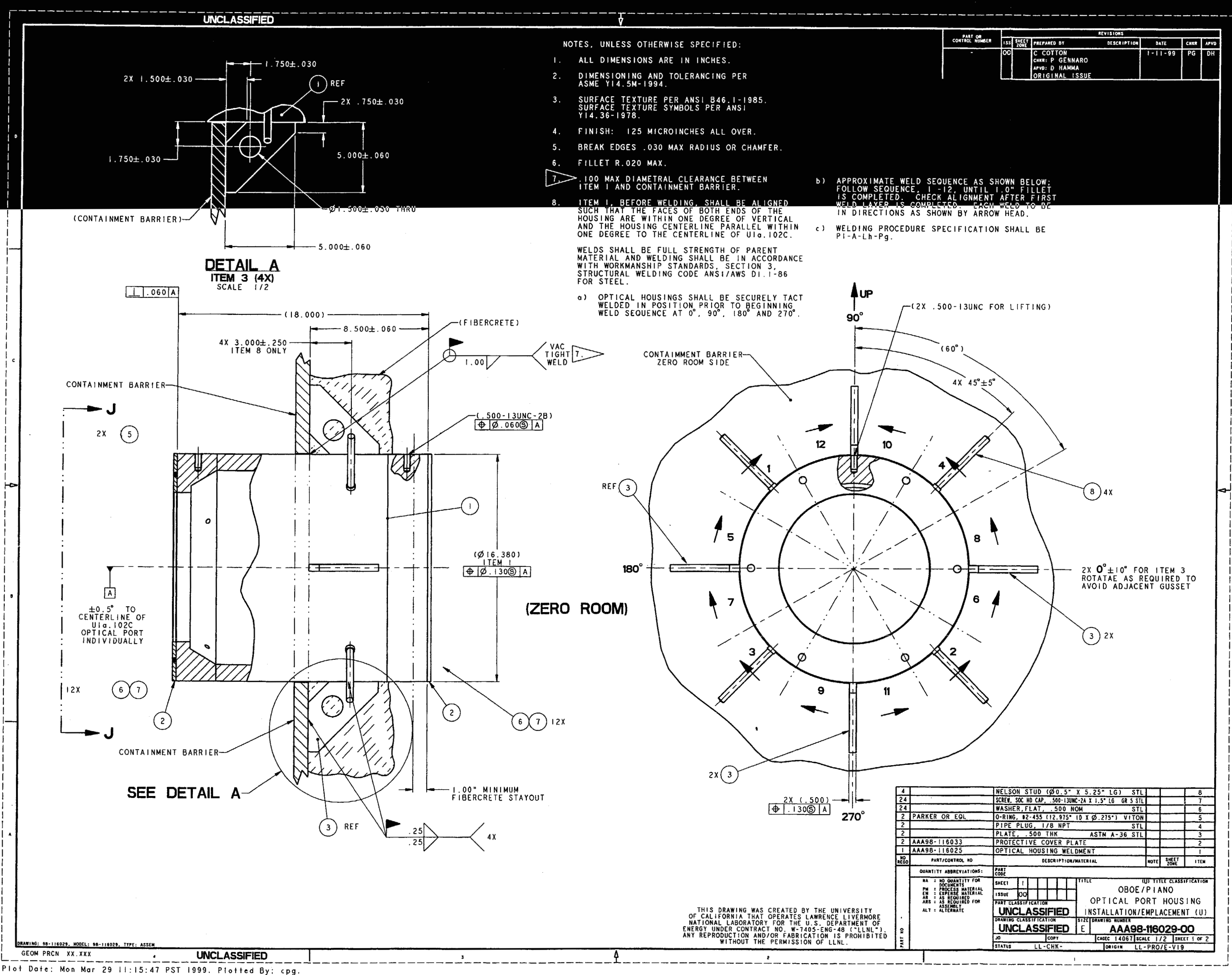


Appendix 7

Shrapnel Shield Sketch 



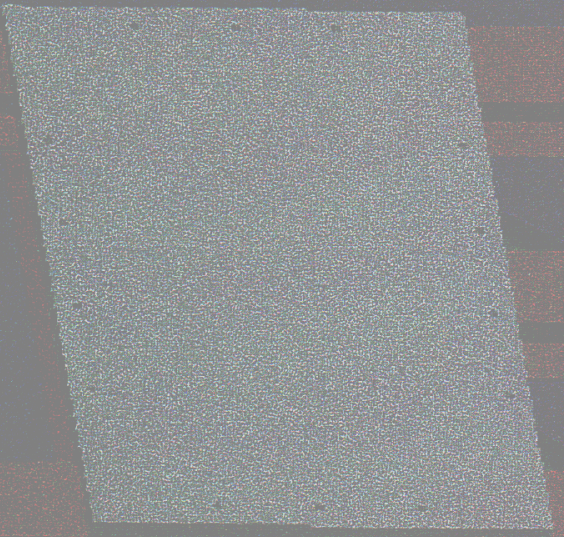

